Florida International University

FIU Digital Commons

$3-20-2020$

\title{
Social Network Analysis for Improvement of Safety in Construction Industry: An Ego-Centric Approach
}

Shraddha Shrestha

sshre024@fiu.edu

Follow this and additional works at: https://digitalcommons.fiu.edu/etd

Part of the Construction Engineering and Management Commons

\section{Recommended Citation}

Shrestha, Shraddha, "Social Network Analysis for Improvement of Safety in Construction Industry: An EgoCentric Approach" (2020). FIU Electronic Theses and Dissertations. 4412.

https://digitalcommons.fiu.edu/etd/4412

This work is brought to you for free and open access by the University Graduate School at FIU Digital Commons. It has been accepted for inclusion in FIU Electronic Theses and Dissertations by an authorized administrator of FIU Digital Commons. For more information, please contact dcc@fiu.edu. 


\section{FLORIDA INTERNATIONAL UNIVERSITY}

Miami, Florida

\section{SOCIAL NETWORK ANALYSIS FOR IMPROVEMENT OF SAFETY IN CONSTRUCTION INDUSTRY: AN EGO-CENTRIC APPROACH}

A thesis submitted in partial fulfillment of

the requirements for the degree of

MASTER OF SCIENCE

in

CONSTRUCTION MANAGEMENT

by

Shraddha Shrestha

2020 
To: Dean John L. Volakis

College of Engineering and Computing

This thesis, written by Shraddha Shrestha, and entitled Social Network Analysis for Improvement of Safety in Construction Industry: An Ego-Centric Approach having been approved in respect to style and intellectual content, is referred to you for judgment.

We have read this thesis and recommend that it be approved.

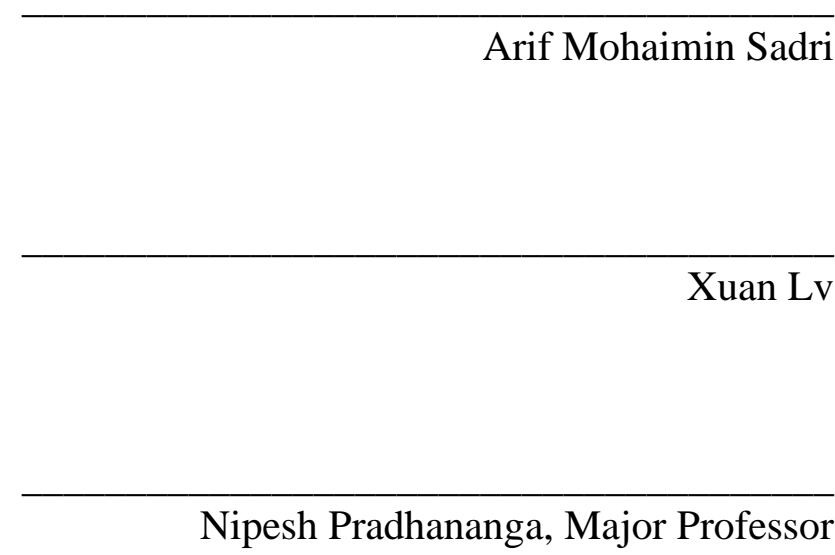

Date of Defense: March 20, 2020

The thesis of Shraddha Shrestha is approved.

Dean John L. Volakis

College of Engineering and Computing

Andrés G. Gil

Vice President for Research and Economic Development and Dean of the University Graduate School

Florida International University, 2020 
(C) Copyright 2020 by Shraddha Shrestha All rights reserved. 


\section{DEDICATION}

To My Mother 


\section{ACKNOWLEDGMENTS}

I would like to express my sincerest gratitude to my advisor Dr. Nipesh Pradhananga for his continuous support and guidance during my graduate study. This thesis would not have been possible without his expert supervision and direction.

I would also like to thank the members of my committee, Dr. Arif Mohaimin Sadri

and Dr. Xuan Lv for their support during my research and for finding time in their busy schedule for my dissertation.

I would like to thank sincerely all the faculty members of the Moss Department of Construction Management, Florida International University for their help and support for my work. Nevertheless, I am also thankful to my friends for their direct and indirect help and support and have been critical about my research helping me to improve this study as well as the report. 


\begin{abstract}
OF THE THESIS
SOCIAL NETWORK ANALYSIS FOR IMPROVEMENT OF SAFETY IN CONSTRUCTION INDUSTRY: AN EGO-CENTRIC APPROACH
\end{abstract}

by

\title{
Shraddha Shrestha
}

Florida International University, 2020

Miami, Florida

\section{Professor Nipesh Pradhananga, Major Professor}

The purpose of this thesis is to investigate how construction workers rely on each other on-site in terms of safety. The research outlines how safety-oriented social networks of construction workers can be modeled to better understand the safety communication practices on site. In this regard, a social network survey is conducted, and the respondents' social network data are collected using a Personal Network Research Design (PNRD) approach to study the connection between the individuals and their close contacts. A total of 142 participants were included in the study. The gathered network data were used to establish their peer-to-peer relationships and quantify the influence of social network characteristics and communication patterns on their safety perspective. This social network analysis incorporated various socio-demographic factors like experience, gender, race, frequency, duration of the communication and the consequence of those variables on workers' attitudes towards construction safety. The findings from this study provide insights on the significance of different social dimensions and their impact on construction safety culture and performance. The results show how individual safety behavior and perception differ based on their social ties and interactions. 


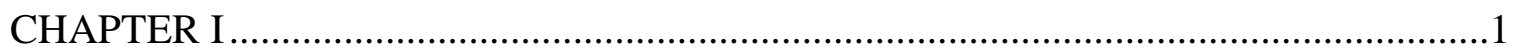

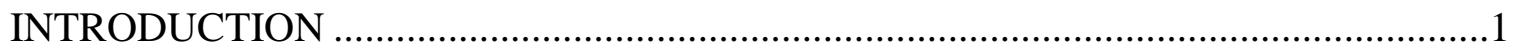

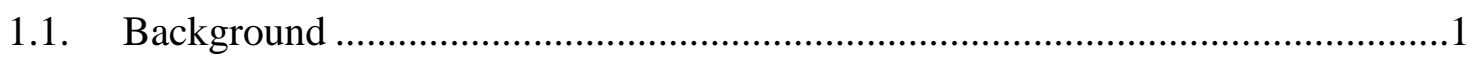

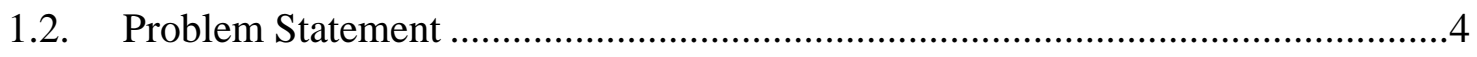

1.3. Objectives of the Study ................................................................................

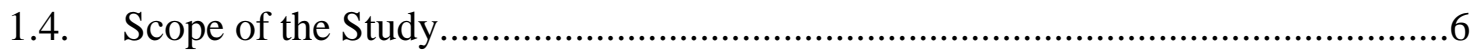

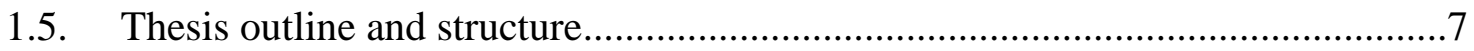

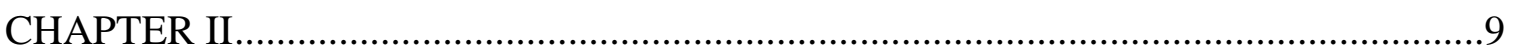

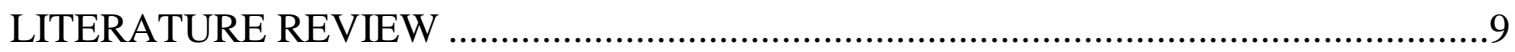

2.1. Safety Statistics in the Construction Industry ..............................................

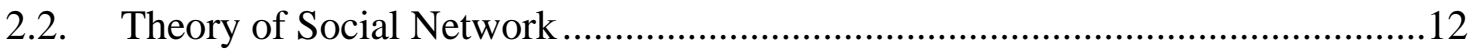

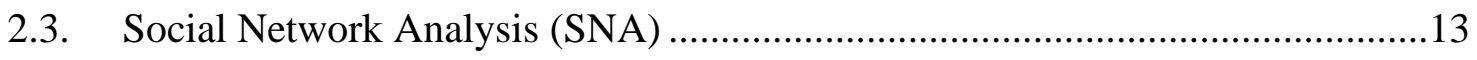

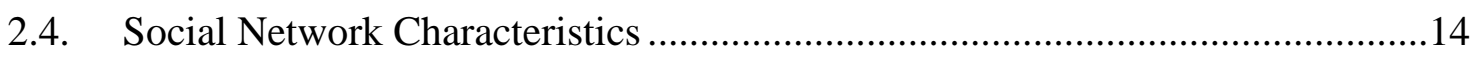

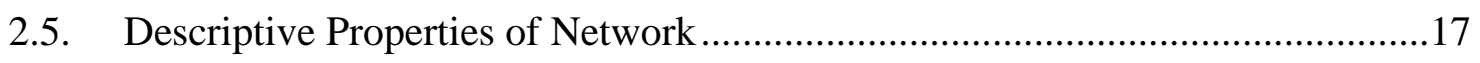

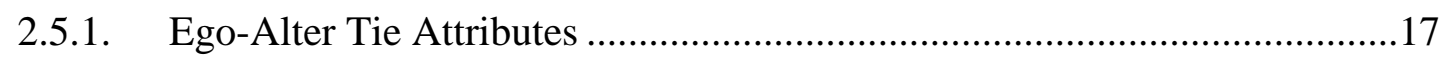

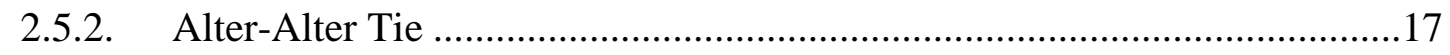

2.5.3. Network Degree Distribution............................................................... 18

2.5.4. Network Composition: Homophily and Heterogeneity ..............................18

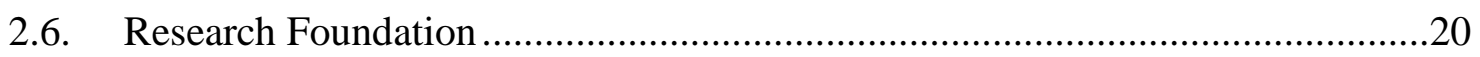

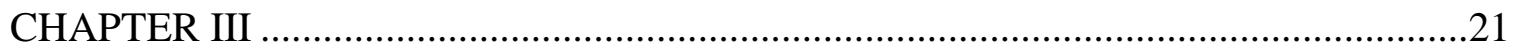

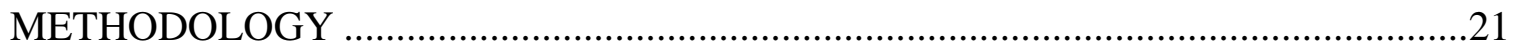

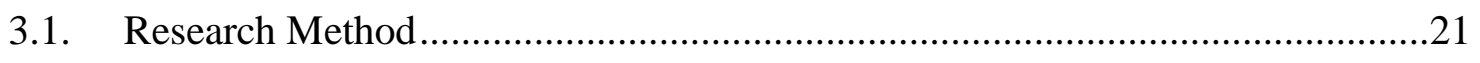

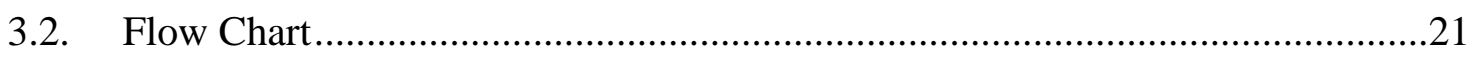

3.3. Personal Network Research Design (PNRD) Approach .................................23

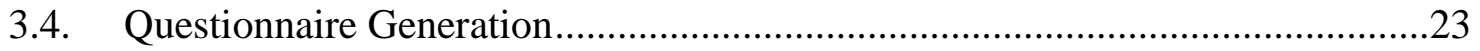

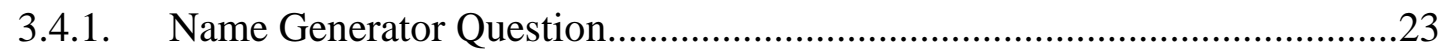

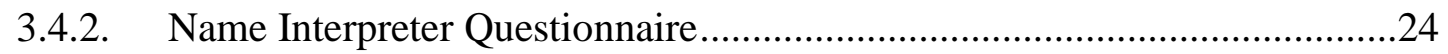

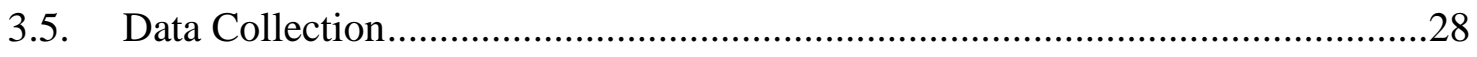




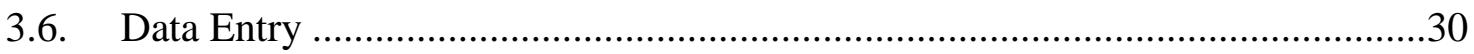

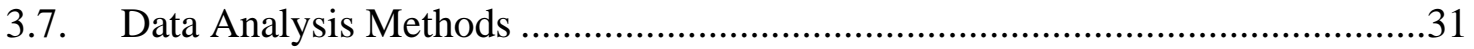

3.7.1. Analysis of Personal Network Data ...............................................................

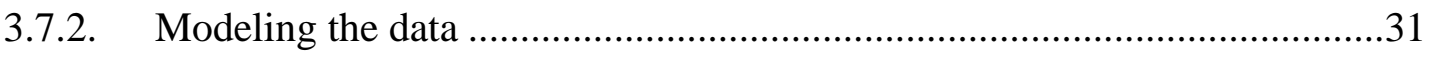

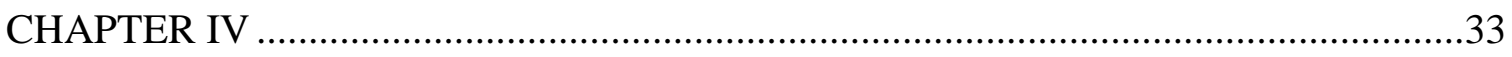

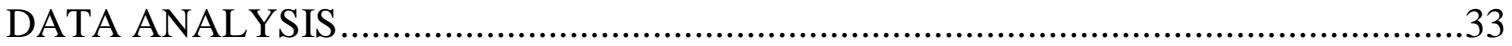

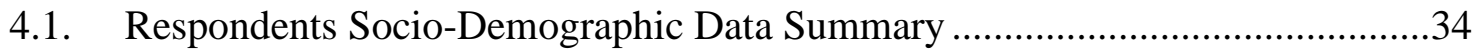

4.2. Personal Network Research Design .......................................................43

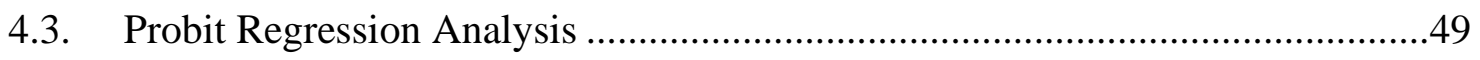

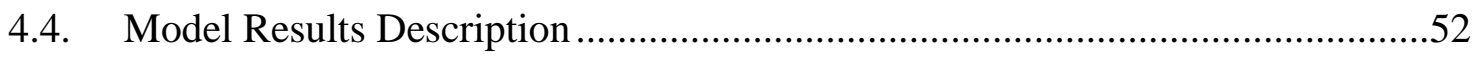

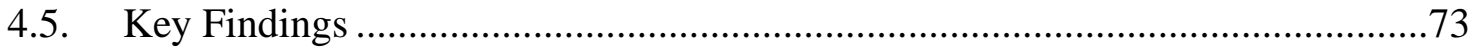

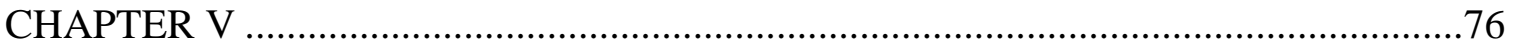

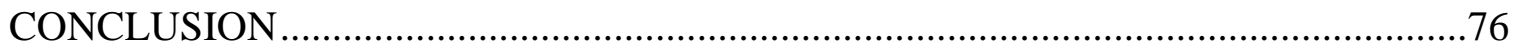

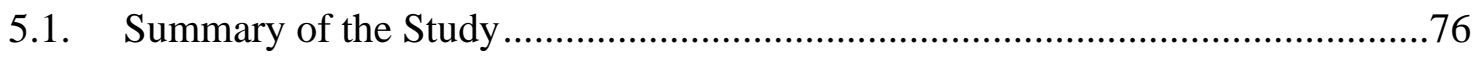

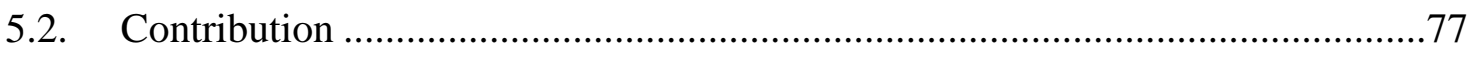

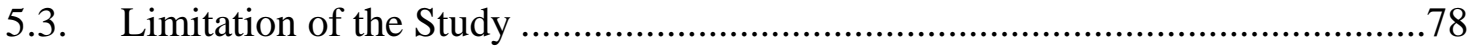

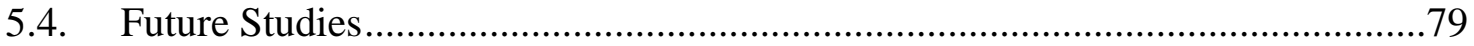

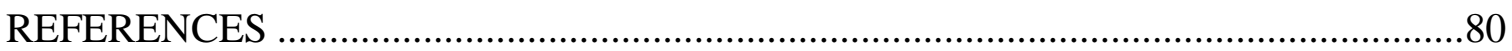




\section{LIST OF TABLES}

TABLE

PAGE

Table 1: A Sample Matrix and the Corresponding Social Network Diagram ................. 26

Table 2: A Sample Matrix Showing Alter-Alter connection ....................................... 27

Table 3: Form Distribution Detail Schedule ............................................................... 29

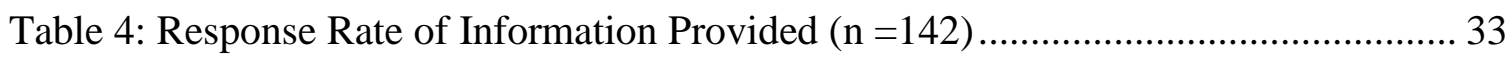

Table 5: Demographic Information of the Participants ............................................. 40

Table 6: Confidence of Respondent in Safety Related Activities.................................. 42

Table 7: Descriptive Statistics of Collected Variables .................................................. 47

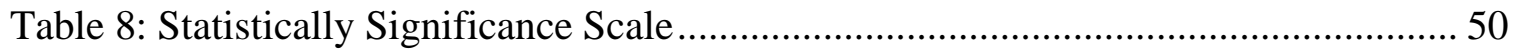

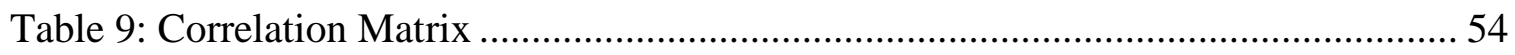

Table 10: Results of Probit Test for Confidence to Provide Safety Information.............. 57

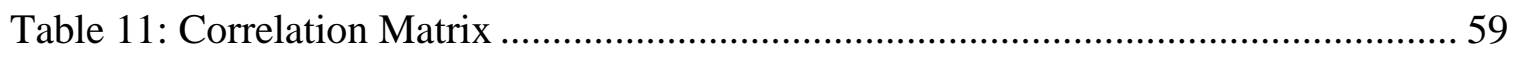

Table 12: Results of Probit Test for Confidence to Receive Safety Information ............. 61

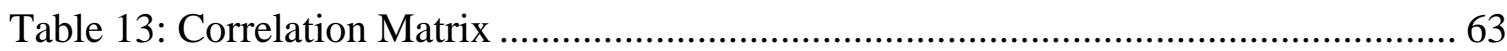

Table 14: Results of Probit Test for Confidence to Perform Newly Assigned Job Safely 65

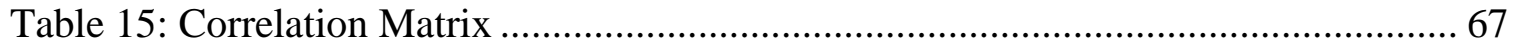

Table 16: Results of Probit Test for Confidence to Discuss Safety Information.............. 69

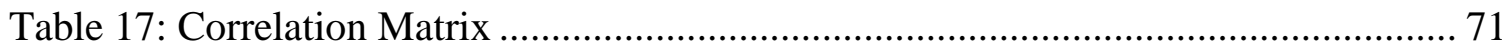

Table 18: Results of Probit Test for Confidence to Watch Safety Information................ 72

Table 19: Summary of the Result Showing Relation Between the Variables ................. 73 


\section{LIST OF FIGURES}

FIGURE

PAGE

Figure 1: Imbalance Nature of Study for Construction Safety Improvement.................... 3

Figure 2: Outline of the Thesis Explaining Each Chapter .......................................... 8

Figure 3: Construction Accident Contributing Factors........................................... 11

Figure 4: A Schematic Representation of a Personal Network .................................... 15

Figure 5: A Schematic Representation of a Full Network ......................................... 15

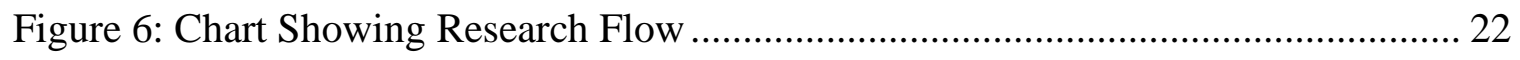

Figure 7: Name Generator Question Formulation ................................................ 24

Figure 8: Name Interpreter Questionnaire Generator ............................................ 25

Figure 9: Ego-Alter Connection Generator Questionnaire ...................................... 25

Figure 10: Question Generator for Alter-Alter Connection....................................... 26

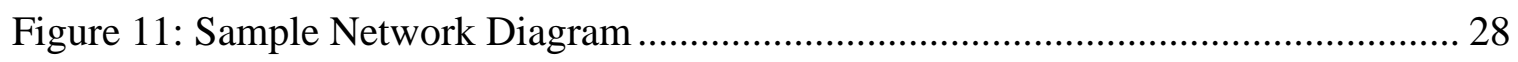

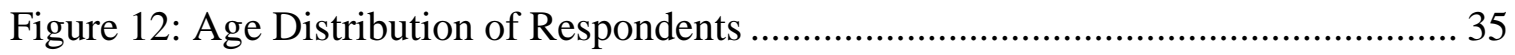

Figure 13: Gender Distribution of Respondents .................................................. 36

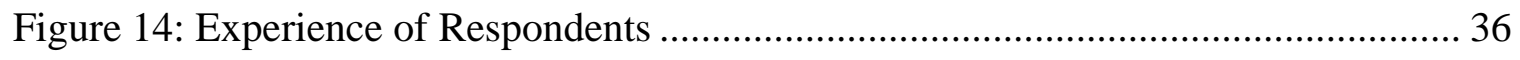

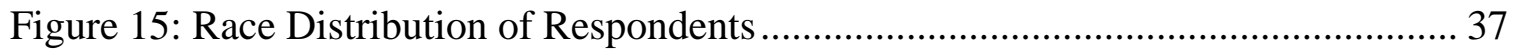

Figure 16: Language Distribution of Respondents ................................................ 38

Figure 17: Education Distribution of Respondents.............................................. 38

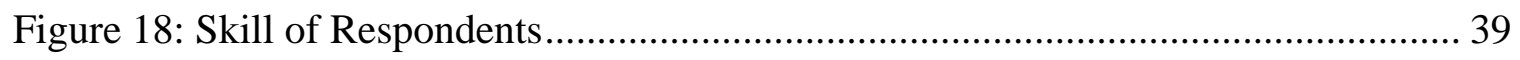

Figure 19: Dependent Variable Questionnaire Formulation...................................... 41

Figure 20: Bar Graph Showing the Summary of Confidence of Respondent.................. 42 
Figure 21: Number of Alter Listed by Ego ......................................................... 44

Figure 22: Personal Network Degree and Density ................................................ 45

Figure 23: Personal Network of Different Characteristics ........................................ 48

Figure 24: Statistically Significance Scale Reference used in the Study [43] ................ 49

Figure 25: Bar Graph Representative of Frequency Distribution ................................. 53

Figure 26: Number of Injury Deaths in U.S. by Gender [13] ..................................... 55

Figure 27: Confidence of Respondent to Receive Safety Information .......................... 58

Figure 28: Confidence of Respondents to Perform Newly Assigned Job ....................... 62

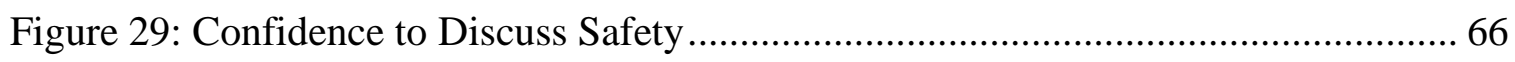

Figure 30: Confidence to Watch for Each other's Safety …...................................... 70 


\section{CHAPTER I \\ INTRODUCTION}

\subsection{Background}

Safety is very important to all aspects of the building and construction industry. It has always been considered very important when it comes to the construction workplace, as it is perceived to be a highly hazardous industry. Despite the advancement in safety management technologies and practices, the construction industry has the highest injury and fatalities rate compared to any other industry [1] [2] [3]. Construction safety is a major concern today which involves any safety procedure that is related to the construction industry. Although some countries have been working for the improvements in health and safety performance, the construction industry continues to lag when compared to any other industries.

As a result of an increasing number of health and safety issues, many federal agencies have been established. Traditionally data from federal agencies such as the Occupational Safety and Health Administration (OSHA), the National Institute for Occupational Safety and Health (NIOSH), and the Bureau of Labor Statistics (BLS) have focused on construction safety studies [4][5]. OSHA has listed four basic causes of construction-related accidents;

i. Management: Management deals with the improvement in systems and procedures. Lack of supervision, lack of adherence to health and safety standards, improper system and procedures can cause an accident. The federal agencies are continuously trying to improve on the management side by implementing new requirements. 
ii. Environment: Environment factors can be physical (temperature), chemical (atmosphere, smoke, vapors) or biological (bacteria) which can cause unsafe surroundings.

iii. Equipment: Equipment is one of the common causes of accidents. During the last couple of years, technology is booming, and researchers are actively inspecting and coming up with various innovative solutions to improve construction safety in terms of equipment use.

iv. Human Behavior: Some research has been done in behavior-based safety and concluded that the main cause of accidents is unsafe behavior; the number of accidents could be decreased by correct behavior and perspective [6].

The causes of injuries have been divided into two groups by De Reamer (1980): immediate causes of incidents and contributing causes of accidents. Immediate causes of incidents cover dangerous behavior and unsafe conditions while contributing causes of accidents include employees' mental and physical situations and policies of management[7]. However, both accident causing factors depend upon how one behaves in the job site. From this research, it is clear that safety performance in a job site does rely upon human behavior.

One's behavior depends upon the people that he/she must deal with every day. Eventually, construction workers depend on each other on the job site to complete any task. This is where an effective social dimension is an important aspect of construction study which should be given equal priority to improve safety in construction. Improvements in health and safety standards have been made in some parts of the construction sector, and very little attention has been given to the improvement of social dimensions to improve 
safety. We can see an imbalance in the effort (see Figure 1) of researches when it comes to safety improvement in terms of worker's behavior and network.

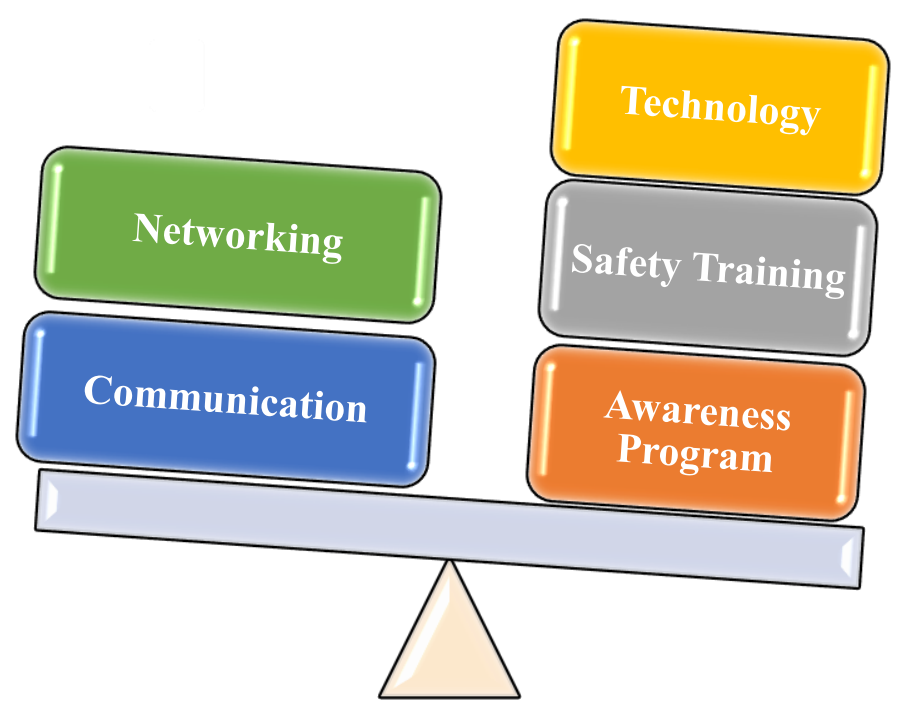

\section{Figure 1: Imbalance Nature of Study for Construction Safety Improvement}

Based on the studies by different agencies, numerous changes are being implemented such as adding a new improved requirement to improve management, inventing new technologies and improved equipment designs. Despite these efforts, the accident still occurred which shows us that these efforts are not enough to reduce the hazardous condition in the construction site. Several studies have shown that to change the issue in health and safety, it is necessary to change the behavior and attitude of people [8]. However, not many works have been done focusing on the people. Whenever it comes to safety improvement, we can see emerging technology, rules and regulations. This existing framework of improving health and safety is inadequate. Hence a new approach for better improvement of health and safety is required which should be more people orientated. 


\subsection{Problem Statement}

Many studies have indicated that social factors can play a key role in understanding the safety situation and best practices on-site [9]. It can influence how workers perceive and respond to the tasks assigned at job sites. Network concepts, theories, and methods have been developed to analyze the structure of a group of people working together[10]. These theories have been used in many other fields and it can also be used in construction.

More specifically, by considering the people working together in construction, it is possible to infer meaningful and relevant information with respect to the local network patterns surrounding the focal individual and those connected to the individual [10]. This approach will create a pattern/network of the individual with his/her friend and provide the information about their structure, size, and composition of people they have to deal with on a daily basis[11]. For this, the influence of the worker's network to their safety behavior and confidence on the construction site has been studied. It examines the network approach to study the influence of characteristics of people and their friends on individual safety behavior. This research is motivated by the current lack of literature on construction worker safety improvement which focuses on people and their friends. Further, the network approach has not been given priority as an influencing approach for health and safety improvement. There has not been any study that has attempted to measure the level of safety confidence of people who must face hazards daily on their job site. Hence, the research is driven by the need to introduce a new approach which will provide an understanding of potential benefits giving a new foundation in the area of improving construction worker health and safety 


\subsection{Objectives of the Study}

The main purpose of this research is to examine the new approach to construction safety improvement. More specifically, the objectives for the study have been listed as follows;

1. To examine the relationship between individual construction workers and their coworkers.

2. To observe the differences in network characteristics among the extremely confident and low confident group of workers in terms of their personal characteristics.

3. To understand the importance of social networking and explore its influence on safety perspectives within a group of workers working together at a site.

To measure the safety confidence of the respondent, confidence has been categorized into five different activities. These are based on the basic safety-related activities which make an individual interact with their friends on the job site;

- Confidence to provide safety information

- Confidence to receive safety information

- Confidence to perform newly assigned jobs

- Confidence in discussing and working with the team about safety

- Confident that the people on the job site will watch for each other's safety

H1. The confidence level of an individual depends upon their individual characteristics

The person's confidence level in terms of safety in the job site is affected by their characteristics such as age, gender, race, education, skill and experience level. 
H2. The confidence level of an individual depends upon the inter-personal characteristics

The confidence level depends on the inter-personal characteristics such as similarity/dissimilarity in their network characteristics, frequency of contact, duration of contact).

H3. The confidence of an individual depends upon the strength of the connections among their closest friends i.e, the connection among the close friends of the individual.

\subsection{Scope of the Study}

The research only focuses on the personal network of unrelated and anonymous respondents. This data has been collected from Miami-Dade and Broward County. This study explores the significance of different social dimensions: personal characteristics, network composition, and their impacts on individual safety behavior and perception using a personal network research design (PNRD). Researchers collect network data in Personal Research Network Design (PNRD) by sampling unrelated and anonymous respondents from a large population and collecting information about each of their friends [12]. It is limited to identify the related social factors between the network that influence their confidence level regarding safety. The data collected provides the information of network members (friends) in the respondent (individual) perspectives. This approach does not assess the accuracy of the respondent's view of his network. The scope of this research will introduce a foundation in which further exploration can be carried out to create awareness of the importance of social dimension as an important parameter to improve safety in construction. 


\subsection{Thesis outline and structure}

This thesis is structured into eight chapters, as shown in Figure 2.

Chapter 1: Introduction - a general insight is given to the study. This provides a research history that discusses the significance of the research topic and explains and defines various key concepts and terminologies involved in the research.

Chapter 2: Literature Review - provides a literature review of various literature on the aspect of the relevant topic. It provides a review of different concepts and terminologies important to the intent and aims of this study.

Chapter 3: Define Methodology and Process - explains the methodology used in conducting the research. The method used in questionnaire formulation and the procedure for the data collection method will be presented in detail.

Chapter 4: Data Interpretation - presents data, results, analysis and deliberates on the survey findings from questions asked and results obtained from the industry.

Chapter 5: Conclusion and Suggestions for Future work - a summary of conclusions and recommendations from the research work will be presented in summary. 


\section{Chapter 1: Introduction}

Outlines the research by giving information of the area, and the objective of study and the research significance and expected outcomes also structure used for research.

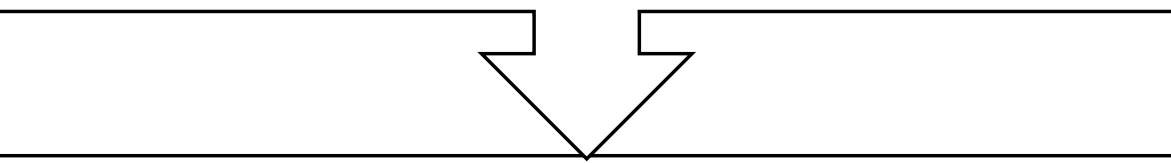

\section{Chapter 2: Literature Review}

Present the major background infromation, reviews the safety isuue in construction, previous works that have been done to improve safety and define research directions.

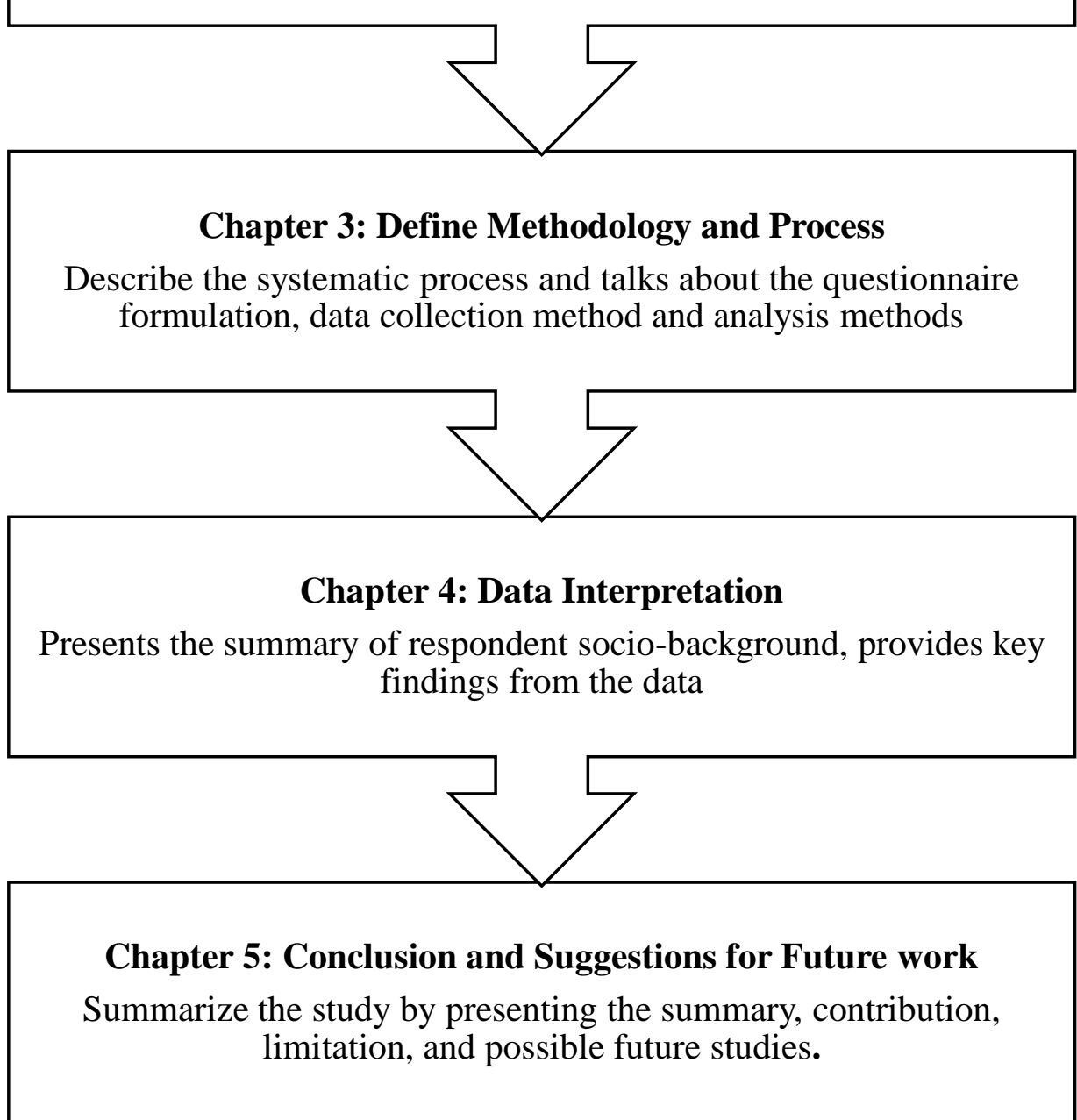

Figure 2: Outline of the Thesis Explaining Each Chapter 
CHAPTER II

\section{LITERATURE REVIEW}

This chapter will discuss the construction safety performance scenario in, the characteristics of social network analysis and methods that have been used to improve safety performance in the constructions industry

\subsection{Safety Statistics in the Construction Industry}

The construction industry is one of the most injury-prone industries and has consistently suffered numerous fatalities every year [13]. It has experienced the highest rate of occupational fatality rate when compared to other industry [14]. In the U.S, construction remains one of the most hazardous industries in terms of the number of fatalities each year. From the U.S. Bureau of Labor Statistics 2017, the construction industry has reported 971 fatal injuries in 2017 [13]. Likewise, more than 200,000 nonfatal injuries had been stated every year in construction[13]. Injuries can cause a significant impact on the workers and add the expense of over $\$ 48$ billion each year [15]. However, the factors that influence the occurrence of accidents are not always apparent [16].

Occupational safety has always been a major issue on the job site and numerous studies have been conducted to understand the accidents [15]. Construction safety has been invested in various levels by researchers such as safety activity analysis [6], attributes analysis [7], social network role on hazard recognition [15] and micro-level personal factors that leads to fatalities [17].

Every job site avoids workplace injuries, accident, and fatalities. Different safety measures are taken to provide a safe working place. Despite these safety measures and 
enforcement from legal entities such as OSHA (Occupational Safety and Health Administration) in the US, workplace safety is an issue in construction. Bureau of Labor Statics shown in Figure 2 shows improvement in construction safety is lagging [13]. The construction industry shows a trend of the highest rate of occupational fatality rate [13]. The chart describes the number of fatalities experienced some decrease in the past year after 2008 which is due to economic condition and it has been increasing recently, particularly between 2014 till today.

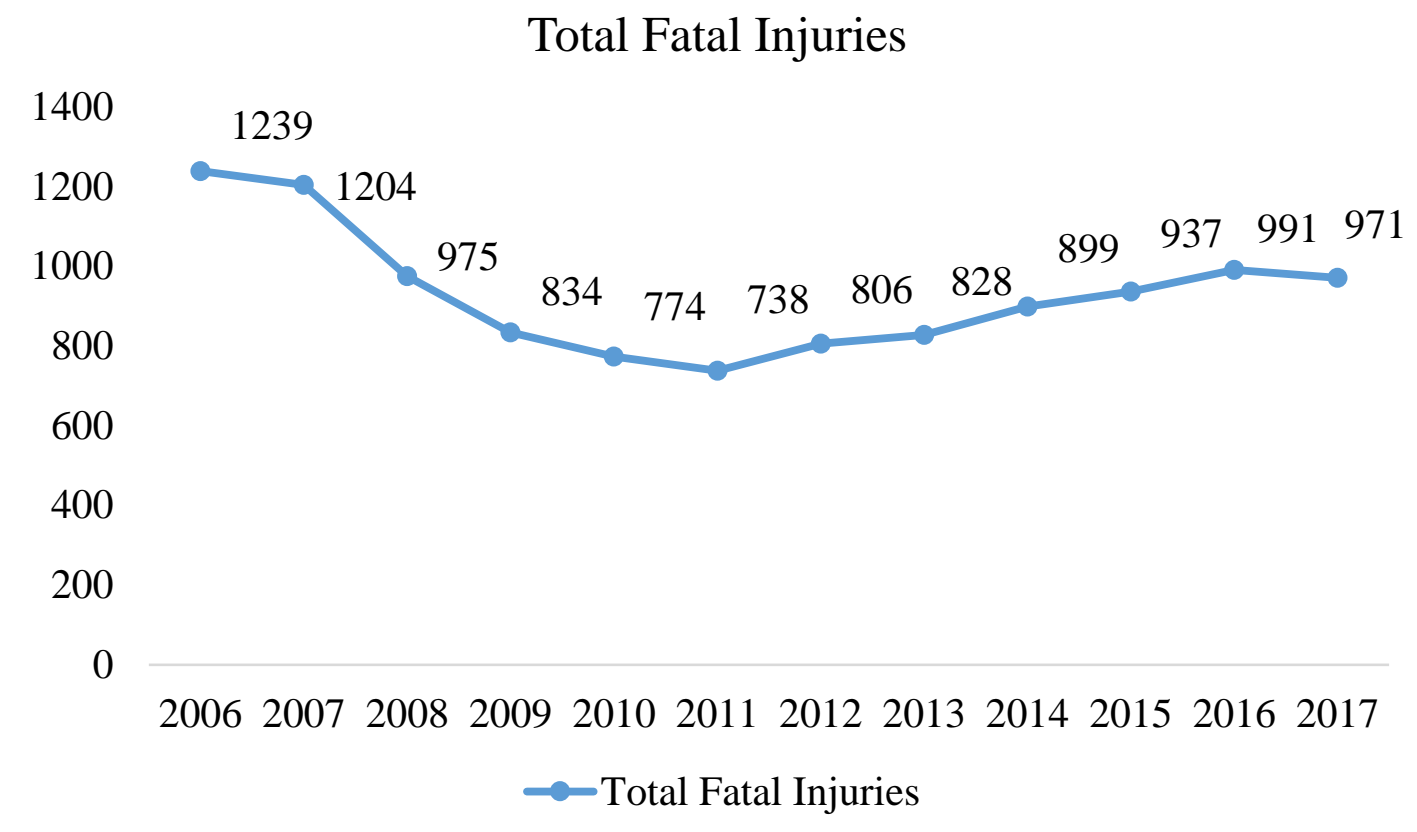

Figure 2: Number of Fatalities in Construction Every Year

Construction safety improvement has been prioritized in the due to its high severe and fatal injuries rates. Various studies have been conducted to identify the contribution to improving construction safety [18]. To enhance safety performance many safety programs, pieces of training, safety practice, new techniques, and initiatives have been implemented 
[17]. The safety of the job site depends upon various factors like the technology used, work processes, the interaction between the workers, knowledge, awareness, and training [18].

Safety improvement has been gaining importance in construction. Various techniques and fields have been studied to improve safety such as safety management, awareness safety program, safety training, accident investigation, safety meetings, safety regulation and role of government towards safety [19][20]. The research shows that most companies use various tools and techniques to measure safety performance. This method results in the workers remain unaware of hazards until they face the incident in their real life. However, past research has also shown that when there is effective communication within the workforce, workers are more likely to perform the job safely [15]. An effective method has also been used known as behavior-based safety (BSS) that focuses on the people and their behavior [20]. The result suggested that the majority of construction hazard depends upon the unsafe behavior of an individual. The factors contributing to the injury and accident in the job site have been shown in Figure 3

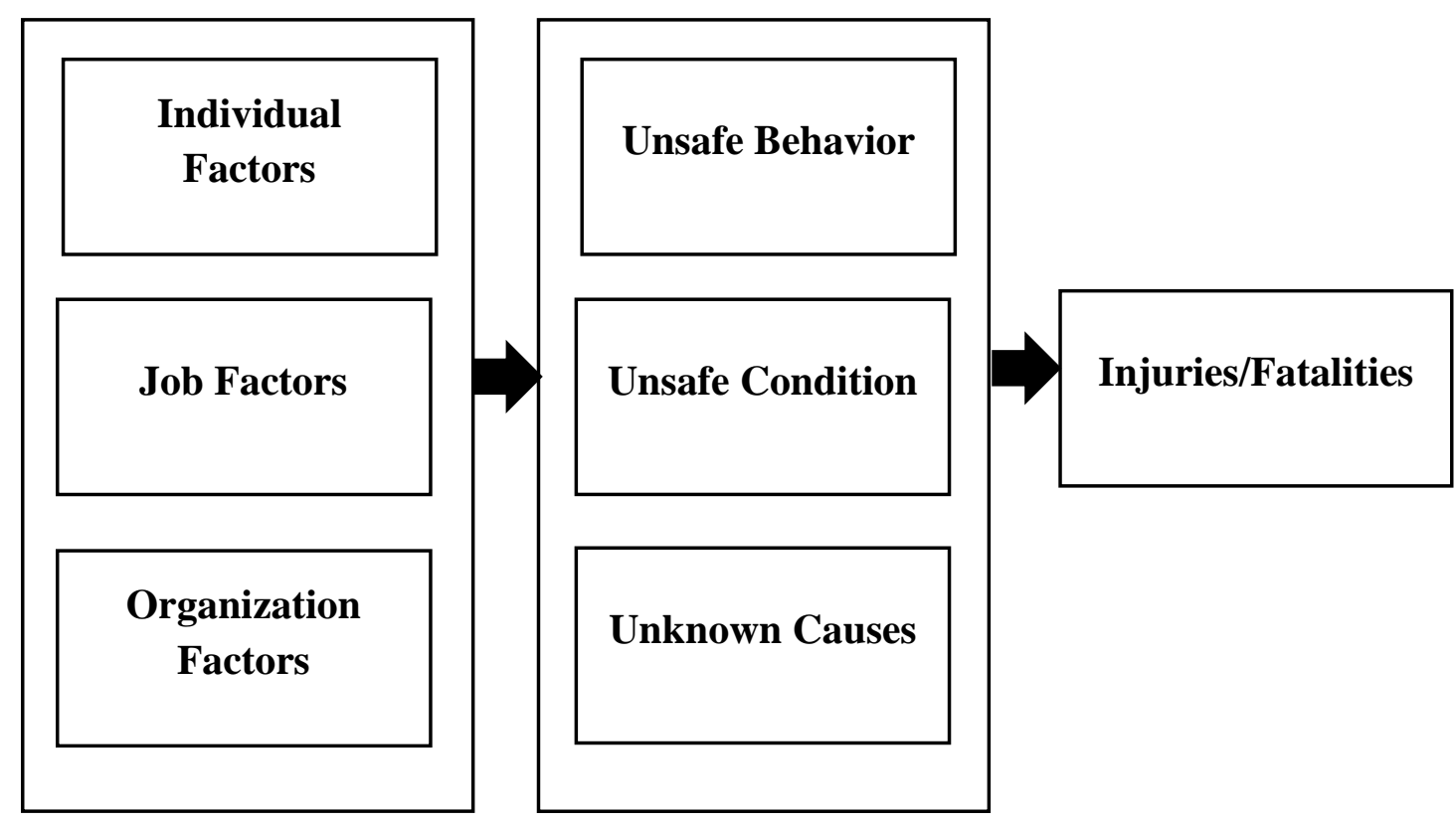

Figure 3: Construction Accident Contributing Factors 
There are many benefits of improving safety in the construction site which has been summarized below;

- Reduce construction site accidents.

- Help to complete the projects on time.

- Increase productivity and quality of work.

- Decrease the number of compensations.

This study focusses on factors influencing the unsafe behavior of people and the friends they work with. For this, the literature has been focused on the theory of social networks to learn the benefits from this concept that could be utilized in construction safety improvement.

\subsection{Theory of Social Network}

The study of the social network has gained significant recognition in various research filed. Social network analysis studies interdependencies between the individual in their behavior and various social factors [21]. It is a process of communication in which information is circulated between two or more people through various channels of interactions. For example, people may get influenced by the people whom they frequently contact face-to-face, however online communications via social media may also affect decision-making and perceptions. Researchers and scientists have been using the theory of social networks to understand the significance of network phenomena in many disciplines [22]. This type of analysis has the benefit of understanding individual attitudes, abilities, and behaviors in a network [23].

Social Network Analysis has been extensively studied in various fields. It is based on concept of social network; A set of social ego (individuals, groups or companies) from 
a network through relationship between them. SNA deals with the structure and pattern of relationships and seeks to establish their causes and effects [24]. Techniques have already been developed for the identification and study of network structures and interpretative theories [24]. This theory is popular in construction management over last two decade in the area of supply chain management [25], improving social sustainability in construction [26], hurricane evacuation decision making [27], post disaster recovery and resilience [26], construction project management [28]

Networking is the flow of information and resources through ideas, knowledge, skills, and technology through various means [2] while safety culture is the value, attitude, perception, competencies, and patterns of behavior within the group that determines the mutual trust, sharing perception and confidence towards safety [29]. Both are crucial in the construction site's ecosystem because the workers rely upon one another in various aspects. For instance, employers adopt different safety strategies like safety meetings, motivational talk, and training programs in which they share their knowledge. In all these strategies, a worker is influenced by their team members' experience, safety knowledge levels, position in the company and many other safety-related factors [30].

The following section explains the key concept for social network analysis;

\subsection{Social Network Analysis (SNA)}

Social Network Analysis (SNA) is a process for analyzing the relationships within a social network through a visualization and modeling approach [31]. This process has been utilized by the researchers since 1934 (Moreno) [32]. It was originally developed as a part of social sciences such as balance theory and social comparison in social psychology 
[28]. Later, researchers started using this approach to mainly focus on the indirect relationship of the social group of an individual [33]. This method is considered as a formal representation of the patterns of interpersonal relationships on which larger social aggregates are created in the original concept formulation. This approach can visualize the relationships, interactions, and attributes of network components [34][35].

\subsection{Social Network Characteristics}

Social network analysis provides a methodology for both small and large social scale. This study the social relations and their consequences in the individual or the group behavior [33]. Social Networks are defined as a set of nodes, actors or networks that are tied by one or more types of relations. Networks consist of a focal node (ego) as an individual and the nodes to whom the individual (ego) is directly connected (alters) [12] [36]. There are two design approaches for social network analysis; Personal Network Research Design (PNRD) also known as ego-centric network research design and Full Network Research Design (FNRD) also known as whole network research design [12]. The typical example of these two types of the network has been shown in Figures 4 and 5 respectively. 


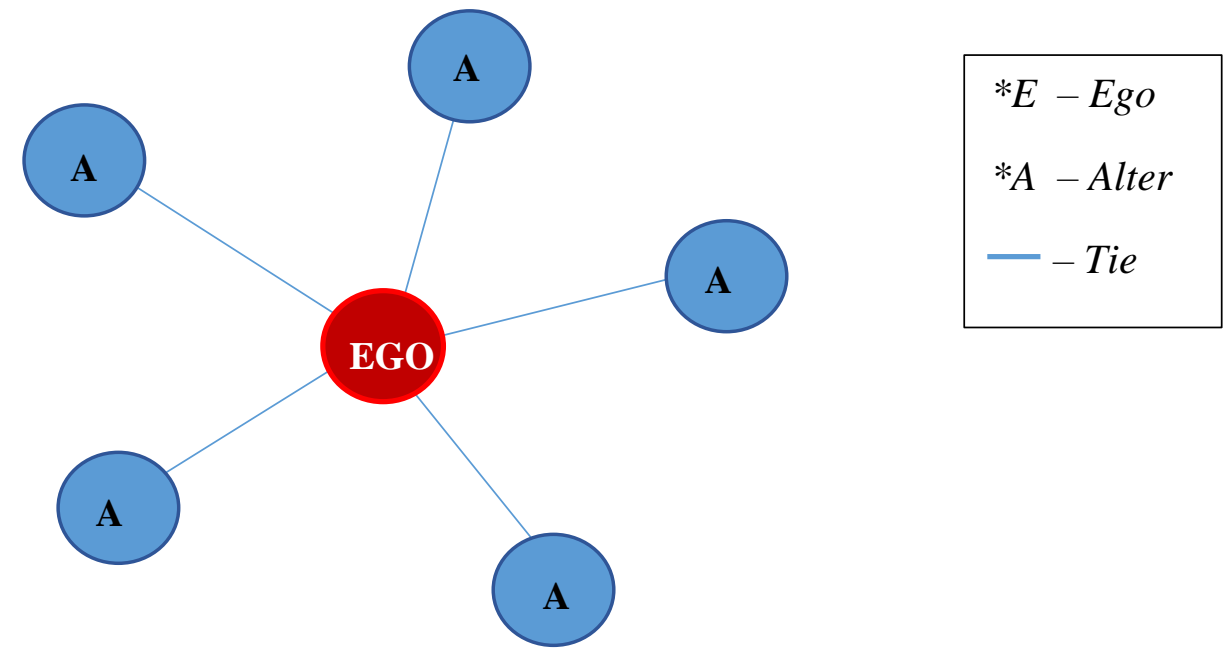

Figure 4: A Schematic Representation of a Personal Network

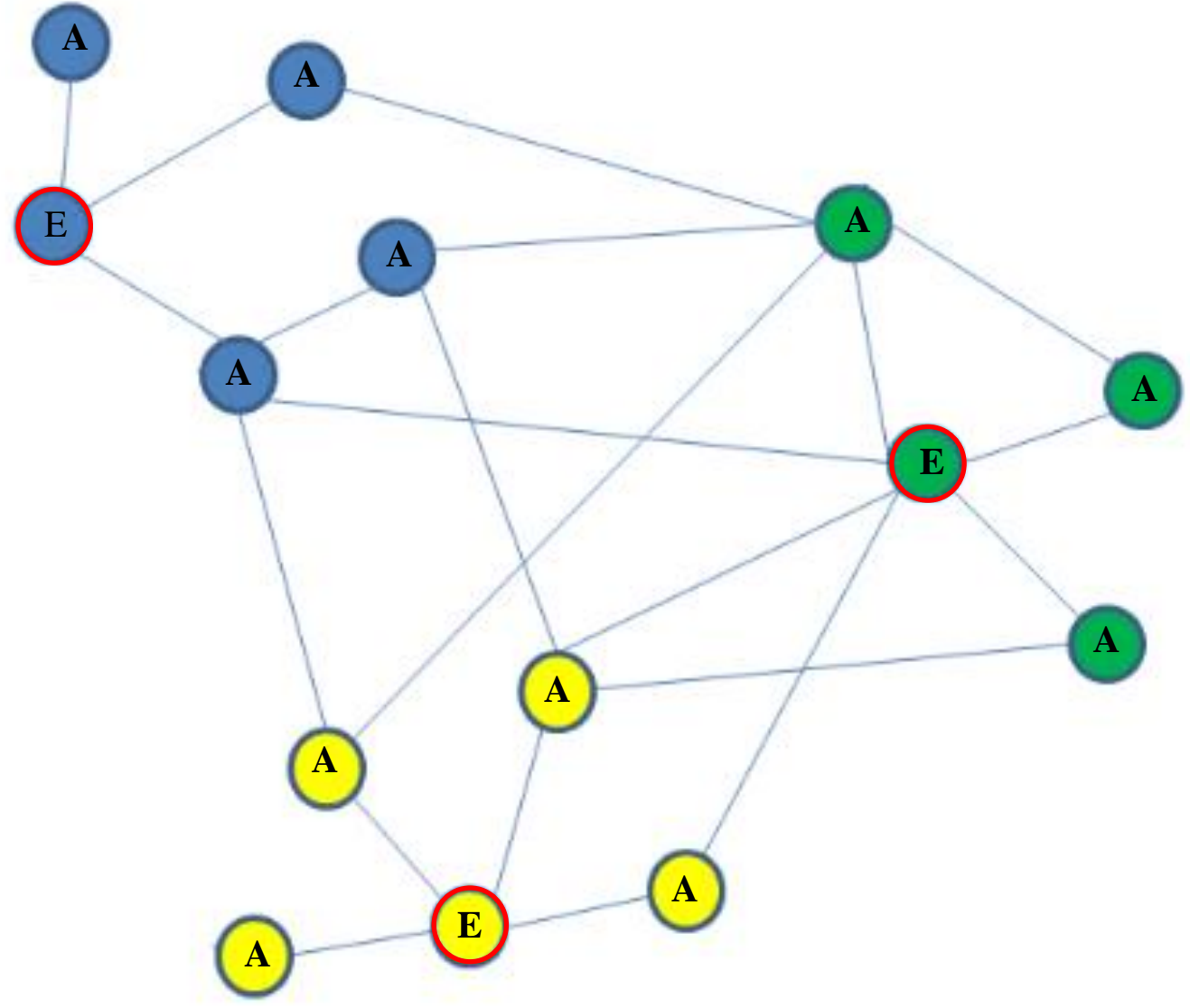

Figure 5: A Schematic Representation of a Full Network 
In the FNRD approach, a whole network is considered to study the network (as opposed to PNRD). This type of approach is suitable for the study of a small or large group of people[12]. It collects data from group members about their ties to other group members in a selected social setting. However, in PNRD, data is collected from the unrelated respondents about interactions with network members in all social settings and ask each one about the resources that they derive from their personal contacts. This network is also known as personal networks, ego-centric network or first-order neighborhoods of ego and could be extracted from the full network[37]. From this approach, it is possible to gather meaningful information from the nature of the tie between ego and alter including the ties among the alters [21].

For this research PNRD approach has been used as we are just interested in the social factors that influence the unrelated construction workers and each one of them will be asked about their close friend. This approach allows surveying any construction worker working in the different job sites and related aspects of their networks with some chosen dependent variables in terms of safety confidence such as confidence to provide safety information to the friends, to receive the safety information. This will summarize the results as an ego-centric network. By considering an individual's personal networks (also known as ego-centric networks) it is possible to infer meaningful and relevant information with respect to the local network patterns surrounding the focal individual (also known as ego) and those connected to the individual (also known as alters) [9]. Such ego-centric networks focus on individual egos and alter which in turn, study their structure, size, and composition [11]. 


\subsection{Descriptive Properties of Network}

\subsubsection{Ego-Alter Tie Attributes}

Ego and alter connection attributes represent different related dimensions between the focal person (ego) and their close contacts (alters) [21]. Personal attitude and confidence of an individual are influenced by the relationship with their contact person [6]. The nature of the relationship between the ego and alters is provided by the information obtained from the respondent about how close he/she feels to each alter that has been listed[12]. The tie within the network is determined by various factors such as frequency of contact, duration, mode of communication, etc. which provides the strength of the connection between alter and ego. The strength of a tie is dependent on all these factors which characterize the tie. These attributes provide the information about the closeness and the frequency of commutation that has been exchanged, it will be related to how safety confidence activities of an individual are affected by these attributes.

\subsubsection{Alter-Alter Tie}

The strength of the connection between alters is studied by structural characteristics of personal networks such as density. Density is the percent of ties that exist in a network out of all possible ties [38]. A density of 1.0 implies that every alters is connected to every other alter whereas a density of 0 implies that no alters know any other alter [12]. Density is a measurement that indicates the ratio of the actual links or relationships available between the network actors to the maximum possible number of links that the network could have [39]. The higher the density value, the more likely it is that actors are connected 
to each other (see Equation i). Connections are defined by information or knowledge exchange among each other directly or indirectly.

$$
D=\frac{\mathbb{N}}{\frac{g(g-1)}{2}} \ldots \ldots \ldots \ldots \ldots \ldots \ldots \ldots \ldots(i)
$$

where $D=$ Network density

$$
\begin{aligned}
& N=\text { Number of existing connections in the network and } \\
& g=\text { Total number of alters }
\end{aligned}
$$

This attribute of the network (Ego-Alter ties and Alter-Alter tie) will be explored to define how the connection among the alters is affecting the safety confidence of an individual.

\subsubsection{Network Degree Distribution}

An ego's degree is the number of connection (alters) that has been listed. The value of 1 indicates the network has one alter in his network, whereas the value of 5 indicated the network has 5 number of alters in his network.

\subsubsection{Network Composition: Homophily and Heterogeneity}

The compositional measures provide a summary of the ego's network characteristics [40]. They clarify the similarity and dissimilarity between ego and alters (Homophily and Heterogeneity). These measures were used to study the characteristics of each alters. People tend to make a connection with those who are like them in various ways.

Homophily is the similarity between ego and alters in various demographic and behavior dimensions such as age, gender, race, education, skill level, etc. It can be measured with Krackhardt and Stern's (1988) E-I score [12]. This measure is calculated by totaling ego's ties to alters who are "external" (i.e., those that are in a different attribute 
category), subtracting the number of ego's ties to alters who are "internal" (i.e., from the same attribute category) and dividing by network size[12]. Egos with ties to only those in the same selected category (e.g., the ego is Female and only has ties to other Female) will have an E-I race score of -1 and those with only ties to those in other categories (e.g., the ego is Female and only has ties to alters who are Male categories will have an E-I race score of +1 [12].

Heterogeneity is the diversity between alter on various demographic and behavioral dimensions. Ego whose alters are mostly the same according to their category such as gender, language or race will have smaller heterogeneity scores whereas those alters with the diverse network will have higher score i.e., a value closer to 1 . Similarly, -1 represents complete homophily, and +1 represents complete heterogeneity [12]. With higher value, it indicates more diversity in the network and with the lesser value indicating similarities. The key advantage of this approach has been discussed below;

- The use of proven mathematical measurements provides a validated basis for evaluating network and quantitative relationships in the network.

- This technique also offers a strong methodology for capturing network constituent relationships, connections, and attributes.

Because of these two fundamental benefits as starting points, Social Network Analysis (SNA) provides an opportunity to visualize the relationships and contrasts between safety perception and networks of construction workers. 


\subsection{Research Foundation}

The theoretical basis for the design of the social network was developed through a series of incremental steps. In summary, the following steps have been followed to build the foundation:

1. The emphasis on network resulted in an analysis of Social Network Analysis (SNA) as a possible technique and tool for studying relationships.

2. For this methodology, the research selected a personal network research design (PNRD) approach to investigate the study in more detail. 


\section{CHAPTER III METHODOLOGY}

This chapter discusses how the research has been carried out in order to meet the study's aim and objectives. The methodology in this research included the research

method, flow chart, questionnaire layout of the respondent, data analysis, and the method of processing and analyzing the data as well as questionnaire content.

\subsection{Research Method}

The method used for the research is a quantitative method for which data is collected and transformed into usable statistics. This method is intended to provide guidelines and suggestions to improve safety performance in construction. Social network analysis has been able to understand and identify a wide range of network functionality with the software package "E-net". This software was selected because of its relative easeof-use and user-friendly nature.

\subsection{Flow Chart}

The methodology flow chart (see Figure 6 ) includes the flow of research from the beginning to the end. It starts with background study and literature review to objective and scope formulation for the research to improve construction safety. A social network analysis approach is used to formulate the questionnaire. Finally, conclusions and recommendations are presented. 


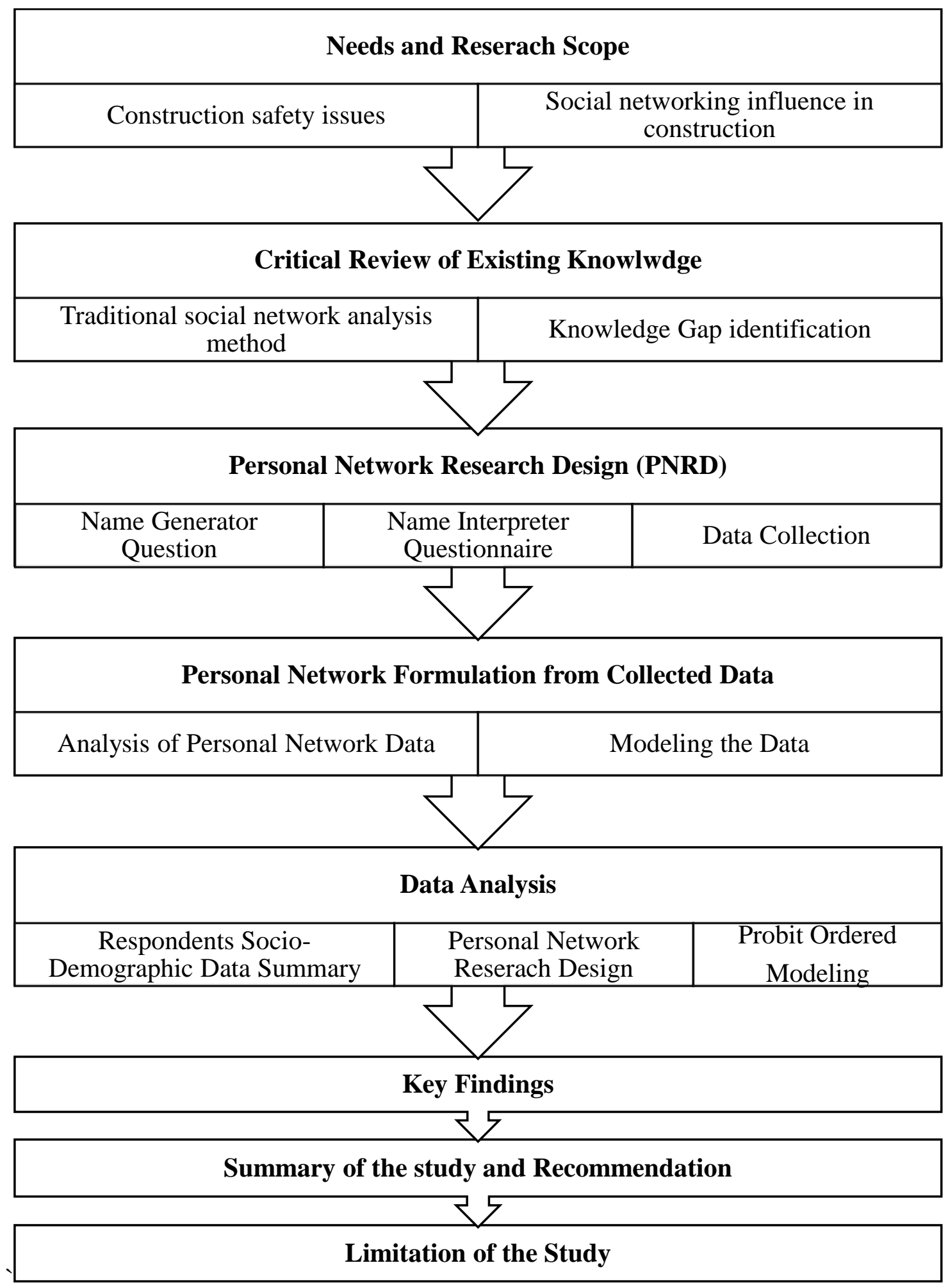

Figure 6: Chart Showing Research Flow 


\subsection{Personal Network Research Design (PNRD) Approach}

This research focus on the PNRD approach hence the data is collected from a set of unrelated and anonymous people working in the construction industry and asking each one of them about their contacts [12]. The personal network of an individual known as the ego can be analyzed by studying their network connection known as alter [12]. These types of networks are called personal networks or ego-centric networks.

The PNRD's usual first step is to create an exhaustive list of alters with whom the respondent has some kind of relationship. Using name generator questions, the researcher usually asks questions after receiving a list of names. These sections have been described in detail in the next section.

\subsection{Questionnaire Generation}

\subsubsection{Name Generator Question}

This is the first step of the PNDR is to list the alters with whom the respondents have a connection/tie. To create the list of alters with whom the ego has a relationship, a name generator question was asked. For the name generator, the respondents were asked to list alters with whom they have been working for at least six months. The name generator used in the survey was, "From time to time, most people discuss important matters with other people. Looking back over the past six months, who are the people with whom you discussed matters important to you? Please list up to five people with whom you discuss safety and health issues on site." The respondents were asked to use a coded name to maintain privacy (see Figure 7 ). The evidence suggests that human can comfortably retain five to seven people at once in their memory[41]. Hence, they were asked to list up to five (minimum of two) people with whom they have worked closely in the last six months. To 
represent each person that has been listed, they were asked to use pseudonyms. Firstly, this will help to keep the privacy and secondly, it will help to keep a systematic track of the alters throughout the questionnaire.

1. From time to time, most people discuss important matters with other people. Looking back over the past 6 MONTHS who are the people with whom you discussed matters important to you? Please list up to 5 people with whom you discuss about safety and health issues on site.

Please use coded names (acronyms or pseudonyms) to list each of these persons. Please remember (or take notes) these coded names since you will be requested to answer some specific questions for each of these persons in the later part of the survey.

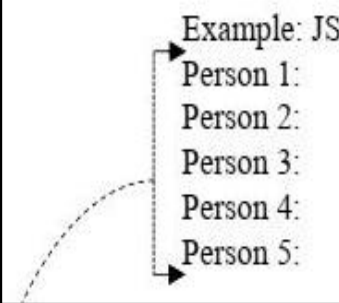

\section{Figure 7: Name Generator Question Formulation}

\subsubsection{Name Interpreter Questionnaire}

After obtaining a list of names, the name interpreter questions were asked. This question provides extra information about the ego's perception of the alters (e.g., gender, age, race, experience, skill, education, etc.). A set of questions were asked to measure the relationship by comparing the age, experience, gender, language, race, degree of closeness, etc (see Figure 8). These questions provide the ego's perception for each alter with the duration and frequency of the shared relation. Later the consequence of that dimension was compared with the workers' safety perspective. 
1. Two sets of names interpreting questions were asked in this survey:

1. From time to time, most people discuss important matters with other people. Looking back over the past 6 MONTHS who are the people with whom you discussed matters important to you? Please list up to 5 people with whom you discuss about safety and health issues on site.

Please use coded names (acronyms or pseudonyms) to list each of these persons. Please remember (or take notes) these coded names since you will be requested to answer some specific questions for each of these persons in the later part of the survey.

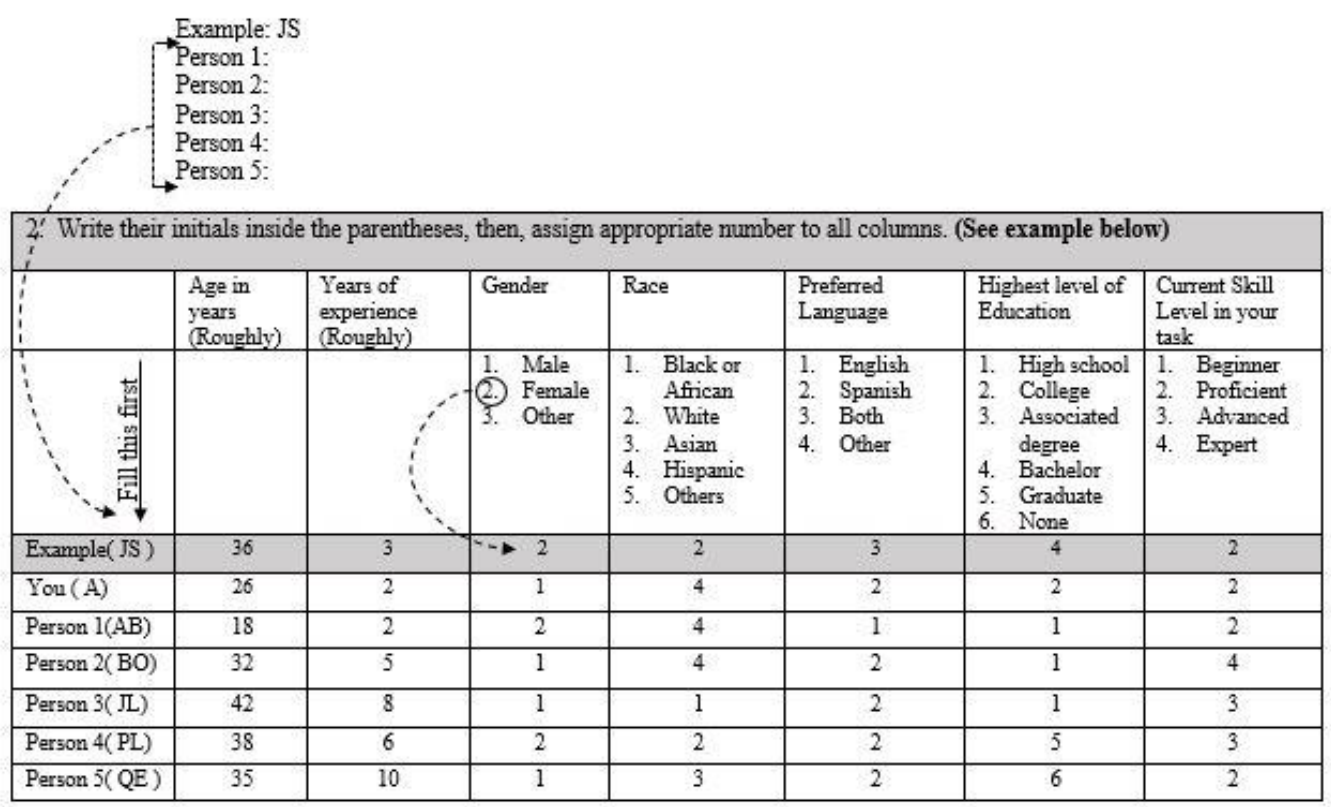

\section{Figure 8: Name Interpreter Questionnaire Generator}

The first section collects information about each alter's characteristics which include age, gender, language, the highest degree of education, skill, and experience.

3. Write their initial inside the parentheses as above and assign appropriate number to other columns

\begin{tabular}{|c|c|c|}
\hline & How long have you known each other? & Frequency of communication \\
\hline & $\begin{array}{l}\text { 1. Less than } 6 \text { months } \\
\text { 2. } 6 \text { months } \\
\text { 3. } 1-3 \text { years } \\
\text { 4. More than } 3 \text { years }\end{array}$ & $\begin{array}{ll}\text { 1. } & \text { Daily } \\
\text { 2. } & \text { Weekly } \\
\text { 3. } & \text { Monthly } \\
\text { 4. } & \text { Less often } \\
\text { 5. } & \text { Never }\end{array}$ \\
\hline Person $1(\mathrm{AB})$ & 2 & 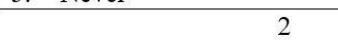 \\
\hline Person 2( BO) & 2 & 2 \\
\hline Person 3( JL) & 3 & 1 \\
\hline Person 4( PL) & 4 & 1 \\
\hline Person 5( QE ) & 4 & 5 \\
\hline
\end{tabular}

Figure 9: Ego-Alter Connection Generator Questionnaire 
The tie strength was examined between ego and alter by two relation characteristics

(i) frequency of communication (ii) duration of the communication. This provides the strength between the networks.

Table 1: A Sample Matrix and the Corresponding Social Network Diagram

\begin{tabular}{|c|c|c|c|c|c|c|c|c|}
\hline $\begin{array}{c}\text { Ego } \\
\text { ID }\end{array}$ & $\begin{array}{c}\text { Alter } \\
\text { ID }\end{array}$ & $\begin{array}{c}\text { Alter } \\
\text { Age }\end{array}$ & $\begin{array}{c}\text { Alter } \\
\text { Experience }\end{array}$ & $\begin{array}{c}\text { Alter } \\
\text { Gender }\end{array}$ & $\begin{array}{c}\text { Alter } \\
\text { Race }\end{array}$ & $\begin{array}{c}\text { Alter } \\
\text { Language }\end{array}$ & $\begin{array}{c}\text { Alter } \\
\text { Education }\end{array}$ & $\begin{array}{c}\text { Alter } \\
\text { Skill }\end{array}$ \\
\hline A & AB & 18 & 2 years & Female & Hispanic & English & $\begin{array}{c}\text { High } \\
\text { School }\end{array}$ & Proficient \\
\hline A & BO & 32 & 5 years & Male & Hispanic & Spanish & $\begin{array}{c}\text { High } \\
\text { School }\end{array}$ & Expert \\
\hline A & JL & 42 & 8 year & Male & Black & Spanish & $\begin{array}{c}\text { High } \\
\text { School }\end{array}$ & Advanced \\
\hline A & PL & 38 & 6 years & Female & White & Spanish & Graduate & Advanced \\
\hline A & QE & 35 & 10 years & Male & Asian & Spanish & None & Proficient \\
\hline
\end{tabular}

2. The second section collects information pertaining to the relationships among alters that have been listed (see Figure 10 ).

\begin{tabular}{|c|c|c|c|c|c|}
\hline & Not at all & $\begin{array}{c}\text { Not very } \\
\text { close }\end{array}$ & $\begin{array}{l}\text { Somewhat } \\
\text { close }\end{array}$ & Pretty close & Very close \\
\hline Person 1( ) and Person 2( ) & $\mathrm{X}$ & & & & \\
\hline Person 1 ( ) and Person 3( ) & & $\mathrm{X}$ & & & \\
\hline Person 1 ( ) and Person 4( ) & & $\mathrm{X}$ & & & \\
\hline Person 1 ( ) and Person 5( ) & & & $\mathrm{X}$ & & \\
\hline Person 2 ( ) and Person 3( ) & & & & $\mathrm{X}$ & \\
\hline Person 2 ( ) and Person 4( ) & & & & & $\mathrm{X}$ \\
\hline Person 2 ( ) and Person 5( ) & $\mathrm{X}$ & & & & \\
\hline Person 3 ( ) and Person 4( ) & & $\mathrm{X}$ & & & \\
\hline Person 3 ( ) and Person 5( ) & & & $\mathrm{X}$ & & \\
\hline Person 4 ( ) and Person 5( ) & & & $\mathrm{X}$ & & \\
\hline
\end{tabular}

Figure 10: Question Generator for Alter-Alter Connection 
This section provides an alter-alter relationship. The question was asked to indicate whether the listed alters are connected in themselves. They were asked to rate (1-5) how close is each alter to the other, " 1 " denoting not at all and " 5 " denoting extremely close.

Table 2 presents a sample matrix of the collected data from the survey.

Table 2: A Sample Matrix Showing Alter-Alter connection

\begin{tabular}{|c|c|c|}
\hline From & To & Knows \\
\hline A & AB_BO & 1 \\
\hline A & AB_JL & 2 \\
\hline A & AB_PL & 3 \\
\hline A & AB_QE & 4 \\
\hline A & BO_JL & 5 \\
\hline A & BO_PL & 1 \\
\hline A & BO_QE & 2 \\
\hline A & JL_PL & 3 \\
\hline A & JL_QE & 3 \\
\hline A & PL_QE & \\
\hline
\end{tabular}

In last section 3, they were asked how confident they felt to provide safety information, receive safety information, to perform the newly assigned job safely, and to discuss safety with their team. For this, the respondent was asked, "How confident are you....?" to provide safety information to others, to receive safety information from others, to perform a newly assigned job safety and in discussing and working with your team about safety.

The response to each question was measured on five-point scaling under categories of 'extremely confident', 'confident', 'neutral', 'somewhat confident' and 'not confident'. It should also be noted that the information collected is from the ego's point of view; nominated alters are not contacted to confirm those data for privacy. The key focus of the 
PNRD approach is the ego-centered network of each respondent and we only see the network through ego's eyes hence we don't know who he/she chooses not to connect with.
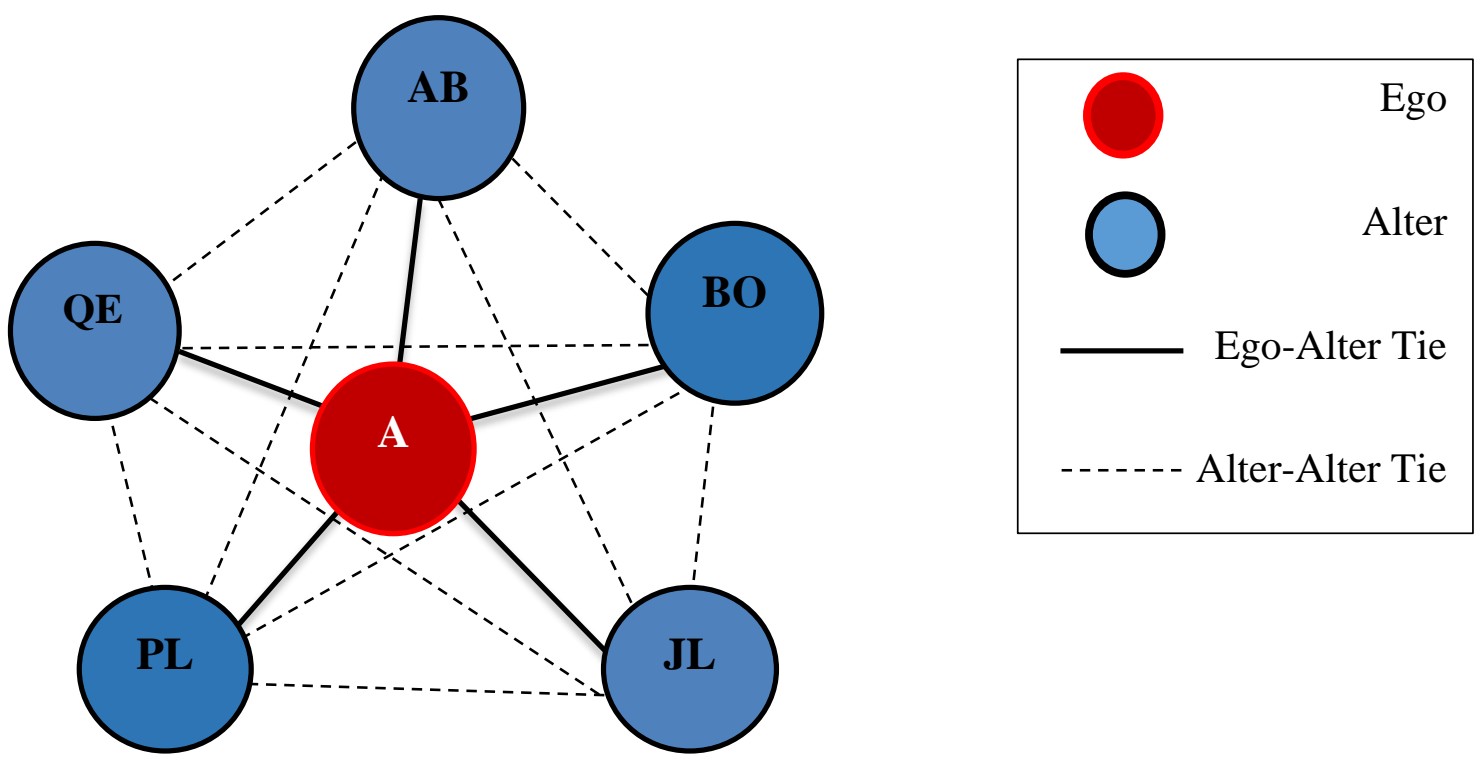

Figure 11: Sample Network Diagram

\subsection{Data Collection}

Before initiating data collection, the first step was to identify participants willing to support the survey. The research survey respondents should be those who have to deal with hazards on their job site. Hence, the respondents who are directly related to the construction environment were chosen to complete the survey. Free Electrical hazard training was conducted under OSHA (Occupational Safety and Health Administration) through Susan Harwood Grant SH-31201-SH7. This training started in November 2018 and was conducted in both English and Spanish. In the three-hour-long training, the participants of this training were asked to fill the survey question at the beginning of the training. The participants of the training were the workers from the construction industry. The individuals attending the training were the respondent for the research. The main objective 
of the electrical hazard training was to establish safe work practices in the job site and the target participants were the construction workers.

After the participating projects were identified, a paper and pencil survey were used to record the information. Out of 441 distributed form, 142 forms were useable and complete, yielding $32.19 \%$ of the response rate. From the collected sample size, the number of participants in terms of their gender was evaluated. From the data it was found that $85.21 \%$ of participants were male and $14.79 \%$ were female. When this data was compared with the data of Bureau Labor of Statistics (BLS), we found approximately the same distribution rate in terms of their gender. Bureau Labor of Statistics (BLS) states that only $9.1 \%$ of construction workers are women [13]. This helped the research to work on the collected sample size.

To filter the forms certain criteria has been set which will be talked about in the next chapter. Table 3 shows the date, time and language from distributed with the number of attendants. The form was distributed in English (56.46\%) and Spanish (43.53\%).

Table 3: Form Distribution Detail Schedule

\begin{tabular}{|c|c|c|c|}
\hline No & Date/Time & Language & Attended \\
\hline 1 & $06 / 11 / 20196: 00 \mathrm{PM}$ & English & 24 \\
\hline 2 & $06 / 11 / 20196: 00 \mathrm{PM}$ & English & 28 \\
\hline 3 & $06 / 12 / 20196: 00 \mathrm{PM}$ & English & 25 \\
\hline 4 & $06 / 13 / 20196: 00 \mathrm{PM}$ & Spanish & 32 \\
\hline 8 & $06 / 22 / 20198: 30 \mathrm{AM}$ & English & 11 \\
\hline 9 & $06 / 28 / 20198: 30 \mathrm{AM}$ & English & 14 \\
\hline 10 & $06 / 29 / 20198: 30 \mathrm{AM}$ & Spanish & 24 \\
\hline 11 & $06 / 11 / 20196: 00 \mathrm{PM}$ & English & 14 \\
\hline
\end{tabular}




\begin{tabular}{|c|c|c|c|}
\hline 12 & 06/11/2019 6:00 PM & Spanish & 28 \\
\hline 13 & 06/12/2019 6:00 PM & Spanish & 25 \\
\hline 14 & 07/13/19 8:30 AM & English & 2 \\
\hline 16 & 08/01/19 4:30 AM & English & 9 \\
\hline 17 & 08/16/19 5:00 PM & Spanish & 25 \\
\hline 18 & 08/26/19 6:00 PM & English & 13 \\
\hline 19 & 08/27/19 6:00 PM & English & 16 \\
\hline 20 & 09/07/19 8:30 PM & English & 6 \\
\hline 21 & 09/07/19 10:00 AM & English & 5 \\
\hline 22 & 09/09/19 6:00 PM & English & 10 \\
\hline 23 & 09/09/19 6:00 PM & Spanish & 18 \\
\hline 24 & 09/09/19 5:30 PM & Spanish & 4 \\
\hline 25 & 09/10/19 6:00 PM & Spanish & 13 \\
\hline 26 & 09/11/19 6:00 PM & Spanish & 33 \\
\hline 27 & 09/12/19 6:00 PM & English & 11 \\
\hline 28 & 09/12/19 8:30 AM & English & 6 \\
\hline 39 & 09/14/19 8:30 AM & English & 4 \\
\hline 30 & 09/21/19 8:30 AM & English & 22 \\
\hline 31 & 09/27/19 7:00 AM & English & 15 \\
\hline 32 & 09/30/19 10:00 AM & English & 4 \\
\hline & Total & & 441 \\
\hline
\end{tabular}

\subsection{Data Entry}

The data collected from the survey were entered manually using Qualtrics. Qualtrics is a free web-based technology that allows the user to create any kind of survey and reports. This software does not need any kind of programming knowledge. Hence it 
was convenient to use for data transformation. Spanish responses were translated to English using google translation which is a free service available to translate any language easily.

\subsection{Data Analysis Methods}

\subsubsection{Analysis of Personal Network Data}

Once collected, personal network data was organized and analyzed using E-NET (Borgatti 2006), free software that specializes in the analysis of ego network data, particularly data obtained via personal network research design. E-NET accepts data pertaining to egos (e.g., age, sex), alters (e.g., the relationship between ego and alter, alter attributes), and relationships among the alters (e.g., whether ego A reports that alter QE is connected with alter $\mathrm{AB}$ ). In discussing the software capabilities, we analyze key ideas in the ego network data analysis and discuss specific measures used to characterize the size, composition, and structure of personal networks.

\subsubsection{Modeling the data}

The specific measures (density, network degree, homophily, and heterogeneity) play a key role in the study to evaluate the relation between the connection (i.e., individual and his/her friends). A statistical process was adopted to estimate the relationship between the variables. One of the objectives of the research was to find how the confidence level (highly confident to not confident at all) in different safety activities was affected by the various measures, the ordinal model would explain the model in a better way. As the dependent variables are in ordered categories i.e., highly confident to not confident at all, ordered models could explain such types of variables [42]. Ordinal regression describes data and explains the relationship between one dependent variable and two or more 
independent variables [43]. In ordinal regression analysis, the dependent variable is ordinal (statistically it is polytomous ordinal) and the independent variables are ordinal or continuous-level (ratio or interval) [44]. Ordinal regression can be used to identify the strength of the effect that the independent variables have on a dependent variable. 


\section{CHAPTER IV}

\section{DATA ANALYSIS}

This chapter presents the data analysis and survey results of the collected data. In total 441 forms were distributed, and we created some criteria while filtering the form;

- The respondent should have filled his/her own information.

- The respondent should have listed at least one friend in his/her network with the complete information.

Table 4: Response Rate of Information Provided (n =142)

\begin{tabular}{|c|c|c|c|c|c|c|c|c|c|}
\hline \multicolumn{10}{|c|}{ Questionnaire Response (142 data collected) } \\
\hline \multicolumn{10}{|c|}{ Ego Characteristics } \\
\hline Age & \multicolumn{2}{|c|}{ Experience } & \multicolumn{2}{|c|}{ Gender } & Race & Language & \multicolumn{2}{|c|}{ Education } & Skill \\
\hline $99.29 \%$ & \multicolumn{2}{|c|}{$95.77 \%$} & \multicolumn{2}{|c|}{$100 \%$} & $100 \%$ & $100 \%$ & \multicolumn{2}{|c|}{$99.29 \%$} & $99.29 \%$ \\
\hline \multicolumn{10}{|c|}{ Personal Characteristics } \\
\hline $\begin{array}{l}\text { Alter } \\
\text { listed }\end{array}$ & $\begin{array}{c}\text { Respons } \\
\text { e }\end{array}$ & \multicolumn{2}{|l|}{ Age } & $\begin{array}{c}\text { Experie } \\
\text { nce }\end{array}$ & Gender & Race & $\begin{array}{c}\text { Langua } \\
\text { ge }\end{array}$ & $\begin{array}{c}\text { Educati } \\
\text { on }\end{array}$ & Skill \\
\hline 1 & 13 & \multicolumn{2}{|c|}{$97.88 \%$} & $97.88 \%$ & $98.59 \%$ & $100 \%$ & $100 \%$ & $98.59 \%$ & $98.59 \%$ \\
\hline 2 & 31 & \multicolumn{2}{|c|}{$97.88 \%$} & $97.88 \%$ & $99.29 \%$ & $100 \%$ & $99.29 \%$ & $98.59 \%$ & $98.59 \%$ \\
\hline 3 & 15 & \multicolumn{2}{|c|}{$97.88 \%$} & $97.88 \%$ & $98.59 \%$ & $100 \%$ & $100 \%$ & $99.29 \%$ & $98.59 \%$ \\
\hline 4 & 10 & 97.88 & & $97.88 \%$ & $99.29 \%$ & $100 \%$ & $0 \%$ & $99.29 \%$ & $98.59 \%$ \\
\hline 5 & 73 & 97.88 & & $97.88 \%$ & $99.29 \%$ & $100 \%$ & $0 \%$ & $98.59 \%$ & $98.59 \%$ \\
\hline & & & & & Ego-alter tie & & & & \\
\hline Alter li & sted & clos & nes: & & Known time & $\begin{array}{r}\text { Commu } \\
\text { freqt }\end{array}$ & $\begin{array}{l}\text { cation } \\
\text { acy }\end{array}$ & Topi & discuss \\
\hline 1 & & & & & $100 \%$ & 99.2 & & & $.29 \%$ \\
\hline 2 & & & & & $100 \%$ & 99.2 & & & $.29 \%$ \\
\hline 3 & & & & & $100 \%$ & 10 & & & $.29 \%$ \\
\hline 4 & & & $\%$ & & $100 \%$ & 10 & & & $.29 \%$ \\
\hline 5 & & & $9 \%$ & & $100 \%$ & 10 & & & $00 \%$ \\
\hline & & & & & DNFIDENC & & & & \\
\hline provi & & & ive & & perform & dis & & watch & ach other \\
\hline 97.88 & & & $8 \%$ & & $97.88 \%$ & 99.2 & & & $.29 \%$ \\
\hline
\end{tabular}


These criteria were important because our objective is to design the personal network which is incomplete without the respondent and his friend's information. When filtering the data, out of 441 forms distributed we were able to filter 142 forms based on the above criteria. The analysis was done based on 142 respondents. The table (see Table 4) shows the response rate for each questionnaire. From the data, it was found that the overall response rate was above $95 \%$ from the filtered forms.

\subsection{Respondents Socio-Demographic Data Summary}

As discussed earlier, participants were asked about their socio background in the first section of the form. The descriptive statistics from the collected data have been presented in this chapter. Descriptive statistics helps to describe the basic feature of the data in a study and simply summarize the sample. The following data has been collected in the first section of the form:

1. Age, 2. Gender, 3. Experience, 4. Race, 5. Language, 6. Education and 7. Skill.

\subsubsection{Age Distribution}

Ten categories of age range have been listed to summarize the participants' age group. The age distribution shown in the Error! Reference source not found. gives us a s ummary of 142 participants in the survey. All range of age groups has participated in the survey with a minimum of $0.71 \%$ for age $\geq 60$ years and maximum participants from age group (21-25) years with $17.61 \%$. More than 50\% of the participants were in there 20 s and 30 s. 
When we compare the collected data with age distribution in the construction industry it was found that $54.58 \%$ of the total workers are in there $20 \mathrm{~s}$ and $30 \mathrm{~s}$ [45].

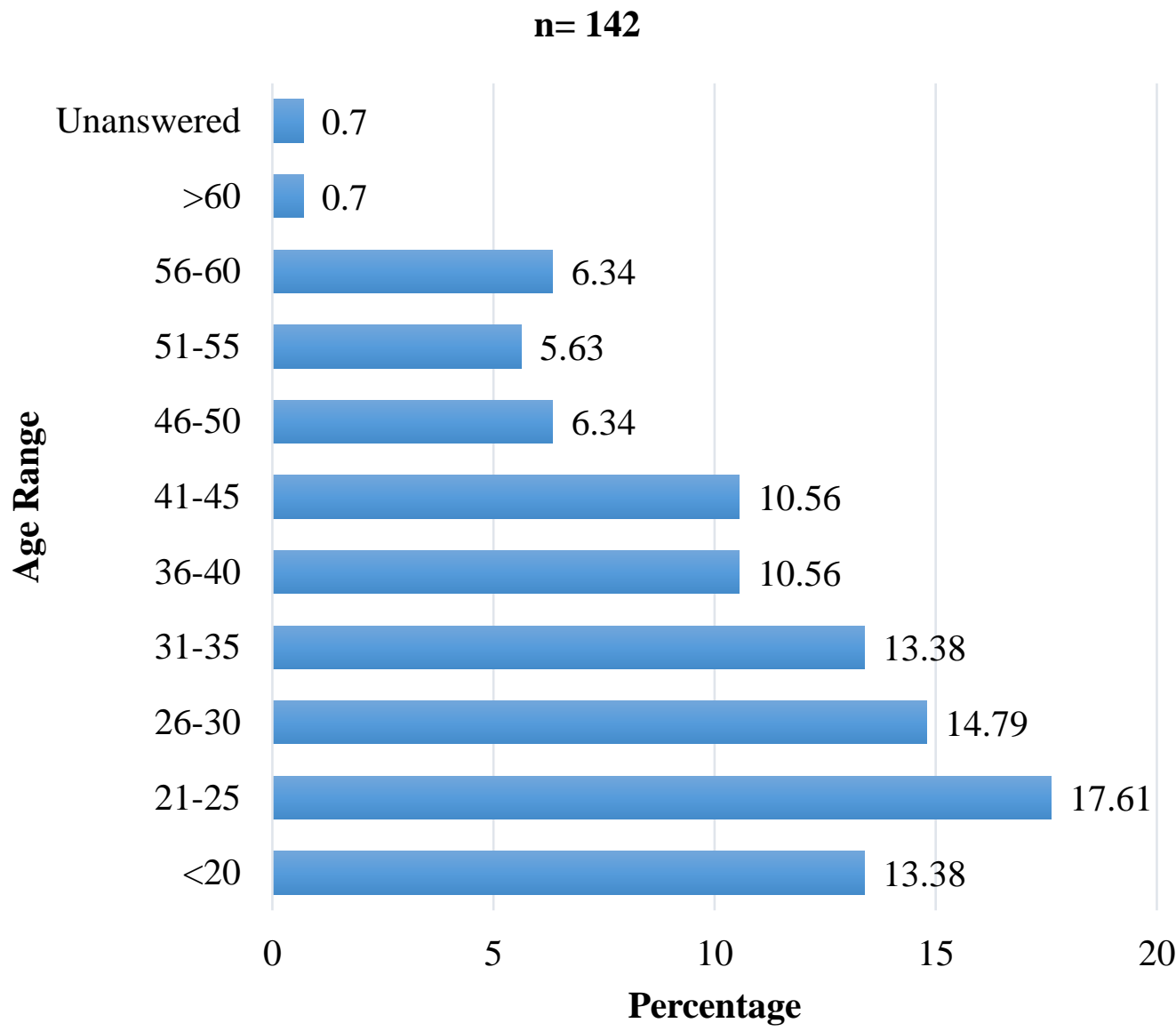

Figure 12: Age Distribution of Respondents

\subsubsection{Gender}

Three categories have been listed to classify gender. We observed the greater number of male participants with $85.21 \%$ and female participants with $14.79 \%$. Bureau Labor of Statistics (BLS) states that only $9.1 \%$ of construction workers are women [13]. When this data is compared with the collected data, we found approximately the same that is $14.79 \%$ of respondents as women. 


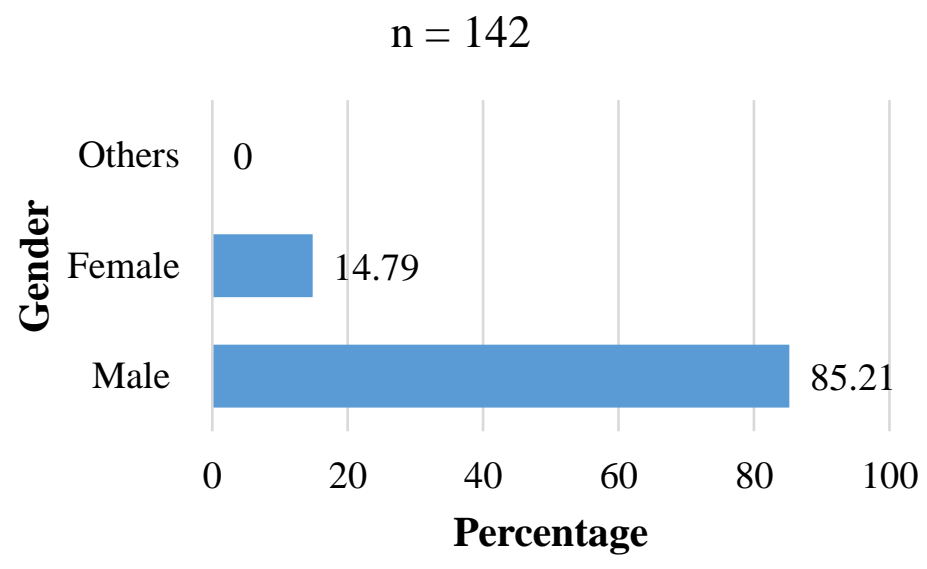

Figure 13: Gender Distribution of Respondents

\subsubsection{Experience}

Six categories have been listed according to the response of the 142 participants in their experience; less than 1 year, 1-2 years, 3-5 years, 6-10 years and more than 10 years of experience. From the data, participants with 2 or less than 2 years of experience have the highest participation in the survey with more than $35 \%$ of total participants. Also, $27.46 \%$ of participants had 3-5 years of experience.

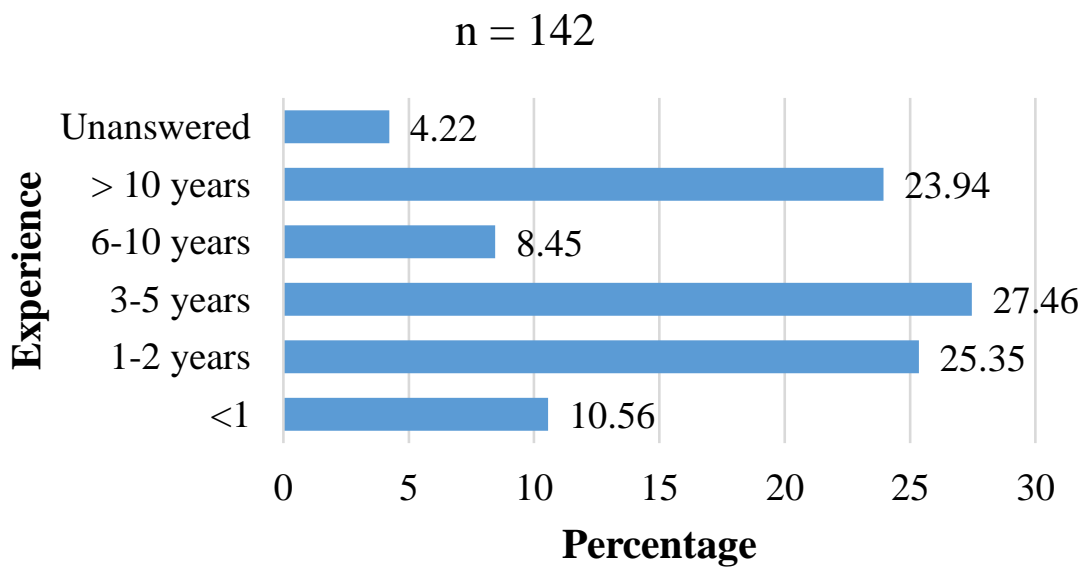

Figure 14: Experience of Respondents 


\subsubsection{Race}

Five categories have been listed according to the response of the 142 participants in their race; Black or African, White, Asian, Hispanic and Others. The research was done in Miami-Dade and Broward County. The maximum number of people living in MiamiDade County are Hispanic and Broward County are White, Black or African. Hence, from the data, it has been observed that the maximum participants were Hispanic with $63.38 \%$.

As the survey was conducted in Miami Dade County and Broward County, more than half of the respondents that is $63.38 \%$ were found to be Hispanic.

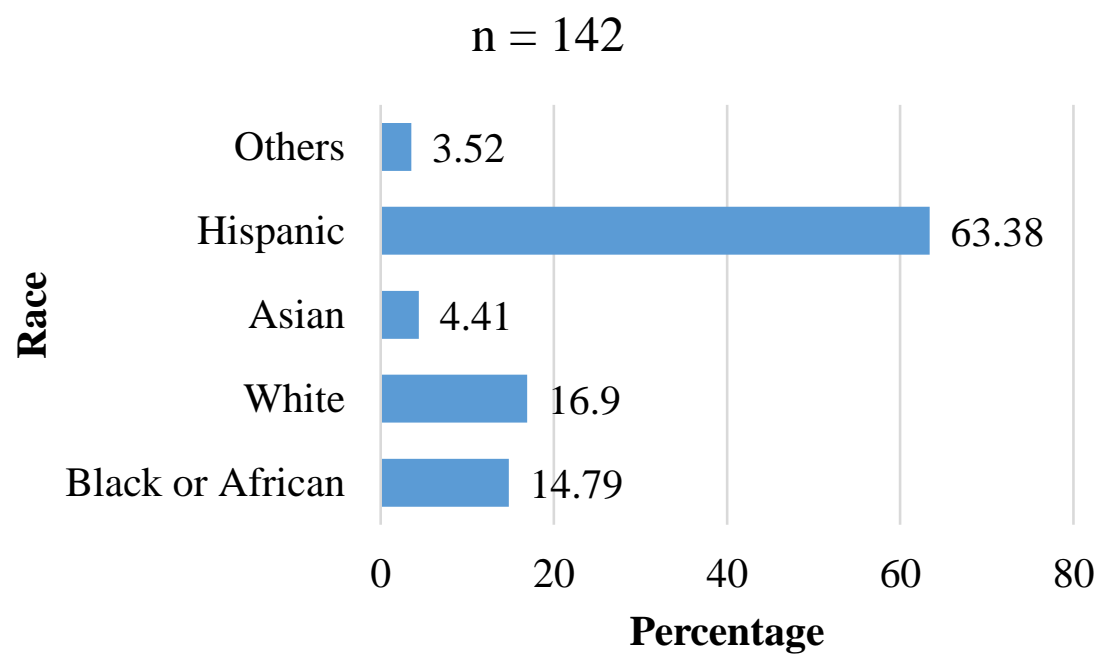

Figure 15: Race Distribution of Respondents

\subsubsection{Language}

Four categories have been listed according to the response of the 142 participants in their language they speak; English, Spanish, Both and others. More than $45 \%$ of participants only speak English and about $25 \%$ of the participants speak only Spanish. While $23.94 \%$ of them speak both languages. 


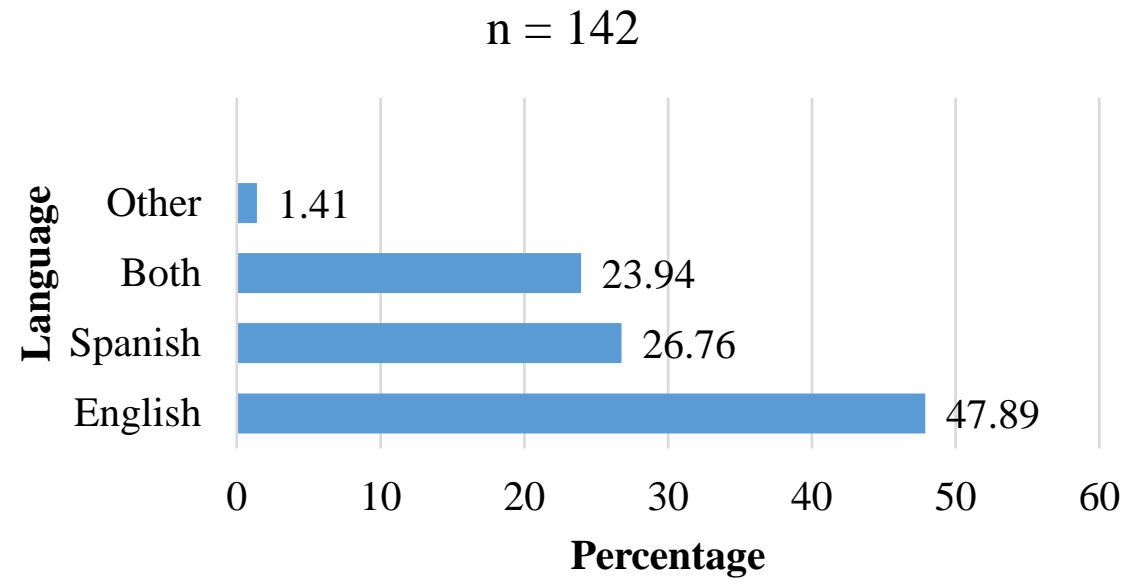

Figure 16: Language Distribution of Respondents

\subsubsection{Education}

Six categories have been listed according to the response of the 142 participants in their level of education; High school, college, associated degree, bachelor, graduate degree and none. The largest number of participants said they had a high school education and a minimum of participants has a graduate degree.

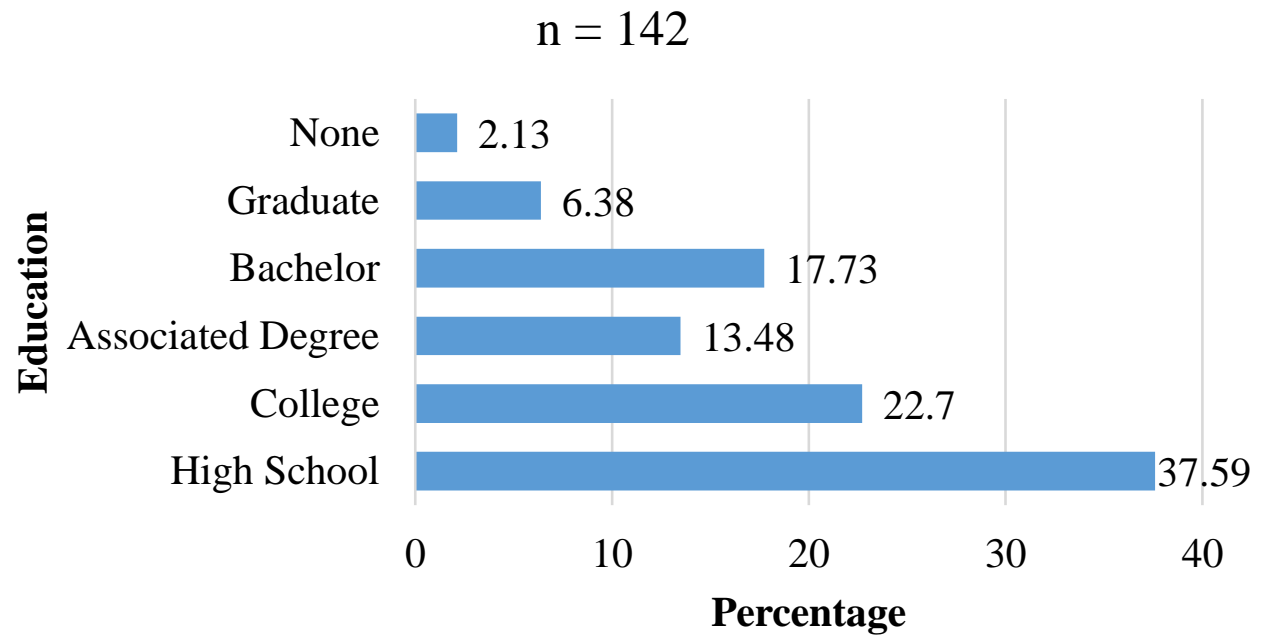

Figure 17: Education Distribution of Respondents 


\subsubsection{Skill}

Five categories have been listed according to the response of the 142 participants in their skill level at the job site; Beginner, Proficient, advanced, Expert and Unanswered. The maximum number of participants were proficient $(36.61 \%)$ at their skill level. Similarity $25.35 \%$ of respondent reported that are a beginner in their skill level.

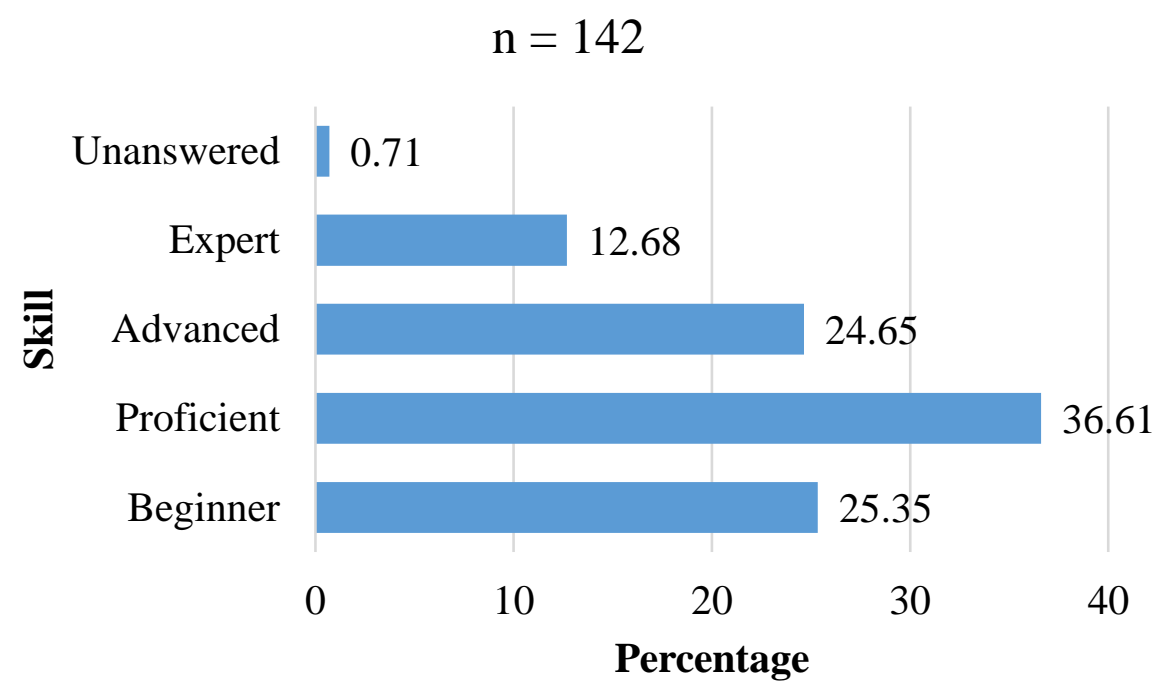

Figure 18: Skill of Respondents

\subsubsection{Summary of Socio-Demographic Data}

Table 5 shows the participants' demographic characteristics with the frequency and percentage. This summary provides information on the ego's characteristics in terms of their age, gender, experience, race, language, education, and skill. This category acts as independent variables. 
Table 5: Demographic Information of the Participants

\begin{tabular}{|c|c|c|c|}
\hline Variables & Category & $\begin{array}{c}\text { Frequency } \\
(n=142)\end{array}$ & Percentage \\
\hline \multirow[t]{11}{*}{ Age } & $<20$ & 19 & $13.38 \%$ \\
\hline & $21-25$ & 25 & $17.61 \%$ \\
\hline & $26-30$ & 21 & $14.79 \%$ \\
\hline & $31-35$ & 19 & $13.38 \%$ \\
\hline & $36-40$ & 15 & $10.56 \%$ \\
\hline & $41-45$ & 15 & $10.56 \%$ \\
\hline & $46-50$ & 9 & $6.34 \%$ \\
\hline & $51-55$ & 8 & $5.63 \%$ \\
\hline & $56-60$ & 9 & $6.34 \%$ \\
\hline & $>60$ & 1 & $0.7 \%$ \\
\hline & unanswered & 1 & $0.7 \%$ \\
\hline \multirow[t]{3}{*}{ Gender } & Female & 21 & $14.79 \%$ \\
\hline & Male & 121 & $85.21 \%$ \\
\hline & Others & 0 & $0 \%$ \\
\hline \multirow[t]{6}{*}{ Experience } & $<1$ year & 15 & $10.56 \%$ \\
\hline & $1-2$ years & 36 & $25.35 \%$ \\
\hline & $3-5$ years & 39 & $27.46 \%$ \\
\hline & 6-10 years & 12 & $8.45 \%$ \\
\hline & $>10$ years & 34 & $23.94 \%$ \\
\hline & unanswered & 6 & $4.22 \%$ \\
\hline \multirow[t]{5}{*}{ Race } & Black or African & 21 & $14.79 \%$ \\
\hline & White & 24 & $16.9 \%$ \\
\hline & Asian & 6 & $4.41 \%$ \\
\hline & Hispanic & 90 & $63.38 \%$ \\
\hline & Others & 5 & $3.52 \%$ \\
\hline \multirow[t]{4}{*}{ Language } & English & 68 & $47.89 \%$ \\
\hline & Spanish & 38 & $26.76 \%$ \\
\hline & Both & 34 & $23.94 \%$ \\
\hline & Others & 2 & $1.41 \%$ \\
\hline \multirow[t]{6}{*}{ Education } & High School & 53 & $37.59 \%$ \\
\hline & College & 32 & $22.7 \%$ \\
\hline & Associated Degree & 19 & $13.48 \%$ \\
\hline & Bachelor & 25 & $17.73 \%$ \\
\hline & Graduate & 9 & $6.38 \%$ \\
\hline & None & 3 & $2.13 \%$ \\
\hline \multirow[t]{5}{*}{ Skill } & Beginner & 36 & $25.35 \%$ \\
\hline & Proficient & 52 & $36.61 \%$ \\
\hline & Advanced & 35 & $24.65 \%$ \\
\hline & Expert & 18 & $12.68 \%$ \\
\hline & Unanswered & 1 & $0.71 \%$ \\
\hline
\end{tabular}




\subsubsection{Overall safety Confidence}

To understand the safety confidence of the respondents, the following question was asked "How confident are you in the following:

(i) To provide safety information to others

(ii) To receive safety information from others

(iii) To perform a newly assigned job safely

(iv) In discussing and working with your team about safety

(v) That people in your job site will watch for each other's safety on site and not just their individual safety”.

The respondents were provided five options to rate their confidence level; Not confidence, somewhat confidence, neutral, confidence and extreme confidence. The analysis part for these three measures has been discussed in detail in the following section;

\begin{tabular}{|l|l|l|l|l|l|}
\hline 5. How confident are you in the following (Tick the appropriate rating, one per line) \\
\hline & $\begin{array}{c}\text { Not } \\
\text { confident }\end{array}$ & $\begin{array}{c}\text { Somewhat } \\
\text { confident }\end{array}$ & Neutral & confident & $\begin{array}{c}\text { Extremely } \\
\text { confident }\end{array}$ \\
\hline A. To provide safety information to others & & & & & \\
\hline $\begin{array}{l}\text { B. To receive safety information from } \\
\text { others }\end{array}$ & & & & & \\
\hline C. To perform a newly assigned job safely & & & & & \\
\hline $\begin{array}{l}\text { D. In discussing and working with your } \\
\text { team about safety }\end{array}$ & & & & & \\
\hline $\begin{array}{l}\text { E. That people in your jobsite will watch for } \\
\text { each other's safety on site and not just } \\
\text { their individual safety }\end{array}$ & & & & & \\
\hline
\end{tabular}

Figure 19: Dependent Variable Questionnaire Formulation 


\section{Overall Confidence}

50

40

30

20

10

0

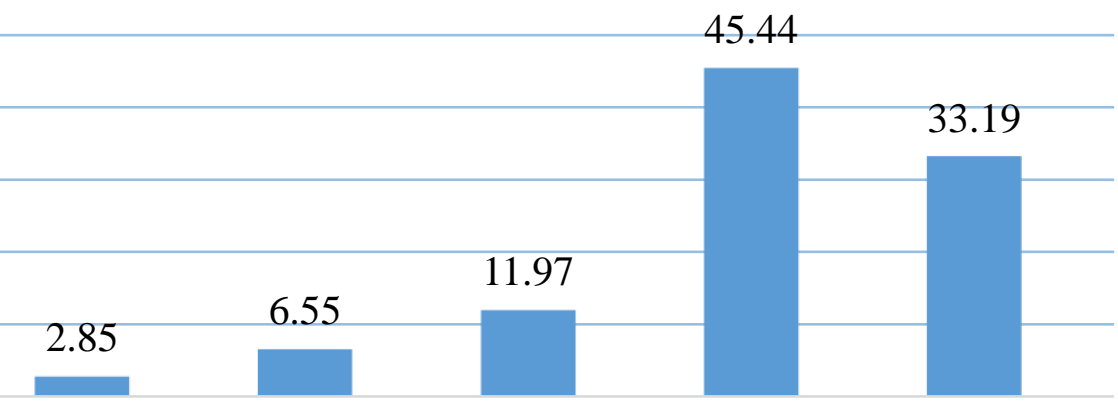

Not confident Somewhat Neutral Confident Confident
Extremely

Confident

\section{Figure 20: Bar Graph Showing the Summary of Confidence of Respondent}

To visualize the confidence of the respondents in general, Table 6 summarizes the overall confidence in safety-related activities. From the overall response collected $(n=142)$, it has been found that more than $75 \%$ of the participants are confident or extremely confident in terms of safety. However, approximately $11.97 \%$ of the respondents state they are neutral. And 9.4\% reported that they are not confident at all or somewhat confident in terms of safety.

Table 6: Confidence of Respondent in Safety Related Activities

\begin{tabular}{|l|c|c|c|c|c|c|}
\hline \multicolumn{7}{|c|}{ 1: not confident at all, 5: Extremely confident } \\
\hline \multicolumn{1}{|c|}{ Response Variable } & $\mathbf{1}$ & $\mathbf{2}$ & $\mathbf{3}$ & $\mathbf{4}$ & $\mathbf{5}$ & Total \\
\hline 1.To provide safety information & 5 & 19 & 25 & 62 & 30 & 141 \\
\hline 2.To receive safety information & 3 & 5 & 14 & 65 & 54 & 141 \\
\hline 3.To Discuss safety information & 1 & 8 & 15 & 71 & 44 & 139 \\
\hline 4.To perform newly assigned job & 3 & 3 & 16 & 63 & 55 & 140 \\
\hline 5.Watch for each other's safety & 8 & 11 & 14 & 58 & 50 & 141 \\
\hline Total & 20 & 46 & 84 & 319 & 233 & 702 \\
\hline Percentage & $2.85 \%$ & $6.55 \%$ & $11.97 \%$ & $45.44 \%$ & $33.19 \%$ & $100 \%$ \\
\hline
\end{tabular}


To evaluate the effect of safety confidence of the respondent the analysis has been done in three different measures from the collected data.

(i) Ego's individual characteristic has been studied to learn the pattern of their confidence level with respect to their personal characteristics.

Age, Gender, Race, Education, Language, and Skill

(ii) The connection between alters (Alter-Alter tie) has been studied to find its influence on confidence.

Density of Network

(iii) Finally, Ego and alter tie (Ego-Alter Tie) have been studied to find the effect of a connection between the network members on ego confidence.

Degree of Network, Frequency of contact, Duration of Contact, Homophily, and Heterogeneity of the network

\subsection{Personal Network Research Design}

This stage aims to present the initial findings with the Personal Network Research Design approach (PNDR). Detailed statistical analysis is done in the next stage after the full data is available.

\section{Network Degree}

The network degree provides information about how many people the respondent has listed. The degree provides the information in the count of social connection that the ego has in his/her network. It is the number of connections that the ego possesses. As the respondent was asked to list one up to five close friends they work with, the density ranges from 1 to 5 for this research. 


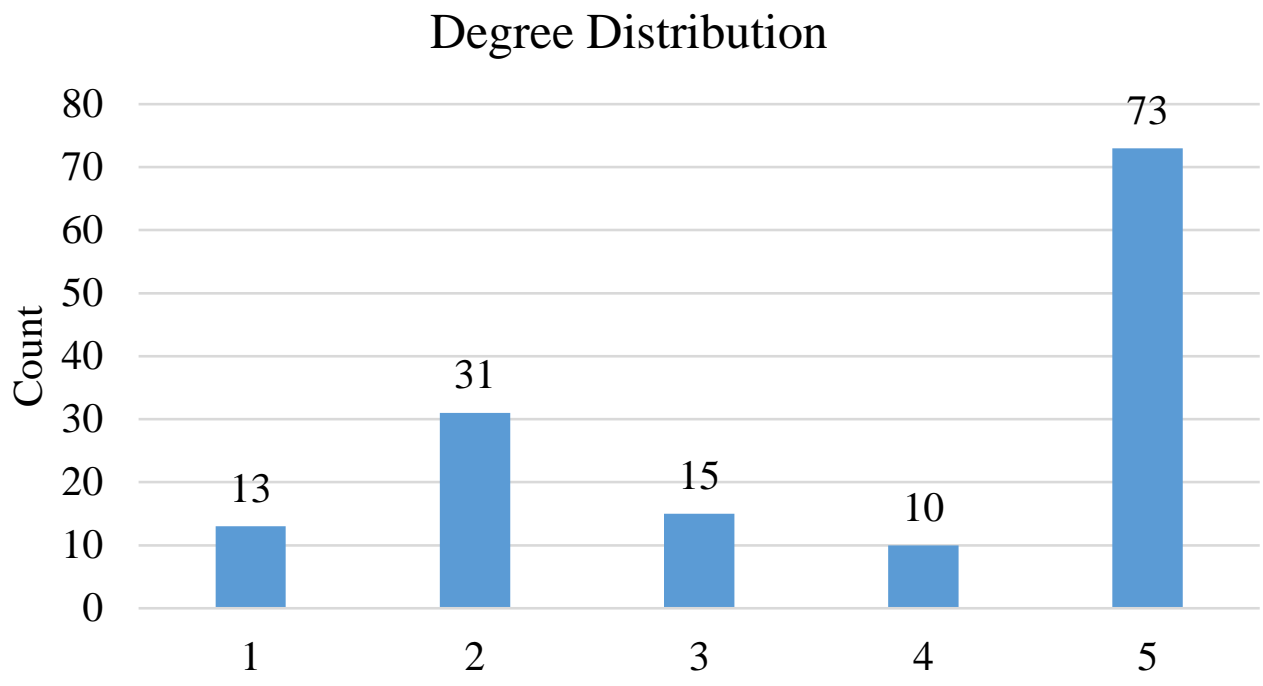

Figure 21: Number of Alter Listed by Ego

The respondents (ego) were asked to list up to 5 number of connections (alter) that he/she knows for the past 6 months or more and with more, they discuss safety and health issues. $54.50 \%$ of the respondent listed five alters, $7.04 \%$ of respondents listed four alters, $10.56 \%$ of respondents listed three alter, $27.83 \%$ of respondents listed two alters and $9.15 \%$ of respondents listed only one alter. The graphical representation has been shown in Figure 21.

\section{Network Density}

The network density shows the connection between the listed alters. Figure 22 presented below shows that the connections among network (alters), it is possible that personal social networks with the same size have different kinds of densities. This means an individual having the same number of friends can have different connection types among their friends which give us different personal network. 


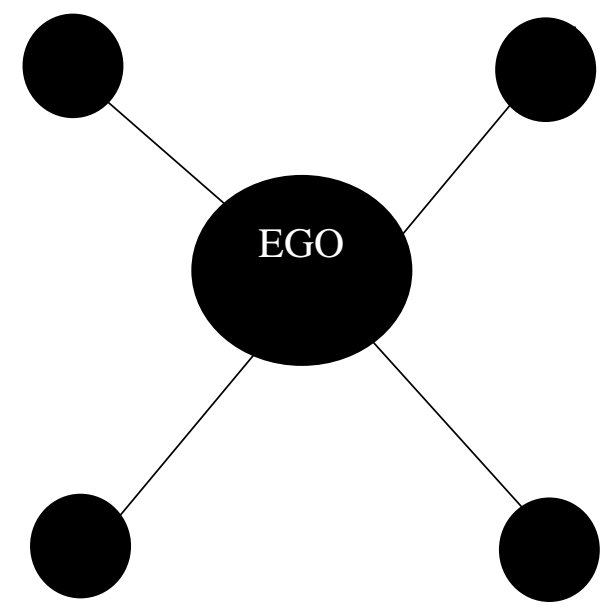

Degree $=4$, Density $=0$

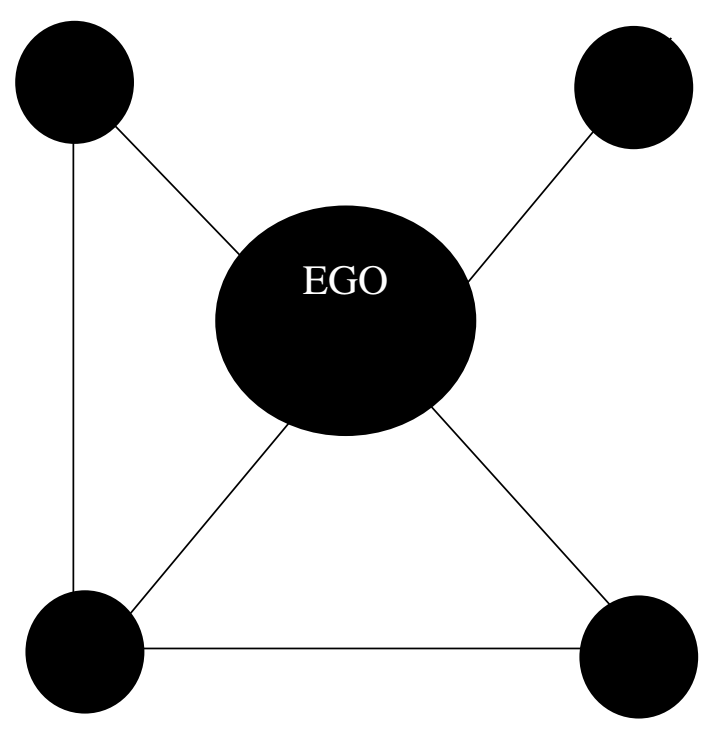

Degree $=4$, Density $=0.5$

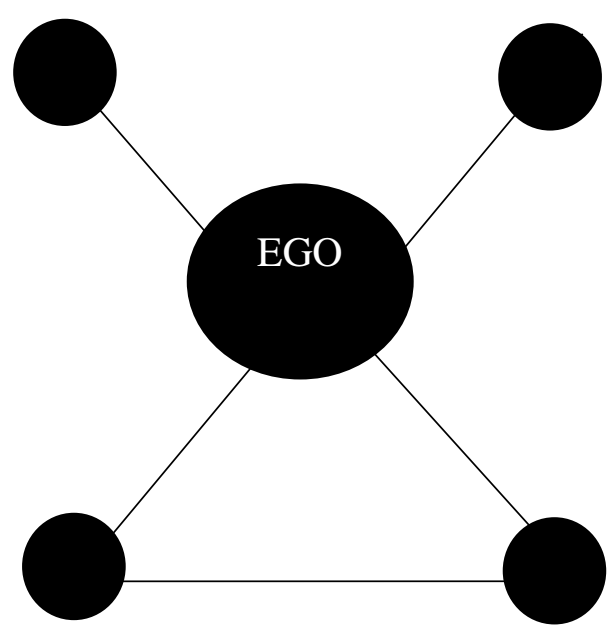

Degree $=4$, Density $=0.17$

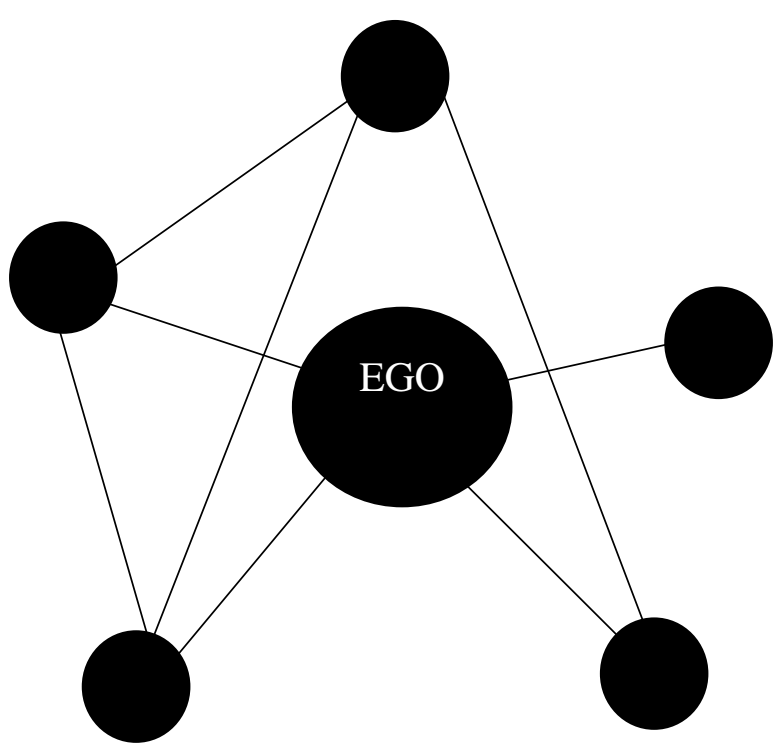

Degree $=5$, Density $=0.14$

Figure 22: Personal Network Degree and Density 


\section{Frequency and Duration of Contact}

To know how strong, the connection between the ego is and alter they were asked how frequently they contact their friends they mentioned. Similarly, the duration of time they have known each other has been asked to find the pattern of the connection that the network has in terms of the frequency and duration.

\section{Homophily and Heterogeneity Concept}

The concept of homophily can explain how the similarity nature between the network can affect their safety confidence in various levels. Similarly, the concept of heterogeneity explains how dissimilarity between the connection in the personal network can affect the confidence in different categories i.e., (i) To provide safety information to others (ii) To receive safety information from others (iii) To perform a newly assigned job safely (iv) In discussing and working with your team about safety and (v) That people in your job site will watch for each other's safety on site and not just their individual safety.

Besides the dependent variable (safety confidence), the independent variables (degree, density, frequency of contact), we gathered additional individual-specific control variables - gender, age, years of experience, skill level - which needed to be added into the data analysis to rule out the effects of individual differences in the findings. Table 7 presents the additional information on the mean, standard deviation of the independent variables.

The sample network from collected data has been presented in Figure 23 which shows the number of connections, ties in the network, similarity and dissimilarity among the networks. 
Table 7: Descriptive Statistics of Collected Variables

\begin{tabular}{|c|c|c|c|c|}
\hline \multicolumn{5}{|c|}{ Confidence of Respondent ( $N=142)$} \\
\hline Variable & Mean & S.D & Minimum & Maximum \\
\hline Density & 0.321 & 0.161 & 0 & 0.72 \\
\hline Degree (average) & 3.606 & 1.282 & 2 & 5 \\
\hline Frequency (average) & 1.519 & 0.803 & 1 & 3.4 \\
\hline Duration (average) & 1.684 & 0.855 & 1 & 3.2 \\
\hline Homophily: Age & 0.636 & 0.518 & -1 & 1 \\
\hline Gender & -0.574 & 0.631 & 0.5 & 1 \\
\hline Race & -0.265 & 0.823 & -1 & 1 \\
\hline Education & 0.787 & 0.538 & -1 & 1 \\
\hline Language & -0.378 & 0.732 & -1 & 1 \\
\hline Skill & 0.242 & 0.734 & -1 & 1 \\
\hline Experience & 0.200 & 0.744 & -1 & 1 \\
\hline Heterogeneity: Age & 0.485 & 0.261 & 0 & 0.72 \\
\hline Gender & 0.137 & 0.230 & 0 & 0.48 \\
\hline Race & 0.187 & 0.233 & 0 & 0.72 \\
\hline Education & 0.329 & 0.257 & 0 & 0.72 \\
\hline Language & 0.191 & 0.226 & 0 & 0.64 \\
\hline Skill & 0.356 & 0.282 & 0 & 0.72 \\
\hline Experience & 0.329 & 0.248 & 0 & 0.64 \\
\hline
\end{tabular}

$* \mathrm{SD}=$ Standard Deviation

*-1 complete homophily +1 complete heterogeneity

*Homophily: -1 to +1

*Heterogeneity: 0 to +1

\begin{tabular}{|c|c|c|c|c|}
\hline (n) & (n) & (n) & - & \\
\hline Ego & Male Alter & Female Alter & $\begin{array}{c}\text { Ego-Alter } \\
\text { connection }\end{array}$ & $\begin{array}{c}\text { Alter-Alter } \\
\text { connection }\end{array}$ \\
\hline
\end{tabular}

*Figure A, B and C: Personal network of the respondent with high, neutral and no confidence to provide safety information

*Score Range for Network Density: 0 to +1

Score Range for Network Degree: 1 to 5

$*_{\mathrm{n}}=$ Age 
A.

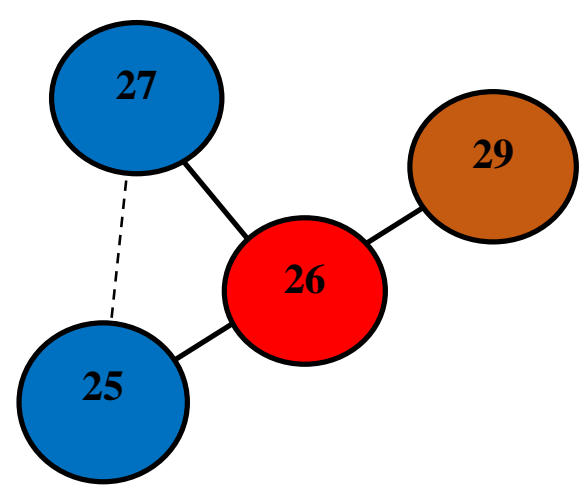

B.

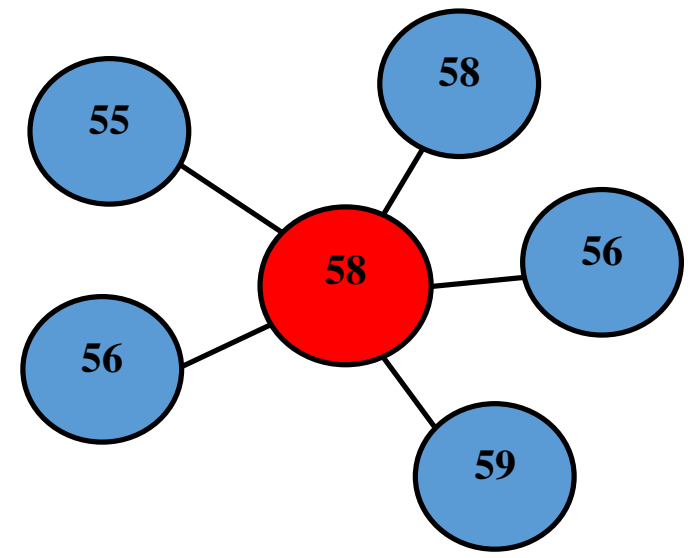

\begin{tabular}{|c|c|}
\hline Network Measures & Value \\
\hline Density & 0.3 \\
\hline Degree & 3 \\
\hline Age Homophily & 1 \\
\hline Age Heterogeneity & 0.5 \\
\hline Gender Homophily & -1 \\
\hline Gender Heterogeneity & 0 \\
\hline
\end{tabular}

\begin{tabular}{|c|c|}
\hline Measure & Value \\
\hline Density & 0 \\
\hline Degree & 5 \\
\hline Age Homophily & 1 \\
\hline Age Heterogeneity & 0.64 \\
\hline Gender Homophily & -1 \\
\hline Gender Heterogeneity & 0 \\
\hline
\end{tabular}

C.

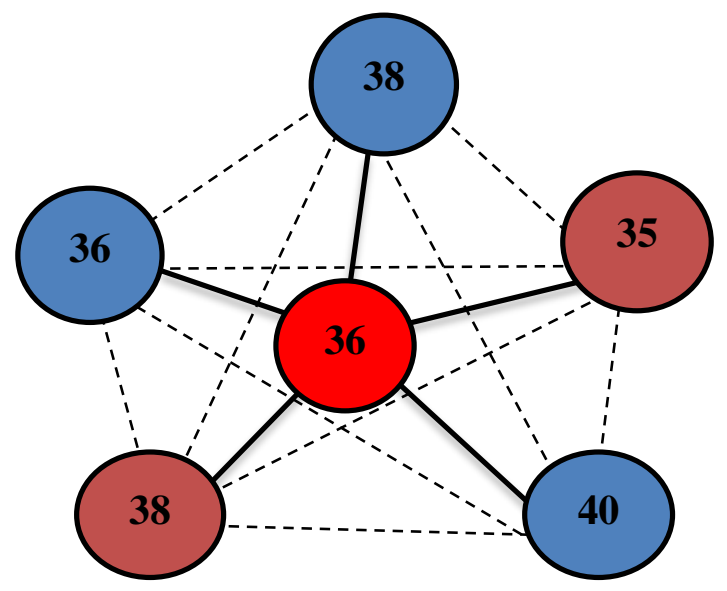

\begin{tabular}{|c|c|}
\hline Measures & Value \\
\hline Density & 1 \\
\hline Degree & 5 \\
\hline Age Homophily & 1 \\
\hline Age Heterogeneity & 0.72 \\
\hline Gender Homophily & -0.2 \\
\hline Gender Heterogeneity & 0.48 \\
\hline
\end{tabular}

Figure 23: Personal Network of Different Characteristics 


\subsection{Probit Regression Analysis}

For further analysis, we used the Ordered Probit modeling analysis approach due to the presence of the dependent variable is ordinal (statistically it is polytomous ordinal) and the independent variables in ordinal or continuous-level (ratio or interval). Ordered regression describes data and explains the relationship between one dependent variable and two or more independent variables. For this research ordered regression analysis was conducted to test the relationship between safety confidence related activities with individual and personal characteristics. It identified the strength of the effect that the independent variables have on a dependent variable. This approach is appropriate to understand the safety confidence of an individual in various aspects. As numerous factors could affect one's safety confidence in job site, these dependent variables can be modeled as ordinal data (i.e., Extremely confident, Confident, Neutral, Somewhat confident, Not confident at all).

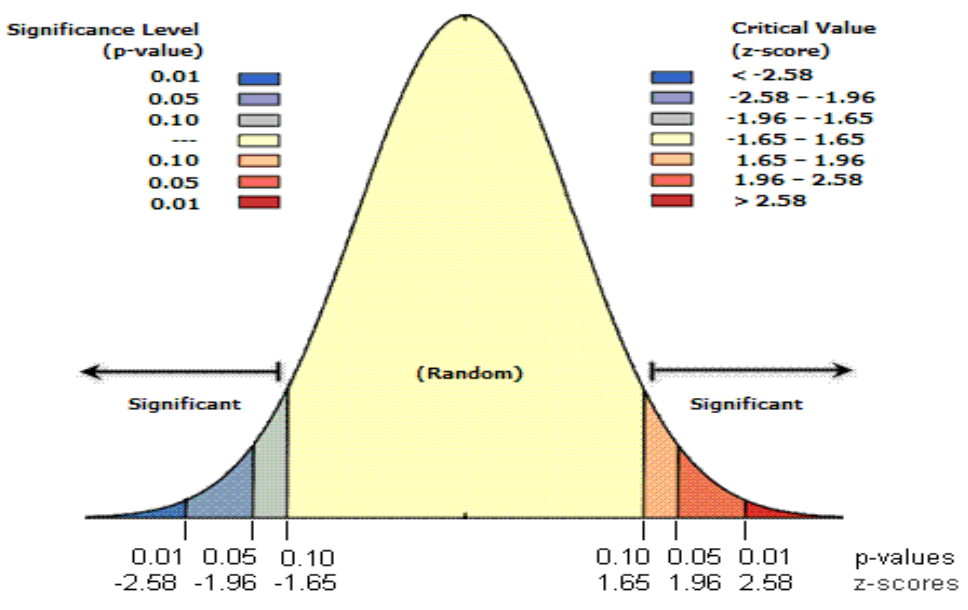

Figure 24: Statistically Significance Scale Reference used in the Study [43] 
Table 8: Statistically Significance Scale

\begin{tabular}{|c|c|c|}
\hline z-score (Standard Deviations) & p-value (Probability) & Confidence level \\
\hline$<-1.65$ or $>+1.65$ & $<0.10$ & $90 \%$ \\
\hline$<-1.96$ or $>+1.96$ & $<0.05$ & $95 \%$ \\
\hline$<-2.58$ or $>+2.58$ & $<0.01$ & $99 \%$ \\
\hline
\end{tabular}

A significant amount of 5 percent (i.e., 0.05) or less was considered statistically significant for this analysis. For this research, the probability of less than $10 \%$ (i.e., 0.10) is considered enough to conclude that there may be a tendency toward statistical significance between two variables. All significant correlations which have $p<0.10$ are disclosed in the study.

An ordinal probit regression analysis is carried out to determine which independent variable has a statistically significant effect on the dependent variable. This would help to determine how well the model would predict it [46]. An ordered probit regression analysis is the selected as an analysis for the collected data, as this is fit for the generalization of cases of more than two outcomes of an ordinal dependent variable (a variable with potential values such as not confident, somewhat confident fair, neutral, confident, highly confident). For this model, the dependent variables are defined as the confidence in different aspect of sharing safety information.

1. to provide safety information to other

2. to receive safety information from others

3. to perform a newly assigned job safely 
4. to discuss safety

5. to watch each other

While the independent variables are categorized into three-level;

\section{Individual Characteristics:}

Age, Gender, Race, Education, Language, Skill, and Experience.

\section{Alter-Alter Connection}

Density of network

\section{Ego-Alter Connection}

Frequency of contact, duration of contact, degree of network, homophily, and heterogeneity in terms of age, gender, language, education, skill, and experience.

The ordinal probit regression model utilizes these parameters through the following equation:

$$
y^{*}=X \beta+\varepsilon
$$

where $\mathrm{y}^{*}$ is the dependent variable measuring the confidence in terms of safety (coded as $1,2,3,4,5) ; \mathrm{X}$ is the vector of observed explanatory variables; $\beta$ is the vector of unknown parameters and $\in$ is the error factor. The observed safety confidence, $y^{*}$ is determined from the model as follows:

$$
y^{*}=\left\{\begin{array}{c}
1 \text { if }-\infty \leq y^{*} \leq \mu_{1} \text { (Not Confident) } \\
2 \text { if } \mu_{1} \leq y^{*} \leq \mu_{2} \text { (Somewhat confident) } \\
3 \text { if } \mu_{2} \leq y^{*} \leq \mu_{3} \text { (Neutral) } \\
4 \text { if } \mu_{3} \leq y^{*} \leq \mu_{4} \text { (Confident) } \\
5 \text { if } \mu_{4} \leq y^{*} \leq \mu_{5} \text { (Extremely Confident) }
\end{array}\right.
$$


By using the statistical software STATA, thresholds $\mu_{\mathrm{n}}$, where $\mathrm{n}=1,2 \ldots 5$ and parameters $\beta$ were estimated.

$$
\mathrm{P}(\mathrm{y}=\mathrm{n})=\mathrm{U}\left(\mu_{\mathrm{n}}-X \beta\right)-\mathrm{U}\left(\mu_{\mathrm{n}-1}-X \beta\right)
$$

Here $\mu_{0}=0, \mu_{1}<\mu_{2}<\mu_{3}<\mu_{4}$ and $\mu_{5}=\infty$ are five thresholds between which categorical are estimated. Here thresholds $\boldsymbol{\mu}$ represents the normal distribution with the values of the response variable.

\subsection{Model Results Description}

Several variables were tested to present the best fit model. The variable that is statistically significant with the dependent variables (safety confidence) were measured in scale 1 to 5 . As discussed earlier the first step was to evaluate if the confidence of the individual has any significant relation with their individual characteristics i.e., age, gender, experience, skill, education, education, etc. And second, their confidence was tested with their personal characteristics (alter-alter tie and ego-alter tie) i.e., the density of the

network, network degree, frequency of contact, duration of contact, homophily and heterogeneity in the network. The results have been interpreted in different level explained as follows;

\section{(A) To provide safety information to others}

From the collected data the response has been collected as shown in Figure 25. Out of 142 respondents, $3.55 \%$ of them reported they were not confident to provide safety information to others, $13.48 \%$ of them were somewhat confident, $17.73 \%$ of them were neutral, $43.97 \%$ of them were confident and $21.28 \%$ of them reported they were extremely 
confident. This data shows that $34.76 \%$ of the respondents reported they were neutral or below neutral to provide safety information to their friends with whom they work on the job site.

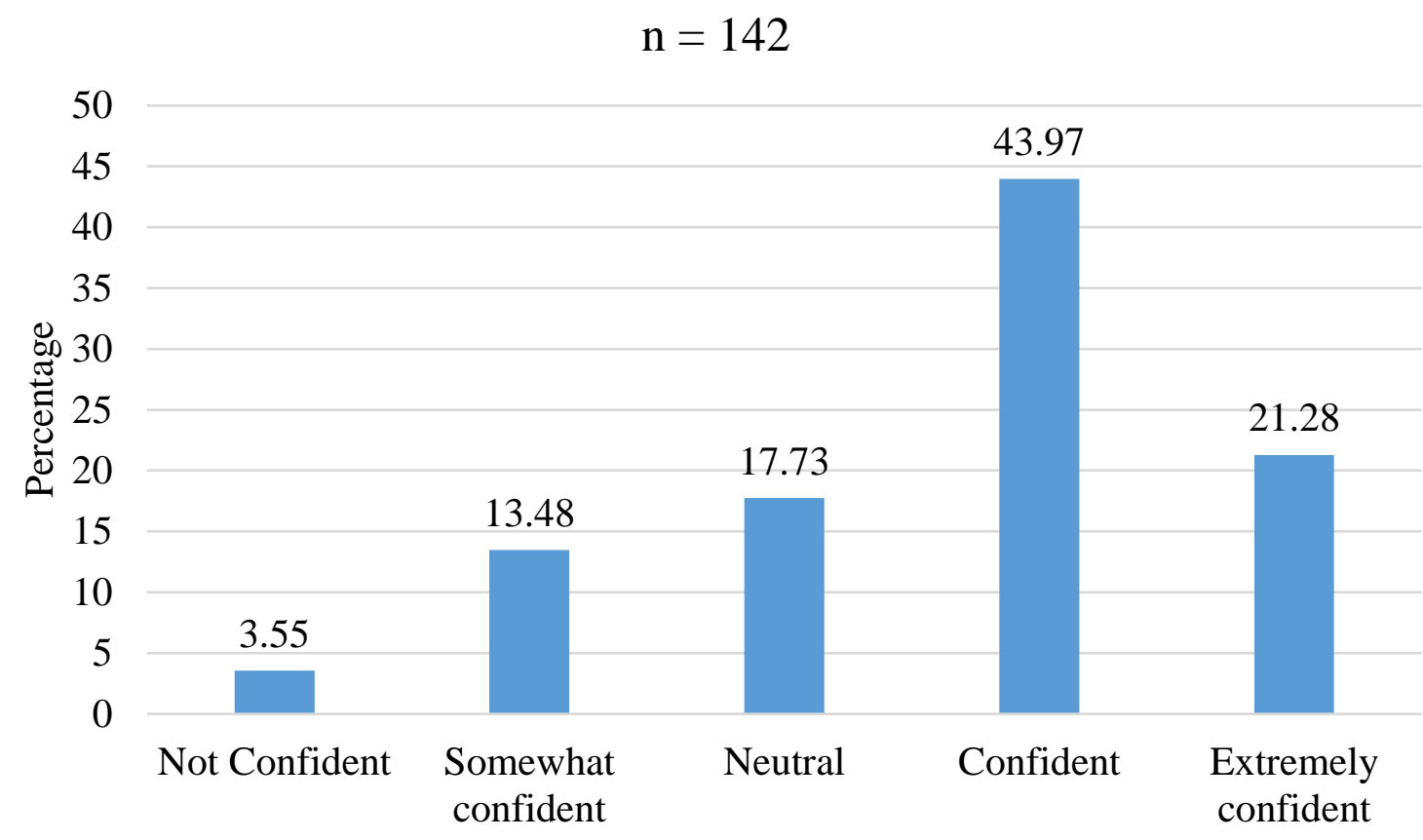

- Confidence to provide safety information

\section{Figure 25: Bar Graph Representative of Frequency Distribution}

For this research, it is important to see if there any correlation between the dependent variables (i.e., their confidence in terms of safety) and other independent variables (i.e., their individual characteristics and personal characteristics). Table 9 shows the correlation matrix of these variables. 
Table 9: Correlation Matrix

\begin{tabular}{|c|c|c|c|c|c|c|c|c|c|c|c|c|c|}
\hline & & 1 & 2 & 3 & 4 & 5 & 6 & 7 & 8 & 9 & 10 & 11 & 12 \\
\hline 1 & $\begin{array}{l}\text { Gender ( } 1 \text { if } \\
\text { Female, } 0 \\
\text { otherwise) }\end{array}$ & 1.0 & & & & & & & & & & & \\
\hline 2 & $\begin{array}{l}\text { Language (1 if } \\
\text { Spanish, } 0 \\
\text { otherwise) }\end{array}$ & $\begin{array}{l}- \\
0.12\end{array}$ & 1.0 & & & & & & & & & & \\
\hline 3 & $\begin{array}{l}\text { Frequency ( } 1 \\
\text { if } \geq 1.25,0 \text { if } \\
\text { otherwise) }\end{array}$ & 0.22 & -0.10 & 1.0 & & & & & & & & & \\
\hline 4 & $\begin{array}{l}\text { Network } \\
\text { Density ( } 1 \text { if } \geq \\
0.35,0 \text { if } \\
\text { otherwise) }\end{array}$ & $\begin{array}{l}- \\
0.06\end{array}$ & 0.01 & -0.02 & 1.0 & & & & & & & & \\
\hline 5 & $\begin{array}{l}\text { Homophily } \\
\text { Age (1 if } \geq \\
0.50,0 \\
\text { otherwise })\end{array}$ & $\begin{array}{l}- \\
0.07\end{array}$ & -0.01 & -0.02 & -0.02 & 1.0 & & & & & & & \\
\hline 6 & $\begin{array}{l}\text { Homophily } \\
\text { Race ( } 1 \text { if } \geq \\
0.50,0 \text { if } \\
\text { otherwise) }\end{array}$ & $\begin{array}{l}- \\
0.02\end{array}$ & -0.02 & -0.04 & 0.38 & -0.04 & 1.0 & & & & & & \\
\hline 7 & $\begin{array}{l}\text { Homophily } \\
\text { Skill ( } 1 \text { is } \geq \text { - } \\
0.6,0 \\
\text { otherwise) }\end{array}$ & $\begin{array}{l}- \\
0.12\end{array}$ & 0.09 & -0.04 & 0.15 & -0.05 & $\begin{array}{l}- \\
0.07\end{array}$ & 1.0 & & & & & \\
\hline 8 & $\begin{array}{l}\text { Homophily } \\
\text { Experience ( } 1 \\
\text { if } \geq 0.5,0 \text { if } \\
\text { otherwise) }\end{array}$ & $\begin{array}{l}- \\
0.14\end{array}$ & 0.009 & -0.05 & 0.45 & -0.06 & 0.33 & 0.41 & 1.0 & & & & \\
\hline 9 & $\begin{array}{l}\text { Heterogeneity } \\
\text { Age ( } 1 \text { if age } \\
\text { heterogeneity } \\
\text { is over } 0.75,0 \\
\text { if otherwise) }\end{array}$ & $\begin{array}{l}- \\
0.06\end{array}$ & 0.12 & -0.02 & -0.02 & 0.26 & $\begin{array}{l}- \\
0.04\end{array}$ & $\begin{array}{l}- \\
0.04\end{array}$ & $\begin{array}{l}- \\
0.05\end{array}$ & 1.0 & & & \\
\hline 10 & $\begin{array}{l}\text { Heterogeneity } \\
\text { Race ( } 1 \text { if } \geq \\
0.50,0 \text { is } \\
\text { otherwise ) }\end{array}$ & $\begin{array}{l}- \\
0.10\end{array}$ & -0.08 & -0.03 & -0.03 & -0.04 & $\begin{array}{l}- \\
0.06\end{array}$ & 0.06 & 0.02 & $\begin{array}{l}- \\
0.03\end{array}$ & 1.0 & & \\
\hline 11 & $\begin{array}{l}\text { Heterogeneity } \\
\text { Skill ( } 1 \text { if } \geq \\
0.40,0 \text { if } \\
\text { otherwise })\end{array}$ & $\overline{-}-06$ & 0.013 & -0.02 & -0.02 & 0.56 & $\overline{0}-\overline{0}$ & $\begin{array}{l} \\
0.04\end{array}$ & $\overline{-}-\overline{0}$ & $\overline{-}-02$ & $\overline{-}-\overline{0}$ & 1.0 & \\
\hline 12 & $\begin{array}{l}\text { Heterogeneity } \\
\text { Experience ( } 1 \\
\text { if } \geq 0.30,0 \text { if } \\
\text { otherwise) }\end{array}$ & $\begin{array}{l}- \\
0.05\end{array}$ & -0.06 & -0.08 & 0.31 & -0.09 & 0.35 & 0.16 & 0.61 & $\begin{array}{l}- \\
0.08\end{array}$ & 0.13 & $\begin{array}{l}- \\
0.08\end{array}$ & 1.0 \\
\hline
\end{tabular}




\section{Effect of Individual characteristics}

The effect of individual characteristics on their confidence level to provide safety information has the effect of attributes which include age, gender, race, language, experience, education, and skill. The findings show that females are less $(\boldsymbol{\beta}=\mathbf{- 0 . 4 5})$ likely to have the confidence to provide safety information to their friends. Among 142 respondents, only $14.79 \%$ of them reported their gender as Female and $85.21 \%$ as Male. This shows the lack of diversity in the workplace in terms of gender. A minimal number of females are involved in the construction industry when compared to males [13]. In Figure 26, it shows the number of workplace injury from 2009 to 2018 by gender. The pattern shows that the number of female related injuries is $8.5 \%$ in 2018 out of total injuries.

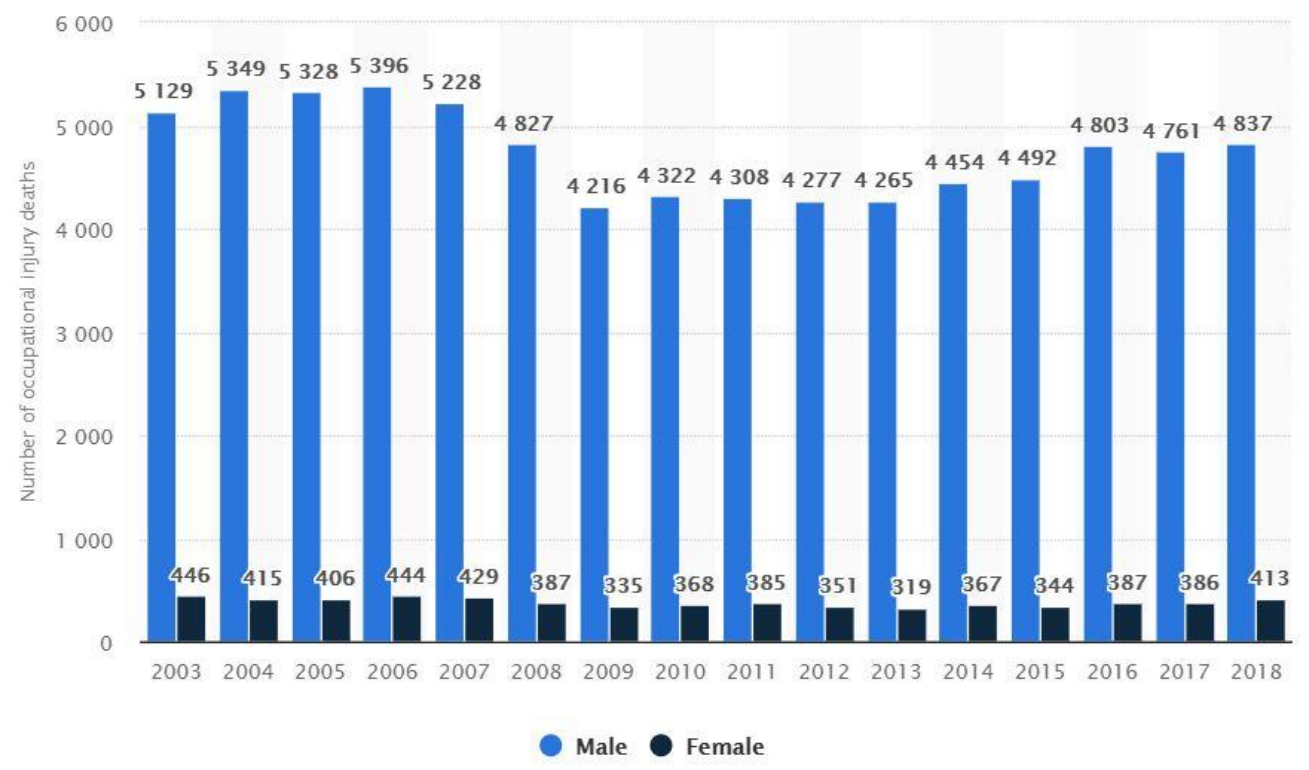

Figure 26: Number of Injury Deaths in U.S. by Gender [13]

Individuals speaking Spanish are less likely to have the confidence to provide safety information to others. From the collected data it has been found that $47 \%$ of the respondent 
speaks only English and $27 \%$ of them reported that they speak Spanish. This result suggested that language can create a barrier to proper communication within the friends. Related research has found that clear communication regarding safety will encourage people and reduce hazards [47]. The result shows that language is also one of the keys to ensuring proper communication to improve safety.

\section{Personal Network Characteristics}

The results presented in Table 10 shows that denser the connection between the network members (density of the network) people are more likely to have higher confidence to provide safety information. This result suggested that when the people working together has stronger connection confidence to provide safety-related information increases. Similarly, frequency of contact between the individual and the friends also showed a significant result $(\boldsymbol{\beta}=\mathbf{+ 1 . 9 6})$ at $95 \%$ of the level of significance. This suggests that more frequently people interact and contact their friends, more confident they are to provide safety information.

The similarity in the network (i.e., homophily) in terms of age, experience, and race shows significance value with a negative coefficient. This indicates that lower the similarity within the people, lower the confidence to provide safety information. The dissimilarity in the network in terms of age and skill is significant with a negative coefficient. This indicates that people with more differences in their age and skill are more likely to have lower confidence to provide safety information. 
Table 10: Results of Probit Test for Confidence to Provide Safety Information

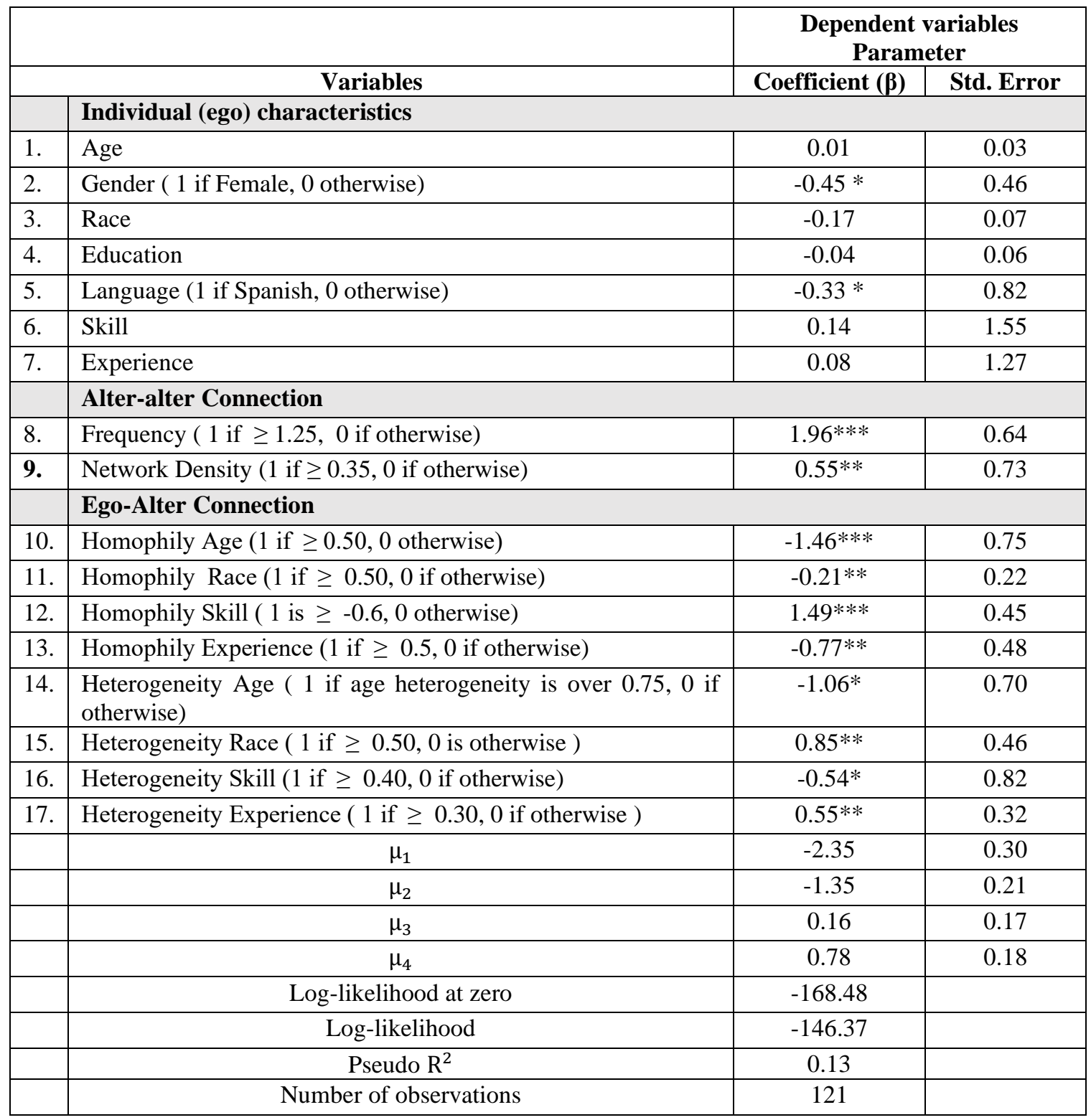

\footnotetext{
* - Not significant

* significant at the level 0.10 level: **at the level .05 level; *** at the level 0.01 level.
} 


\section{(A) To receive safety information to others}

From the collected data the response has been collected as shown in Figure 27. Out of 141 respondents, $2.12 \%$ of them were not confident, $3.54 \%$ of them were somewhat confident, $9.92 \%$ of them were neutral, $46.09 \%$ of them were confident and $38.29 \%$ of them said they were extremely confident.

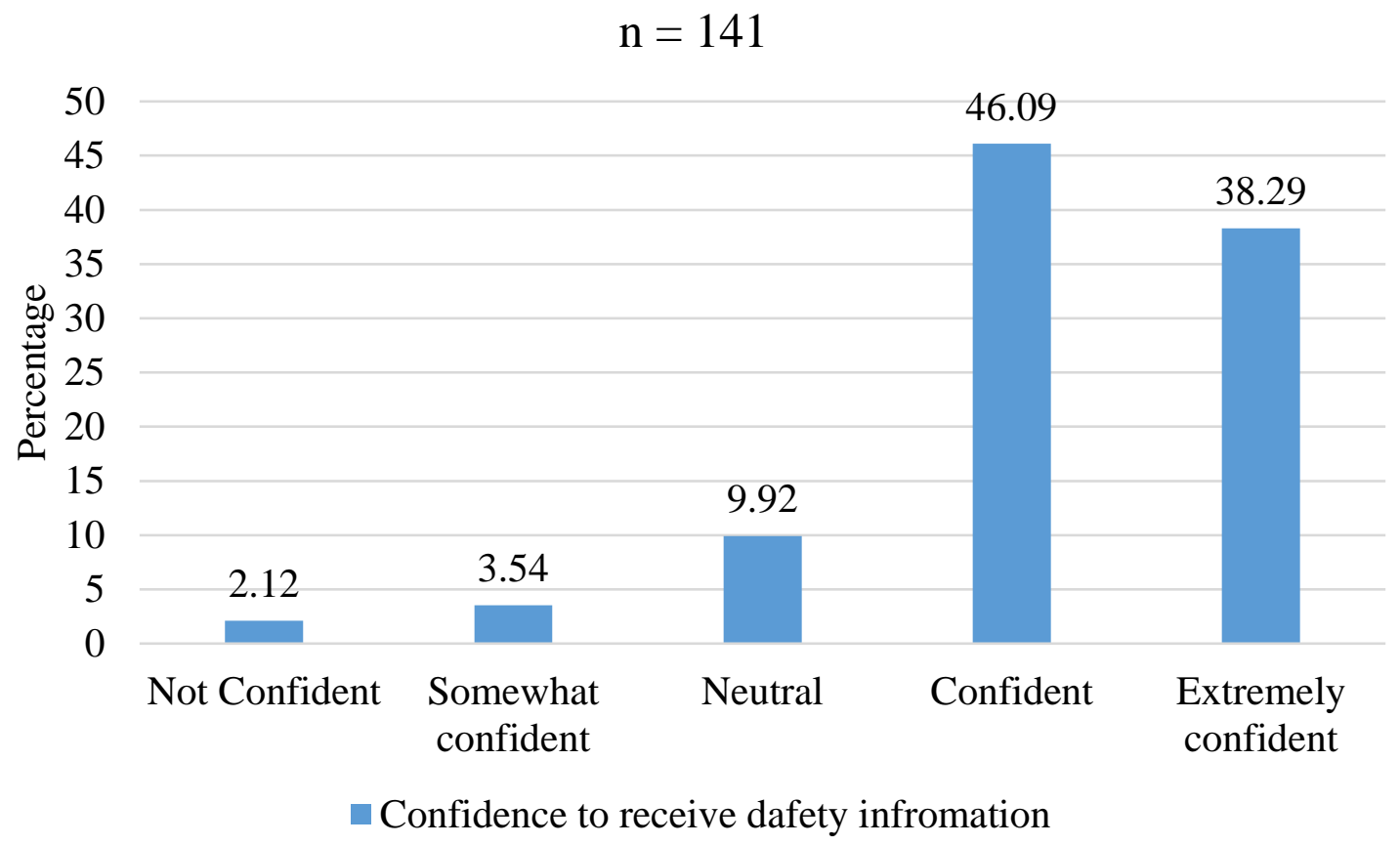

Figure 27: Confidence of Respondent to Receive Safety Information

The data showed that $15.58 \%$ of the respondents reported their confidence are neutral or below to receive information from their friends. The correlation matrix for the variable has been shown in Table 11. 
Table 11: Correlation Matrix

\begin{tabular}{|c|c|c|c|c|c|c|c|c|}
\hline & & 1 & 2 & 3 & 4 & 5 & 6 & 7 \\
\hline 1 & $\begin{array}{l}\text { Gender ( } 1 \text { if } \\
\text { Female, } 0 \\
\text { otherwise) }\end{array}$ & 1.0 & & & & & & \\
\hline 2 & $\begin{array}{l}\text { Education ( } 1 \text { is } \\
\text { Bachelor or } \\
\text { higher, } 0 \\
\text { otherwise) }\end{array}$ & 0.03 & 1.0 & & & & & \\
\hline 3 & $\begin{array}{l}\text { Frequency ( } 1 \text { if } \geq \\
1.25,0 \text { if } \\
\text { otherwise) }\end{array}$ & 0.22 & -0.08 & 1.0 & & & & \\
\hline 4 & $\begin{array}{l}\text { Network Density } \\
(1 \text { if } \geq 0.35,0 \text { if } \\
\text { otherwise) }\end{array}$ & -0.06 & -0.08 & -0.02 & 1.0 & & & \\
\hline 5 & $\begin{array}{l}\text { Homophily Age } \\
(1 \text { if } \geq-0.30,0 \\
\text { otherwise) }\end{array}$ & 0.21 & -0.04 & 0.57 & -0.01 & 1.0 & & \\
\hline 6 & $\begin{array}{l}\text { Homophily } \\
\text { Experience ( } 1 \text { if } \\
\geq-0.60,0 \text { if } \\
\text { otherwise) }\end{array}$ & -0.14 & -0.12 & -0.05 & 0.46 & -0.03 & 1.0 & \\
\hline 7 & $\begin{array}{l}\text { Homophily Age } \\
(1 \text { if } \geq-0.30,0 \\
\text { otherwise })\end{array}$ & 0.05 & 0.008 & -0.02 & -0.02 & -0.01 & -0.06 & 1.0 \\
\hline
\end{tabular}




\section{Effect of Individual characteristics}

The effect of individual characteristics on their confidence level to receive safety information has the effect of the attributes which include age, gender, race, language, experience, education, and skill. The result shows that females are likely to have less

confidence to receive safety information from their network $(\boldsymbol{\beta}=\mathbf{- 0 . 2 2})$. People with a bachelor or higher education level are likely to have less confidence to receive safety information from others $(\boldsymbol{\beta}=\mathbf{- \mathbf { 0 . 4 5 }})$. However other variable doesn't show any significant relationship with the people confidence to receive safety information.

\section{Personal Network Characteristics}

The results presented show that people whose connection are densely connected (density 0.35 or higher) they are more likely to have the confidence to receive safety information from others $(\boldsymbol{\beta}=\mathbf{- 0 . 9 7})$. Similarly, more people contact their friend (frequency of contact) they are more likely to be confident to receive safety information from others. 
Table 12: Results of Probit Test for Confidence to Receive Safety Information

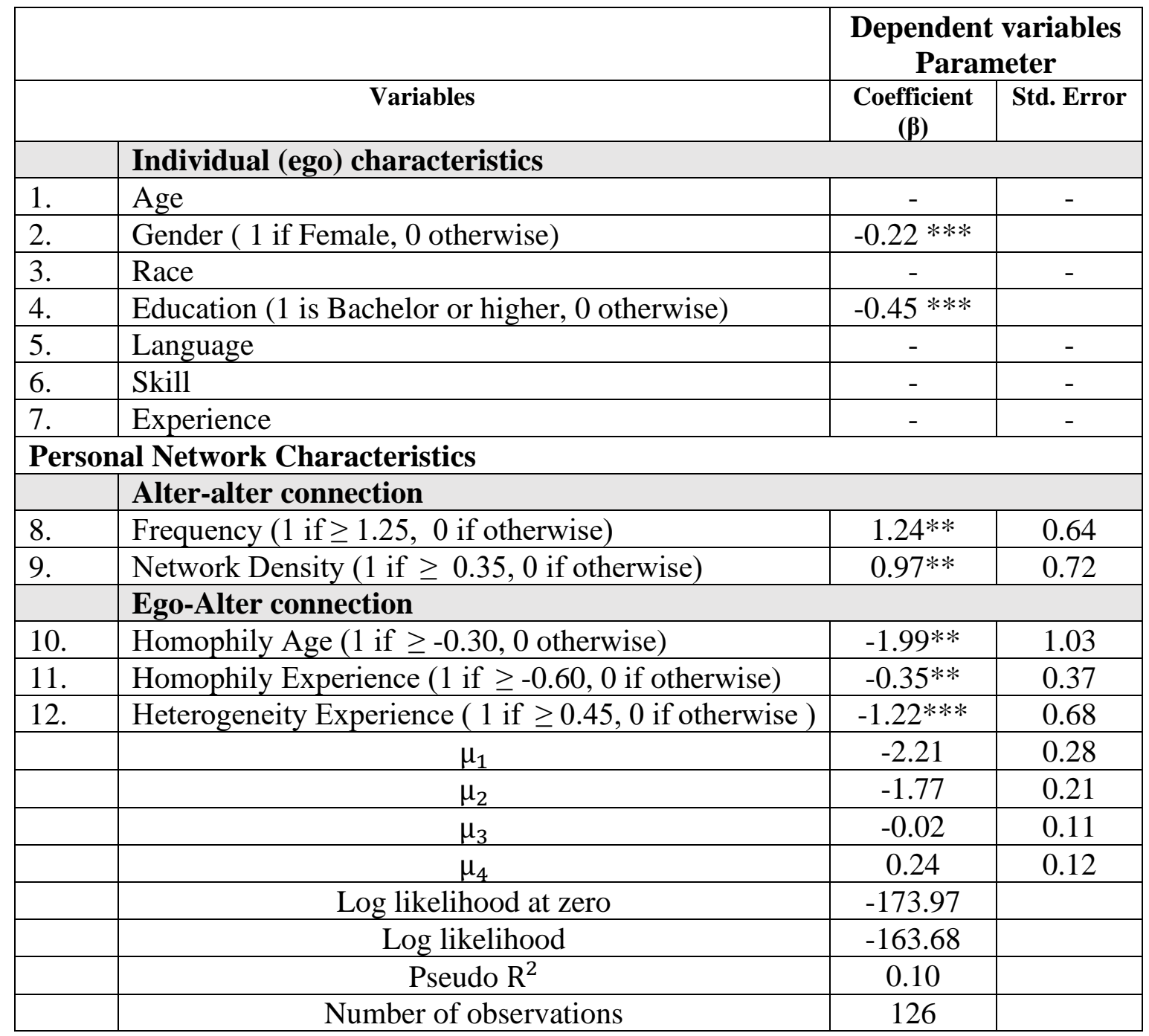

* - Not significant

* significant at the level 0.10 level: **at the level .05 level; *** at the level 0.01 level.

When the variables were tested to measure the effect of similarity and dissimilarity between the individuals, the similarity in age and experience was significant $(\mathrm{p}<0.05)$. Higher in the dissimilarity in experience between the alters people will have lower confidence to receive safety information. 


\section{(C) To perform a newly assigned job safely}

From the collected data the response has been collected as shown in Figure 28. Out of 139 respondents, $0.72 \%$ of them were not confident, $5.75 \%$ of them were somewhat confident, $10.79 \%$ of them were neutral, $51.18 \%$ of them were confident and $31.65 \%$ of them said they were extremely confident.

$$
\mathrm{n}=139
$$

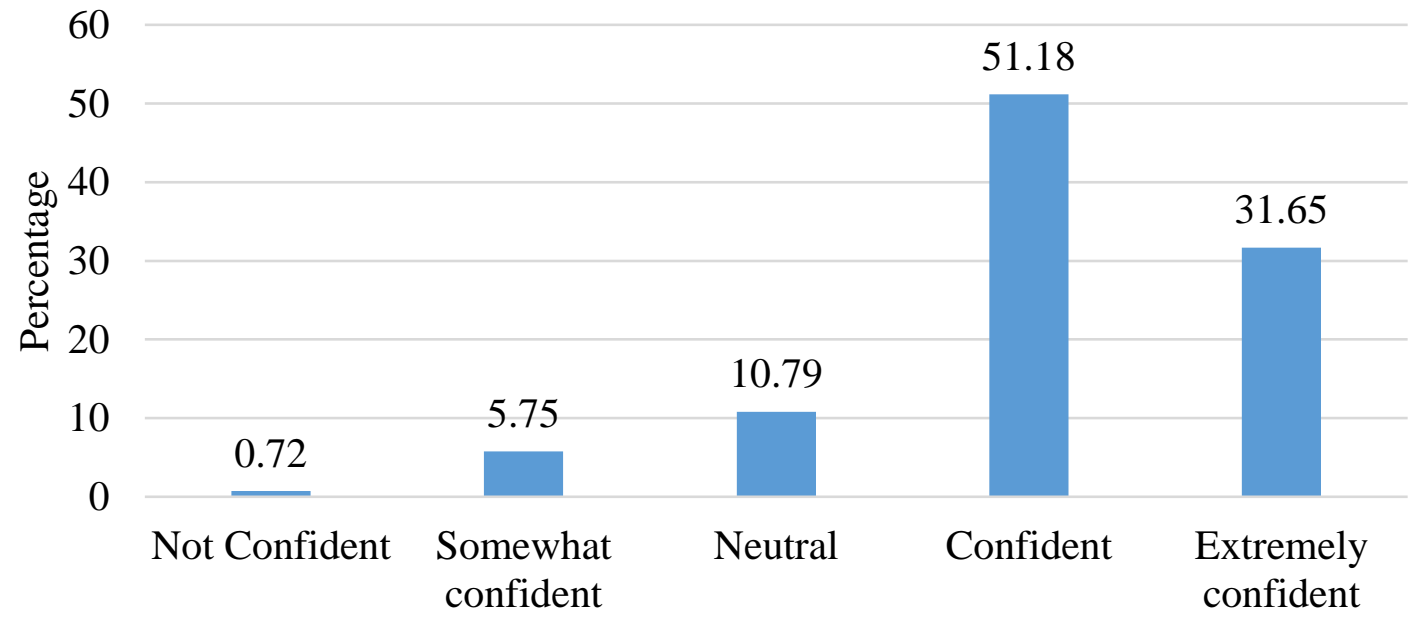

匹 Confidence to perform newly assigned job safely

Figure 28: Confidence of Respondents to Perform Newly Assigned Job 
Table 13: Correlation Matrix

\begin{tabular}{|c|c|c|c|c|c|c|c|c|c|c|c|c|c|}
\hline & & 1 & 2 & 3 & 4 & 5 & 6 & 7 & 8 & 9 & 10 & 11 & 12 \\
\hline 1 & $\begin{array}{l}\text { Skill (1 if } \\
\text { Beginner, } 0 \text { if } \\
\text { otherwise) }\end{array}$ & 1.0 & & & & & & & & & & & \\
\hline 2 & $\begin{array}{l}\text { Network } \\
\text { Density ( } 1 \text { if } \\
\geq 0.35,0 \text { if } \\
\text { otherwise) }\end{array}$ & $\overline{-}-04$ & 1.0 & & & & & & & & & & \\
\hline 3 & $\begin{array}{l}\text { Frequency ( } 1 \\
\text { if } \geq 1.25, \quad 0 \text { if } \\
\text { otherwise) }\end{array}$ & 0.05 & 0.57 & 1.0 & & & & & & & & & \\
\hline 4 & $\begin{array}{l}\text { Homophily } \\
\text { Age (1 if } \geq \\
0.60,0 \\
\text { otherwise) }\end{array}$ & 0.19 & $\overline{-}-04$ & $\overline{-}-07$ & 1.0 & & & & & & & & \\
\hline 5 & $\begin{array}{l}\text { Homophily } \\
\text { Experience ( } 1 \\
\text { if } \geq-0.99,0 \\
\text { if otherwise) }\end{array}$ & $\overline{-}-08$ & $\overline{-}-01$ & 0.02 & 0.07 & 1.0 & & & & & & & \\
\hline 6 & $\begin{array}{l}\text { Homophily } \\
\text { Gender ( } 1 \text { if } \\
\geq-0.99,0 \text { if } \\
\text { otherwise) }\end{array}$ & $\begin{array}{l}- \\
0.32\end{array}$ & $\begin{array}{l}- \\
0.10\end{array}$ & $\overline{-} 0.19$ & 0.10 & 0.13 & 1.0 & & & & & & \\
\hline 7 & $\begin{array}{l}\text { Homophily } \\
\text { Language ( } 1 \\
\text { if } \geq-0.30,0 \text { if } \\
\text { otherwise) }\end{array}$ & $\begin{array}{l}- \\
0.10\end{array}$ & 0.43 & 0.23 & $\overline{-}-09$ & $\begin{array}{l}- \\
0.03\end{array}$ & 0.004 & 1.0 & & & & & \\
\hline 8 & $\begin{array}{l}\text { Homophily } \\
\text { Education ( } 1 \\
\text { if } \geq 0.2,0 \text { if } \\
\text { otherwise) }\end{array}$ & 0.02 & $\begin{array}{l}- \\
0.01\end{array}$ & $\begin{array}{l}- \\
0.02\end{array}$ & $\begin{array}{l}- \\
0.08\end{array}$ & $\begin{array}{l}- \\
0.02\end{array}$ & -0.22 & $\overline{-}-\overline{0}$ & 1.0 & & & & \\
\hline 9 & $\begin{array}{l}\text { Homophily } \\
\text { Skill ( } 1 \text { if } \geq \\
-0.60,0 \text { if } \\
\text { otherwise })\end{array}$ & 0.24 & $\overline{-} \overline{-} .02$ & $\overline{-} \overline{-04}$ & 0.12 & $\overline{-} \overline{-}(04$ & -0.08 & $\overline{-} \overline{-} .05$ & $\begin{array}{l}- \\
0.05\end{array}$ & 1.0 & & & \\
\hline 10 & $\begin{array}{l}\text { Heterogeneity } \\
\text { Age ( } 1 \text { if } \geq \\
0.75,0 \text { if } \\
\text { otherwise })\end{array}$ & $\overline{-}-08$ & $\overline{-}-01$ & 0.02 & 0.07 & 0.65 & 0.13 & $\overline{-}-03$ & $-\overline{-}-02$ & 0.04 & 1.0 & & \\
\hline 11 & $\begin{array}{l}\text { Heterogeneity } \\
\text { Experience ( } 1 \\
\text { if } \geq 0.45,0 \text { if } \\
\text { otherwise) }\end{array}$ & 0.13 & $\begin{array}{l}- \\
0.01\end{array}$ & $\begin{array}{l}- \\
0.02\end{array}$ & $\begin{array}{l}- \\
0.08\end{array}$ & $\begin{array}{l}- \\
0.02\end{array}$ & -0.03 & 0.19 & $\begin{array}{l}- \\
0.03\end{array}$ & $\begin{array}{l}- \\
0.05\end{array}$ & -0.02 & 1.0 & \\
\hline 12 & $\begin{array}{l}\text { Heterogeneity } \\
\text { Skill ( } 1 \text { if } \geq \\
0.48,0 \text { if } \\
\text { otherwise })\end{array}$ & $\overline{-}-08$ & $\overline{-}-02$ & $\overline{-} 0.05$ & 0.15 & $\overline{-}-05$ & 0.02 & $\begin{array}{l}-06 \\
0.06\end{array}$ & $\overline{-}-\overline{0}$ & $\overline{-}-\overline{0}$ & -0.05 & $\overline{-}-\overline{0}$ & 1.0 \\
\hline
\end{tabular}




\section{Effect of Individual characteristics}

The effect of individual's characteristics on their confidence level to perform safety information has the effect of the attributes which include age, gender, race, language, experience, education, and skill. When testing all the variables in the model, no variables were found statistically significant expect the skill of an individual. People who are beginners in their assigned work is likely to have low confidence to perform a newly assigned job compared to another skilled person $(\boldsymbol{\beta}=\mathbf{- 0 . 4 2})$. This data suggests that people who just started working on the related field has less confidence to perform the job safely.

\section{Personal Network Characteristics}

The results presented in Table 14 shows that denser the network ( 0.35 or higher), people are likely to have less confidence to perform a newly assigned job. More connection among the friend of an individual, higher is the confidence to perform the job safely. This result suggests that when an individual and his/her friend has some kind of connection it makes a pathway to share the knowledge with each other. This results to increase their confidence to perform the newly assigned job safely. Similarly, the frequency of contact between the network has a positive effect on the confidence level. Higher the similarity in age (homophily 0.60 or higher), the ego is likely to have a high confidence level to perform the newly assigned job safely. 
Table 14: Results of Probit Test for Confidence to Perform Newly Assigned Job Safely

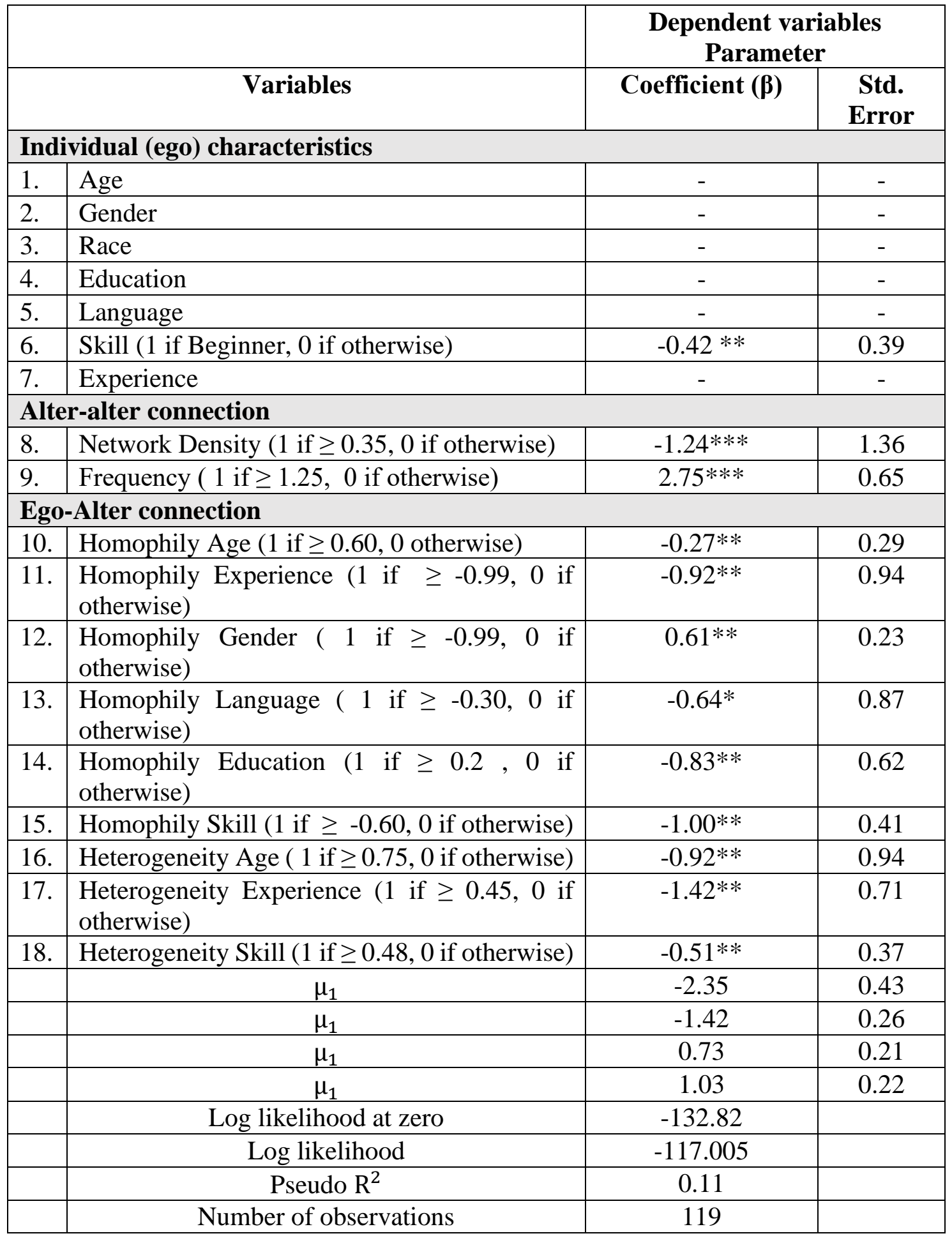

* - Not significant

* significant at the level 0.10 level: **at the level .05 level; *** at the level 0.01 level. 


\section{(D) To discuss safety on the job site}

From the collected data the response has been collected as shown in Figure 29. Out of 140 respondents, $2.14 \%$ of them reported they were not confident to provide safety information to others, $2.14 \%$ of them were somewhat confident, $11.43 \%$ of them were neutral, $45 \%$ of them were confident and $39.28 \%$ of them reported they were extremely confident.

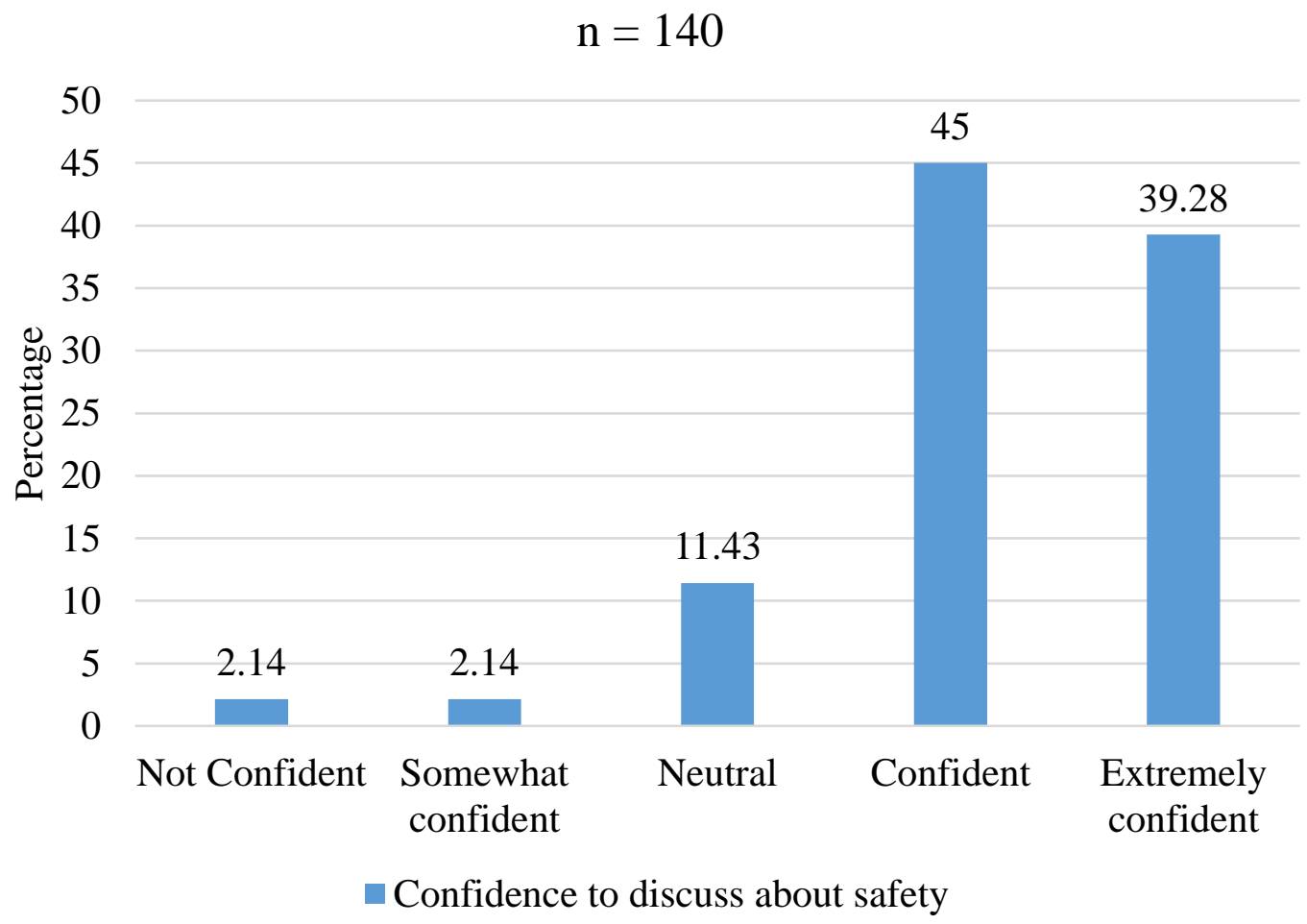

Figure 29: Confidence to Discuss Safety 
Table 15: Correlation Matrix

\begin{tabular}{|c|c|c|c|c|c|c|c|c|c|c|c|}
\hline & & 1 & 2 & 3 & 4 & 5 & 6 & 7 & 8 & 9 & 10 \\
\hline 1 & $\begin{array}{l}\text { Network } \\
\text { Density ( } 1 \text { if } \geq \\
0.20,0 \text { if } \\
\text { otherwise) }\end{array}$ & 1.0 & & & & & & & & & \\
\hline 2 & $\begin{array}{l}\text { Frequency ( } 1 \\
\text { is } \geq 2,0 \text { if } \\
\text { otherwise) }\end{array}$ & -0.008 & 1.0 & & & & & & & & \\
\hline 3 & $\begin{array}{l}\text { Homophily } \\
\text { Age (1 if } \geq \\
0.60,0 \\
\text { otherwise) }\end{array}$ & -0.04 & 0.19 & 1.0 & & & & & & & \\
\hline 4 & $\begin{array}{l}\text { Homophily } \\
\text { Experience ( } 1 \\
\geq 0.5,0 \text { if } \\
\text { otherwise) }\end{array}$ & -0.01 & -0.01 & -0.07 & 1.0 & & & & & & \\
\hline 5 & $\begin{array}{l}\text { Homophily } \\
\text { Language ( } 1 \\
\text { if } \geq-0.30,0 \text { if } \\
\text { otherwise) }\end{array}$ & 0.43 & -0.01 & -0.09 & $\overline{-}-\overline{0}$ & 1.0 & & & & & \\
\hline 6 & $\begin{array}{l}\text { Homophily } \\
\text { Skill ( } 1 \text { if } \geq- \\
0.60,0 \text { if } \\
\text { otherwise })\end{array}$ & -0.02 & -0.02 & 0.12 & $\begin{array}{l}- \\
0.04\end{array}$ & -0.05 & 1.0 & & & & \\
\hline 7 & $\begin{array}{l}\text { Heterogeneity } \\
\text { Age ( } 1 \text { if } \geq \\
0.75,0 \text { if } \\
\text { otherwise) }\end{array}$ & -0.01 & -0.01 & -0.07 & 0.65 & -0.03 & -0.04 & 1.0 & & & \\
\hline 8 & $\begin{array}{l}\text { Heterogeneity } \\
\text { Gender }(1 \geq \\
0,0 \text { if } \\
\text { otherwise })\end{array}$ & -0.12 & -0.12 & -0.15 & 0.11 & -0.01 & -0.11 & 0.11 & 1.0 & & \\
\hline 9 & $\begin{array}{l}\text { Heterogeneity } \\
\text { Language ( } 1 \text { if } \\
\geq 0.45,0 \text { if } \\
\text { otherwise) }\end{array}$ & 0.34 & -0.02 & -0.11 & $\begin{array}{l}- \\
0.04\end{array}$ & 0.078 & -0.07 & -0.04 & 0.05 & 1.0 & \\
\hline 10 & $\begin{array}{l}\text { Heterogeneity } \\
\text { Skill ( } 1 \text { if } \geq \\
0.40,0 \text { if } \\
\text { otherwise })\end{array}$ & -0.02 & -0.02 & 0.14 & $\begin{array}{l}- \\
0.05\end{array}$ & -0.06 & -0.09 & -0.05 & -0.04 & -0.08 & 1.0 \\
\hline
\end{tabular}




\section{Effect of Individual characteristics}

The effect of ego's characteristics on their confidence level to discuss safety information has the effect of the attributes which includes age, gender, race, language, experience, education and skill. When testing all the variables in the model, no variables were found statistically significant. This result suggested that to discuss safety information with the network member, individual characteristic doesn't have a significant role.

\section{Personal Network Characteristics}

The results presented in Table 16 shows that denser the network ( 0.20 or higher), people are more likely to be confident to discuss safety-related information with their friends. Similarly, people who frequent contact with their friends are likely to have higher confidence to discuss safety.

The higher dissimilarity among the friend of an individual in terms of age and language will have a positive effect on the confidence to discuss safety with their friend (positive $\beta$ value). People with higher dissimilarity between the listed friend in terms of age, language, and skill are less likely to have the confidence to discuss safety. This finding suggests that when a person has a friend with similar age, language and skill level, they feel more confident to discuss safety with them openly. 
Table 16: Results of Probit Test for Confidence to Discuss Safety Information

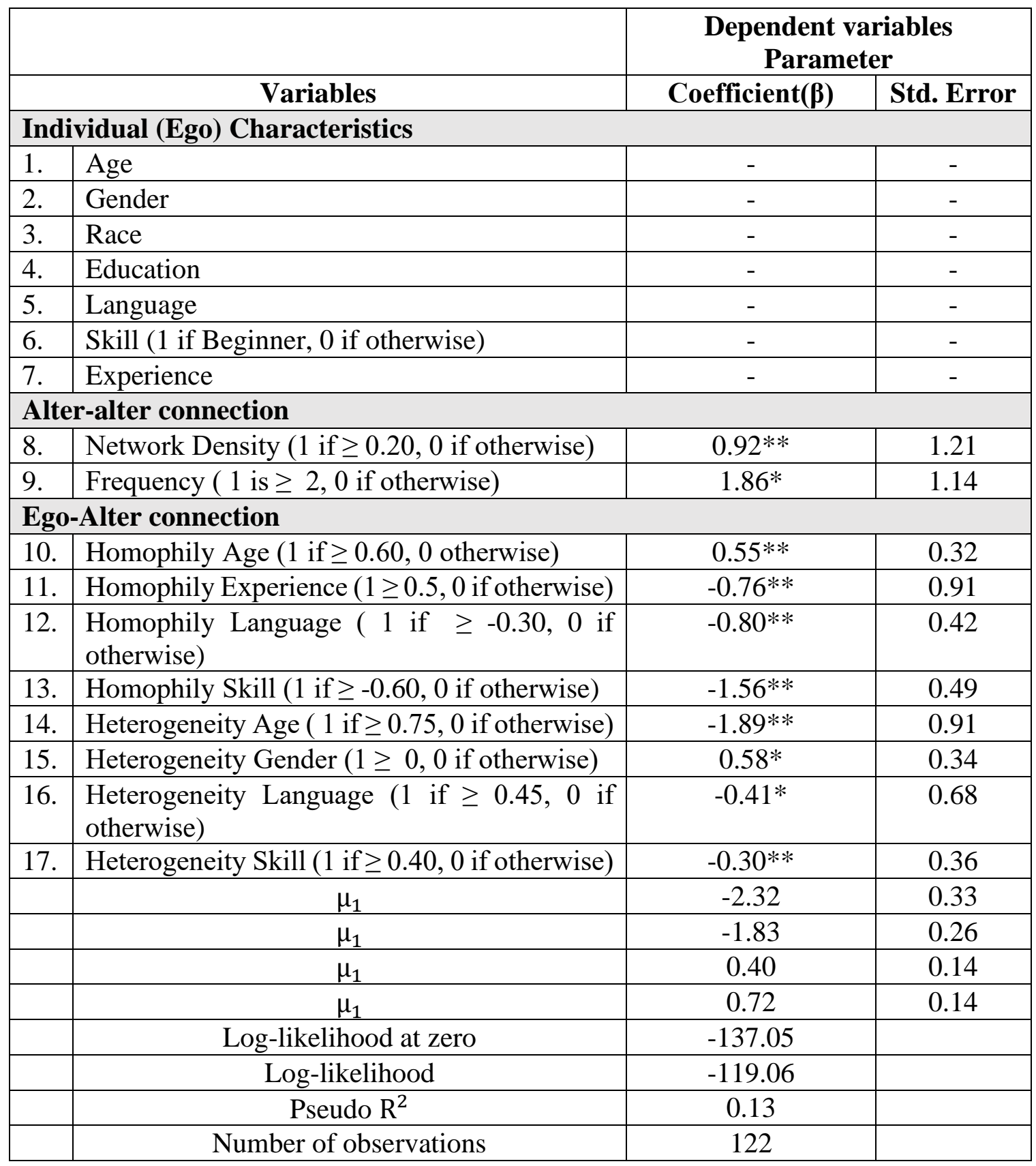

\footnotetext{
* - Not significant

* significant at the level 0.10 level: **at the level .05 level; *** at the level 0.01 level.
} 
(E) To watch for each other safety on the job site

From the collected data the response has been collected as shown in Error! R eference source not found.. Out of 141 respondents, 5.67\% of them reported they were not confident to provide safety information to others, $7.80 \%$ of them were somewhat confident, $9.92 \%$ of them were neutral, $41.13 \%$ of them were confident and $35.46 \%$ of them reported they were extremely confident.

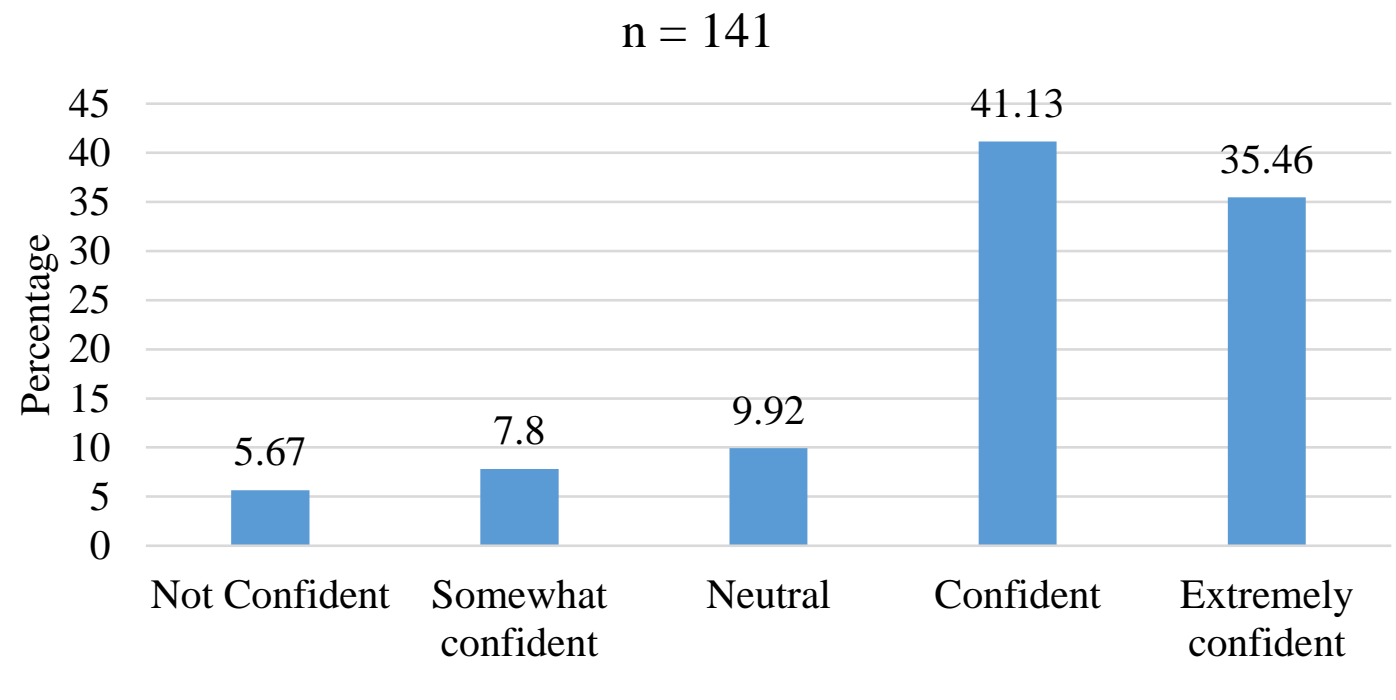

- Confidence to watch for eachother safety

Figure 30: Confidence to Watch for Each other's Safety 
Table 17: Correlation Matrix

\begin{tabular}{|l|l|l|l|l|l|l|l|l|l|}
\hline & & 1 & 2 & 3 & 4 & 5 & 6 & 7 & 8 \\
\hline 1 & $\begin{array}{l}\text { Age (1 if 35 or less 0 } \\
\text { otherwise) }\end{array}$ & 1.0 & & & & & & & \\
\hline 2 & Density & -0.01 & 1.0 & & & & & & \\
\hline 3 & $\begin{array}{l}\text { Frequency (1 is } \geq 2, \\
\text { if otherwise) }\end{array}$ & -0.04 & 0.01 & 1.0 & & & & & \\
\hline 4 & $\begin{array}{l}\text { Homophily Age (1 if } \\
\geq 0.50,0 \text { otherwise) }\end{array}$ & 0.07 & -0.02 & -0.07 & 1.0 & & & & \\
\hline 5 & $\begin{array}{l}\text { Homophily } \\
\text { Experience }(1 \geq 0.5, \\
0 \text { if otherwise) }\end{array}$ & 0.10 & -0.01 & 0.05 & -0.03 & 1.0 & & & \\
\hline 6 & $\begin{array}{l}\text { Homophily Skill( } 1 \text { if } \\
\geq-0.60,1 \text { if } \\
\text { otherwise) }\end{array}$ & -0.006 & -0.03 & -0.05 & -0.04 & -0.05 & 1.0 & & \\
\hline 7 & $\begin{array}{l}\text { Heterogeneity } \\
\text { Language (1 if } \geq \\
0.45,0 \text { if otherwise) }\end{array}$ & -0.09 & 0.48 & -0.04 & -0.04 & -0.07 & -0.04 & 1.0 & \\
\hline 8 & $\begin{array}{l}\text { Heterogeneity Skill } \\
(1 \text { if } \geq 0.30,0 \text { if } \\
\text { otherwise) }\end{array}$ & -0.03 & -0.04 & -0.05 & -0.05 & -0.09 & -0.08 & -0.10 & 1.0 \\
\hline
\end{tabular}

\section{Effect of Individual characteristics}

The effect of ego's characteristics on their confidence level to watch for each other safety information has the effect of the attributes which include age, gender, race, language, experience, education, and skill. When testing all the variables in the model, no variables were found statistically significant except age. Age of people with 32 or lower will have less confidence to watch for each other safety in the job site.

\section{Personal Network Characteristics}

Like other dependent variables, frequency of contact has a positive effect on safety confidence in watching for each other safety in the job site. People with higher dissimilarity in the network in terms of age, experience, and skill are less likely to have the confidence to watch for each other's safety. 
Table 18: Results of Probit Test for Confidence to Watch Safety Information

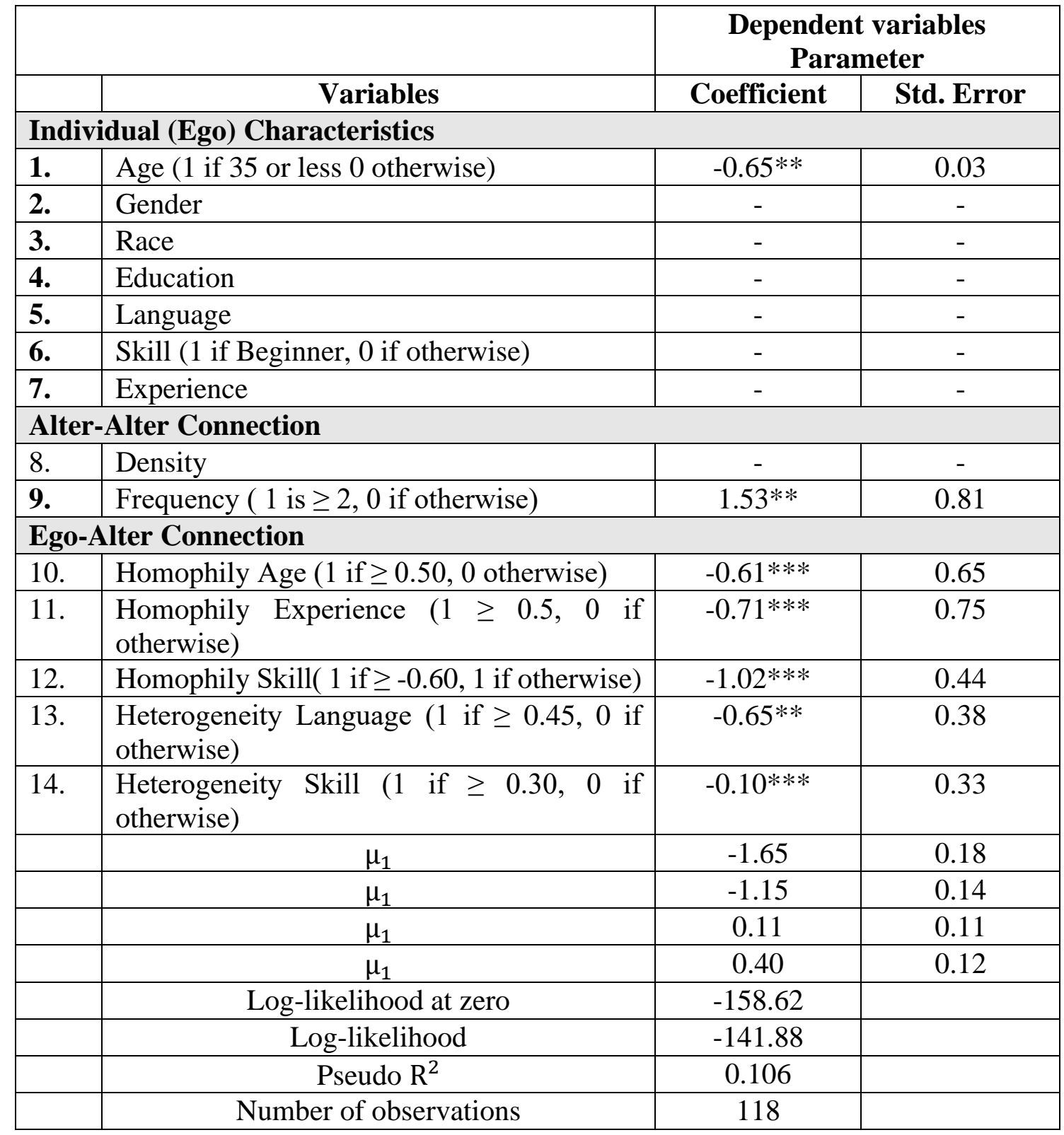

\footnotetext{
*- Not significant

*significant at the level 0.10 level: **at the level .05 level; *** at the level 0.01 level.
} 


\subsection{Key Findings}

From the analysis five different categories of safety confidence the result has been presented in Table 19 showing the key findings from the overall result;

Table 19: Summary of the Result Showing Relation Between the Variables

\begin{tabular}{|c|c|c|c|c|c|c|}
\hline & & Provide & Receive & Perform & Discuss & Watch \\
\hline 1. & Age (35 or less) & & & & & $(-)^{* *}$ \\
\hline 2. & Gender Female & $(-)^{*}$ & $(-)^{* * *}$ & & & \\
\hline 3. & Race & & & & & \\
\hline 4. & $\begin{array}{l}\text { Education (Bachelor or } \\
\text { higher) }\end{array}$ & & $(-) * * *$ & & & \\
\hline 5. & Language Spanish & $(-)^{*}$ & & & & \\
\hline 6. & Skill Beginner & & & $(-)^{* *}$ & & \\
\hline 7. & Experience & & & & & \\
\hline 8. & Density & $(+)^{* *}$ & $(+)^{* *}$ & $(+) * * *$ & $(+)^{* *}$ & \\
\hline 9. & Degree & & & & & \\
\hline 10. & Frequency & $(+)^{* * *}$ & $(+)^{* *}$ & $(+) * * *$ & $(+)^{*}$ & $(+)^{* *}$ \\
\hline 11. & Duration & & & & & \\
\hline 12. & Homophily: Age & $(-)^{* * *}$ & $(-)^{* *}$ & $(-)^{* *}$ & $(+)^{* *}$ & $(-)^{* * *}$ \\
\hline 13. & Gender & & & $(+)^{* *}$ & & \\
\hline 14. & Race & $(-)^{* *}$ & & & & \\
\hline 15. & Education & & & & & \\
\hline 16. & Language & & & $(-)^{*}$ & $(-)^{* *}$ & \\
\hline 17. & Skill & $(+)^{* * *}$ & & $(-)^{* *}$ & $(-)^{* *}$ & $(-)^{* * *}$ \\
\hline 18. & $\begin{array}{r}\text { Experience } \\
\end{array}$ & $(-)^{* *}$ & $(-)^{* *}$ & $(-)^{* *}$ & $(-)^{* *}$ & $(-)^{* * *}$ \\
\hline 19. & Heterogeneity: Age & $(-)^{*}$ & & $(-)^{* *}$ & $(-)^{* *}$ & \\
\hline 20. & Gender & & & & $(+)^{*}$ & \\
\hline 21. & Race & $(+) * *$ & & & & \\
\hline 22. & Education & & & & & \\
\hline 23. & Language & & & & $(-)^{*}$ & $(-)^{* *}$ \\
\hline 24. & Skill & $(-)^{*}$ & & $(-)^{* *}$ & $(-)^{* *}$ & $(-)^{* * *}$ \\
\hline 25. & Experience & $(+)^{* *}$ & $(-) * * *$ & $(-)^{* *}$ & & \\
\hline
\end{tabular}


The research findings from this thesis have significant implications in the construction field. The result revealed that the perception and safety confidence of people is dependent on various factors that are their own personal characteristics and the people the characteristics of people they interact within their job site. The result has also shown that the pattern of connection one has with his/her network in the job site can affect safety confidence.

\section{Effect of Individual Characteristics}

H1. The confidence level of an individual depends upon their individual characteristics The first hypothesis states that individual confidence is affected by his/her own characteristics. From the result, it has been proven that individual characteristics have some kind of relationship with each safety activity.

- People age 35 or less are less likely to be confident to watch for each other safety in the job site.

- Female is less likely to confident while it comes to safety in the job site.

- People with a bachelor's or higher degrees of education are less likely to be confident to receive safety information from others.

- People who just started to work are more likely to have the confidence to perform a newly assigned job.

\section{Effect of Personal Characteristics}

H2. The confidence level of an individual depends upon the interpersonal characteristics

H3. The confidence of an individual depends upon the strength of the connections among their friends. 
The second and third hypothesis was about the connection an individual has with his friends and the connection among his/her friend. It has been proven that one's safety confidence is influenced by his/her friend.

- Higher the frequency of contact with each other individual is likely to have higher safety confidence.

- Stronger is the connection of people in the job site they are more likely to be confident in terms of safety.

- Higher the dissimilarity in age among the people, people are less likely to become confident in terms of safety-related activity.

- Higher the dissimilarity in terms of skill among the people, more likely they become confident to provide safety information but has a negative impact on safety performance and safety discussion.

- Higher the dissimilarity in the experience of people, less likely to have confidence in various safety-related activities. 


\section{CHAPTER V \\ CONCLUSION}

\subsection{Summary of the Study}

People that we work with daily have a significant role to improve safety performance. Hence it is important to consider the social factors when it comes to safety improvement. Based on the results obtained by the study, the following observations were made.

The result showed that females are less likely to be confident when it comes to providing or receiving safety information from their friends on the job site. Only $9.1 \%$ of workers in the construction industry are female. Recent research has proven that gender diversity helps the construction industry to improve performance [48]. Overall, this finding suggested that gender diversity can create a positive impact in terms of safety. Another important factor that is important is the connections among people working together. The result showed that the network with densely connected people within the group has a positive impact on safety confidence. The dense network represents a strong tie between the people in the workplace which can be an important and effective source for information flow and resource sharing.

Another interesting finding is, the more frequently the people contact their friends, the more positive impact it has on individual confidence. This tells us that frequently communicating with friends makes you more confident in various safety relating activities because the information is shared more frequently. This result encourages the workplace should have an interacting platform where workers get the opportunity to communicate 
with each other more often. The finding also revealed that language can create a barrier within the workers reducing their safety confidence to perform job safety. Past researcher have also found that employee must take steps to provide safety training in the languages preferred by the workers to increase the safety performance of the work crew [49]. This suggests that language is one of the essential factors for the flow of information within the employees. Hence, individuals working with a group where they can communicate without any difficulty or trained inappropriate language will make a positive impact on their communication pattern within the group they work with.

\subsection{Contribution}

This study explores a new way of study (PNRD) to improve safety in construction which was lacking in the literature. The methodology adopted in this study leverages an egocentric social network approach in the construction industry and can open new areas of research in construction safety. This is one of the main contributions of this study as the result suggested that the network plays an important role in safety improvement.

The analysis of this study revealed various factors such as individual characteristics (age, gender, skill, experience) and interpersonal characteristics (density, frequency of contact, similarities within the network and dissimilarities among the people) plays an important role in improving safety in construction. These factors should be considered in the workforce for better performance.

This study has investigated and revealed many important factors that contribute to safety improvement in the job site. This study will provide a guideline to policymakers to consider seemingly minor things in the workplace that could give major safety 
improvement. The results can be useful for construction professionals to enhance safety on site by considering the effect of the social influence of the workers on one another. This understanding will nurture a positive environment in the workplace, encouraging workers to take responsibility for their own and each other's safety.

\subsection{Limitation of the Study}

Besides the findings presented in this research, several limitations must be acknowledged. The primary limitation is the research only focuses on the personal network of unrelated and anonymous respondents. Hence the collected data represents only the view of the respondent. Another relevant concern with such approach is that we do not assess the accuracy of the individual's view of his/her network. Also, we cannot determine the accuracy of all reported connections in the individual's actual life. We only see the network through the individual's eye, so we don't know who he/she chooses not to connect with and why. The connection between his/her network member is perceived by the individual and may be inaccurate. Alternative methods have not been tested in this research hence the methodology only focuses on the PNRD approach.

Finally, the pencil survey was adopted, hence some error while manual entry the data is possible. Due to the relatively short time period for the study, a small number of respondents were targeted. The survey can and needs to be done on a larger scale in the future. Furthermore, the study has targeted Miami-Dade and Broward counties in Florida due to which the result might not be generalizable to other geographical locations. 


\subsection{Future Studies}

The limitations that have been described opens a new possibility of future research. The research is a motivation to encourage the researchers to fill the gap in the social network study to improve safety in construction. This research will act as a foundation for future researchers to explore further on this topic. As the research focused more on the methodology to explore the PNDR approach in construction, future studies can explore other social dimensions that may affect the safety confidence of an individual.

Also, this study is based on Miami-Dade County and Broward County in Florida, future research may gather data from specific categories of individuals to test if the pattern is appropriate and transferable to another specific region. The research only showed the result using ordered probit model. Future research can focus on using more sophisticated modeling approach and compare the results. A larger-scale survey can be done to analyze the scenario in a larger population. As the research focuses on the unrelated respondents working in the construction industry, the future study can be conducted to study full network targeting a certain group of people working in the same worksite. 


\section{REFERENCES}

[1] B. McCabe, D. Karahalios, and C. Loughlin, "Attitudes in construction safety," Constr. Res. Congr. 2005 Broadening Perspect. - Proc. Congr., pp. 471-479, 2005.

[2] E. W. L. Cheng, H. Li, P. E. D. Love, and Z. Irani, "Network communication in the construction industry," Corp. Commun. An Int. J., vol. 6, no. 2, pp. 61-70, 2001.

[3] Bureau of Labor Statistics, "Occupational Injury and Illness Classification Manual," U.S. Dep. Labor, no. September, pp. 1-353, 2007.

[4] "The National Institute for Occupational Safety and Health (NIOSH)," Choice Rev. Online, vol. 52, no. 08, pp. 52-3982-52-3982, 2015.

[5] Occupational Safety and Health Administration, "Commonly Used Statistics | Occupational Safety and Health Administration," OSHA Data and Statistics, 2018. [Online]. Available: https://www.osha.gov/oshstats/commonstats.html. [Accessed: 08-Nov-2019].

[6] I. G. Awolusi and E. D. Marks, "Safety activity analysis framework to evaluate safety performance in construction," J. Constr. Eng. Manag., vol. 143, no. 3, pp. 1$12,2017$.

[7] M. V. Prades, "Attribute-based Risk Model for Assessing Risk to Industrial Consturction Tasks,” 2014.

[8] A. Shibani, M. Saidani, and M. Alhajeri, "Health and safety influence on the construction project performance in United Arab Emirates (UAE)," Int. J. Public Adm., vol. 4, no. 2, pp. 32-44, 2013.

[9] P. X. W. Zou, "Fostering a strong construction safety culture," Leadersh. Manag. Eng., vol. 11, no. 1, pp. 11-22, 2011.

[10] S. Badi, L. Wang, and S. Pryke, "Relationship marketing in Guanxi networks: A social network analysis study of Chinese construction small and medium-sized enterprises," Ind. Mark. Manag., vol. 60, pp. 204-218, 2017.

[11] J. A. Carrasco, B. Hogan, B. Wellman, and E. J. Miller, "Collecting social network data to study social activity-travel behavior: An egocentric approach," Environ. Plan. B Plan. Des., vol. 35, no. 6, pp. 961-980, 2008.

[12] S. D. Halgin and P. S. Borgatti, "An Introduction to Personal Network Analysis and Tie Churn Statistics Using E-NET," Connect. - J. Princ. Prep. Dev., vol. 32, no. 1, 2012. 
[13] US BLS, "National Census of Fatal Occupational Injuries in 2017," Bur. Labor Stat. US Dep. Labor, no. 202, pp. 1-14, 2017.

[14] Centers for Disease Control and Prevention, "NIOSH workers health chartbook," 2004.

[15] A. Albert and M. R. Hallowell, "Modeling the Role of Social Networks on Hazard Recognition and Communication," Pract. Period. Struct. Des. Constr., vol. 22, no. 4, p. 04017016, 2017.

[16] V. Kaskutas, A. M. Dale, J. Nolan, D. Patterson, H. J. Lipscomb, and B. Evanoff, "Fall hazard control observed on residential construction sites," Am. J. Ind. Med., vol. 52, no. 6, pp. 491-499, 2009.

[17] J. Wanberg, C. Harper, M. R. Hallowell, and S. Rajendran, "Relationship between construction safety and quality performance," J. Constr. Eng. Manag., vol. 139, no. 10, 2013.

[18] S. Bhattacharjee, S. Ghosh, and D. Young-Corbett, "Safety Improvement Approaches in Construction Industry: A Review and Future Directions," 47th ASC Annu. Int. Conf. Proc., no. Ilo 1985, p. 8, 2011.

[19] M. L. Barnes, J. Lynham, K. Kalberg, and P. Leung, "Social networks and environmental outcomes," Proc. Natl. Acad. Sci. U. S. A., vol. 113, no. 23, pp. 6466$6471,2016$.

[20] H. Li, M. Lu, S. C. Hsu, M. Gray, and T. Huang, "Proactive behavior-based safety management for construction safety improvement," Saf. Sci., vol. 75, pp. 107-117, 2015.

[21] N. Park, S. Lee, and J. H. Kim, "Individuals' personal network characteristics and patterns of Facebook use: A social network approach," Comput. Human Behav., vol. 28, no. 5, pp. 1700-1707, 2012.

[22] K. Y. Lin and H. P. Lu, "Why people use social networking sites: An empirical study integrating network externalities and motivation theory," Comput. Human Behav., vol. 27, no. 3, pp. 1152-1161, 2011.

[23] A. M. Sadri, S. Lee, and S. V Ukkusuri, "Modeling social network influence on joint trip frequency for regular activity travel decisions," Transp. Res. Rec., vol. 2525, no. 1, pp. 83-93, Jan. 2015.

[24] N. M. Tichy, M. L. Tushman, and C. Fombrun, "Social Network Analysis For Organizations," Acad. Manag. Rev., 1979.

[25] M. M. Kumaraswamy, A. M. Anvuur, and H. J. Smyth, "Pursuing 'relational integration' and 'overall value' through 'RIVANS,"” Facilities, 2010. 
[26] H. Wang, X. Zhang, and W. Lu, "Improving Social Sustainability in Construction: Conceptual Framework Based on Social Network Analysis," J. Manag. Eng., vol. 34, no. 6, pp. 1-9, 2018.

[27] A. Mohaimin et al., "The role of social capital, personal networks, and emergency responders in post-disaster recovery and resilience: a study of rural communities in Indiana," Nat. Hazards, vol. 90, no. 3, pp. 1377-1406, 2018.

[28] X. Zheng, Y. Le, A. P. C. Chan, Y. Hu, and Y. Li, "Review of the application of social network analysis (SNA) in construction project management research," Int. J. Proj. Manag., vol. 34, no. 7, pp. 1214-1225, 2016.

[29] HSE, "Common Topic 4: Safety Culture. Extract from: Inspectors Toolkit - Human factors in the management of major accident hazards.," 1993.

[30] A. Albert, M. R. Hallowell, M. Skaggs, and B. Kleiner, "Empirical measurement and improvement of hazard recognition skill," Saf. Sci., vol. 93, pp. 1-8, 2017.

[31] T. Castillo, L. F. Alarcón, and E. Pellicer, "Influence of Organizational Characteristics on Construction Project Performance Using Corporate Social Networks," J. Manag. Eng., vol. 34, no. 4, pp. 1-9, 2018.

[32] "Networks of Political Action: Toward Theory Construction Author ( s ): David Knoke Published by: Oxford University Press Stable URL: https://www.jstor.org/stable/2579133 Networks of Poliical Action : Toward Theory Construction," vol. 68, no. 4, pp. 1041-1063, 2020.

[33] J. A. Carrasco, B. Hogan, B. Wellman, and E. J. Miller, "Collecting social network data to study social activity-travel behavior: An egocentric approach," Environ. Plan. B Plan. Des., vol. 35, no. 6, pp. 961-980, 2008.

[34] O. M. Salem, "hereby submit this work as part of the requirements for the degree of: Master of Science in: Civil Engineering It is entitled: Job Satisfaction of Women in Construction Trades," vol. 9364, no. November 2014, pp. 333-341, 2008.

[35] A. M. Sadri, S. V. Ukkusuri, and H. Gladwin, "Modeling joint evacuation decisions in social networks: The case of Hurricane Sandy," J. Choice Model., vol. 25, no. February, pp. 50-60, 2017.

[36] M. Everett and S. P. Borgatti, “Ego network betweenness,” vol. 27, pp. 31-38, 2005.

[37] P. V Mardsen, "Egocentric and sociocentric measures of network centrality," Soc. Networks, vol. 24, no. 4, pp. 407-422, 2002.

[38] M. Canut et al., "Time-aware Egocentric network-based User Profiling To cite this version : HAL Id : hal-01343052,” 2016. 
[39] A. Abbasi, K. S. K. Chung, and L. Hossain, "Egocentric analysis of co-authorship network structure, position and performance," Inf. Process. Manag., vol. 48, no. 4, pp. 671-679, 2012.

[40] "An Introduction to Personal Network Analysis and Tie Churn Statistics Using ENET," Connect. - J. Princ. Prep. Dev., vol. 32, no. 1, pp. 1-30, 2012.

[41] R. Burt, “'Network Items and the General Social Survey,' Social Networks 6:293339.," Soc. Networks, vol. 6, pp. 293-339, 1984.

[42] C. M. Norris et al., "Ordinal regression model and the linear regression model were superior to the logistic regression models," J. Clin. Epidemiol., vol. 59, no. 5, pp. 448-456, 2006.

[43] P. McCullagh, "Regression Models for Ordinal Data," J. R. Stat. Soc. Ser. B, 1980.

[44] J. S. Long and J. Freese, Regression Models for Categorical Dependent Variables Using STATA. 2001.

[45] Bureau of Labor Statistics, "HOUSEHOLD DATA 18b. Employed persons by detailed industry and age.," pp. 1-8, 2015.

[46] S. Strand, S. Cadwallader, and D. Firth, "Module 5 - Ordinal Regression," Using Stat. Regres. Methods Educ. Res., 2011.

[47] R. Alsamadani, M. Hallowell, and A. N. Javernick-Will, "Measuring and modelling safety communication in small work crews in the US using social network analysis," Constr. Manag. Econ., vol. 31, no. 6, pp. 568-579, 2013.

[48] R. Y. Sunindijo, D. Ph, I. Kamardeen, and D. Ph, "Work Stress Is a Threat to Gender Diversity in the Construction Industry," vol. 143, no. 10, pp. 1-11, 2017.

[49] J. Alsamadani, R., Hallowell, M.R., Javernick-Will, A. \& Cabello, "Relationships among Language Proficiency, Communication Patterns, and Safety Performance in Small Work Crews in the United States," J. Constr. Eng. Manag., vol. 139, no. 5, pp. 556-563, 2013. 